\title{
Baseline household survey: Jaffarabad district
}

Pakistan Initiative for Mothers and Newborns (PAIMAN)

Follow this and additional works at: https://knowledgecommons.popcouncil.org/departments_sbsr-rh

Part of the Family, Life Course, and Society Commons, and the Maternal and Child Health Commons How does access to this work benefit you? Let us know!

\section{Recommended Citation}

Pakistan Initiative for Mothers and Newborns (PAIMAN). 2006. "Baseline household survey: Jaffarabad district." Islamabad: Population Council. 


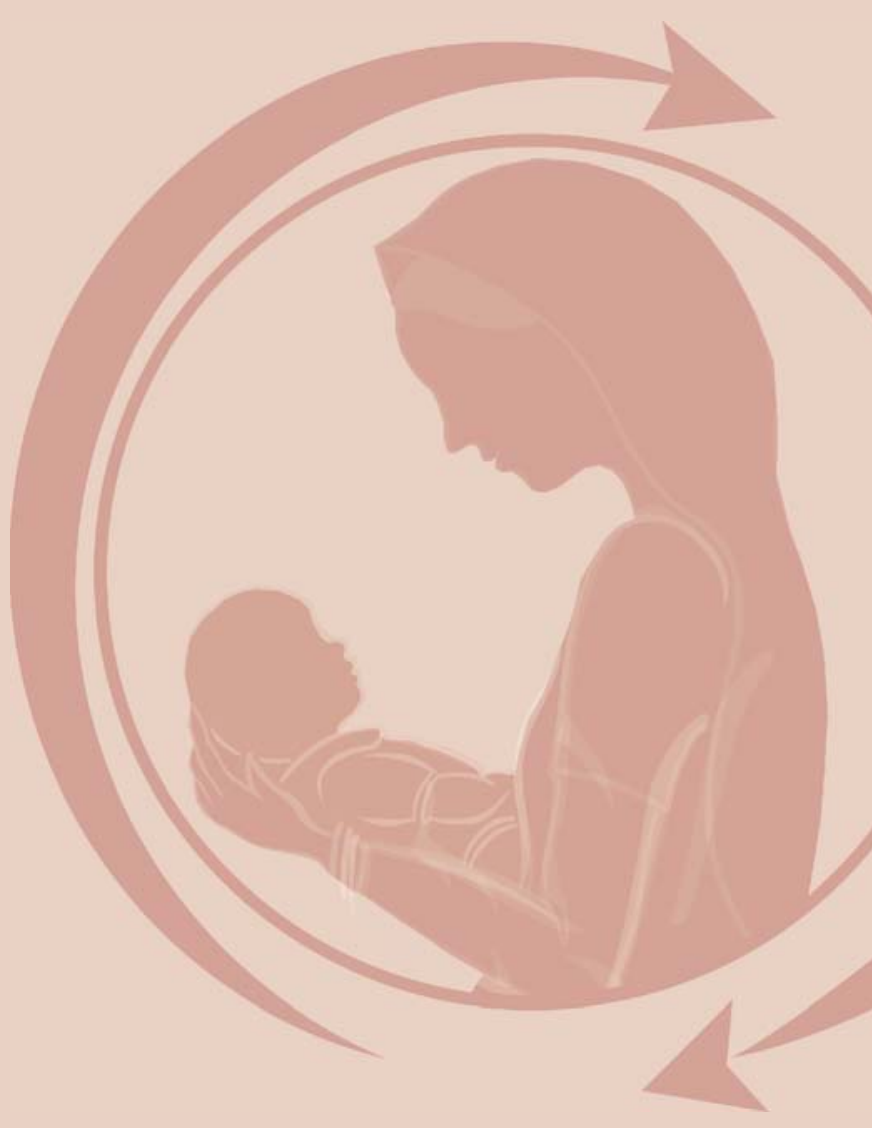

\section{Baseline Household Survey}

Jaffarabad

DISTRICT 



\section{Pakistan Initiative for Mothers and Newborns (PAIMAN)}

\section{Jaffarabad Baseline Household Survey}




\section{(1) Population Council}

The Population Council, an international, non-profit, non-governmental organization established in 1952, seeks to improve the well-being and reproductive health of current and future generations around the world and to help achieve a humane, equitable, and sustainable balance between people and resources.

The Council analyzes population issues and trends; conducts research in the reproductive sciences; develops new contraceptives; works with public and private agencies to improve the quality and outreach of family planning and reproductive health services; helps governments design and implement effective population policies; communicates the results of research in the population field to diverse audiences; and helps strengthen professional resources in developing countries through collaborative research and programs, technical exchanges, awards, and fellowships.

\section{For inquiries, please contact:}

Population Council

\#7, Street 62, F-6/3, Islamabad, Pakistan

Tel: 92512277439

Fax: 92512821401

Email: info@pcpak.org

web: http://www.popcouncil.org

Layout \& Design : Ali Ammad

Printed by: Crystal Printers, Islamabad

Disclaimer:

"This study/report is made possible by the generous support of the American people through the United States Agency for International Development (USAID). The contents are the responsibility of JSI Research \& Training Institute, Inc. and do not necessarily reflect the views of USAID or the United States Government." 


\section{Contents}

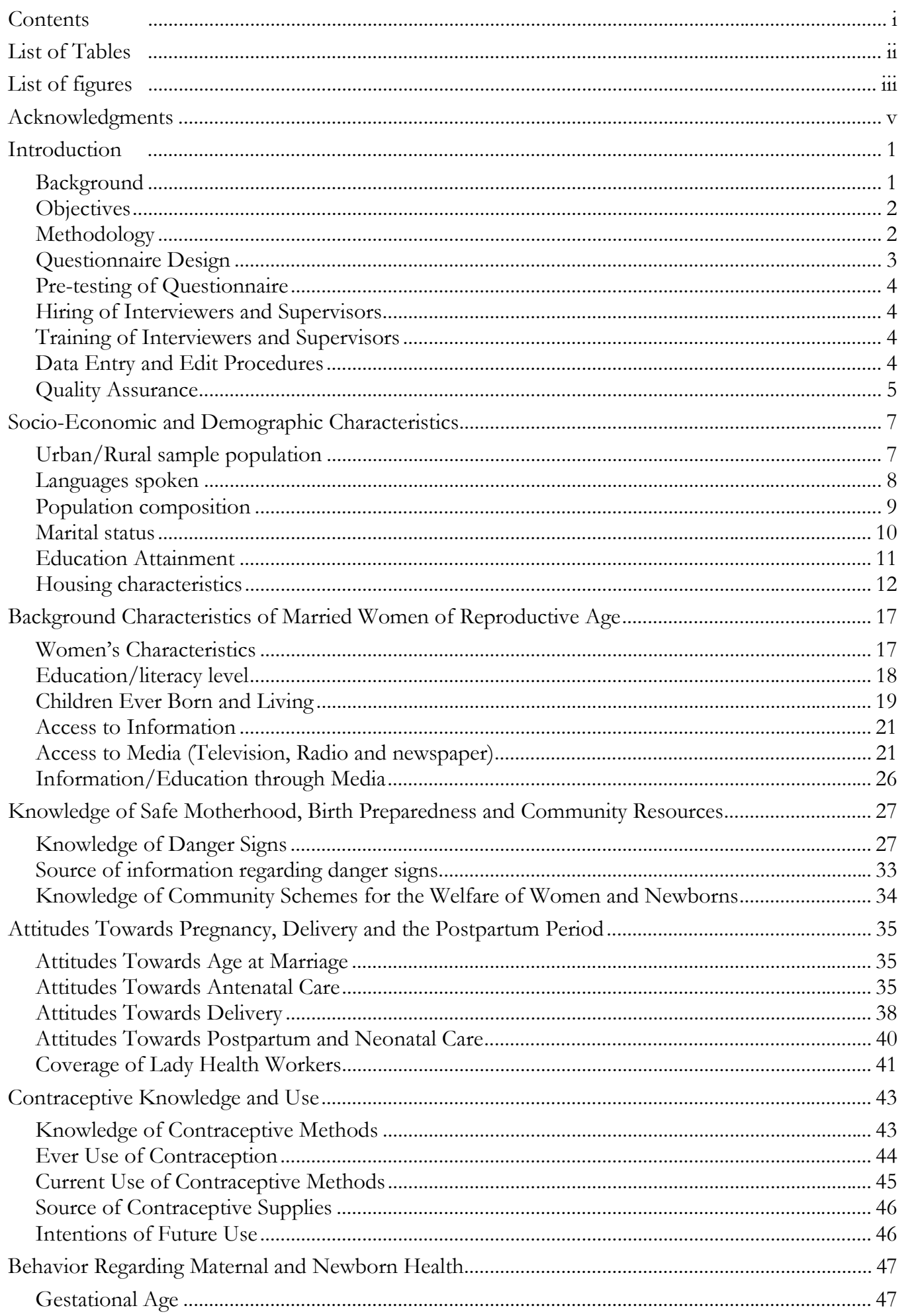




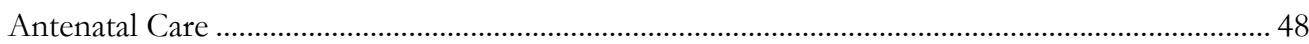

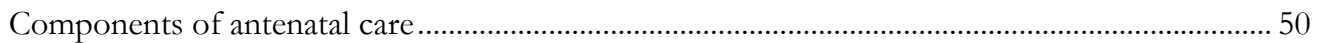

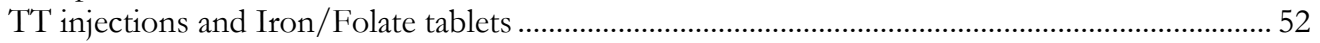

Experience of complications and birth preparedness .................................................................. 53

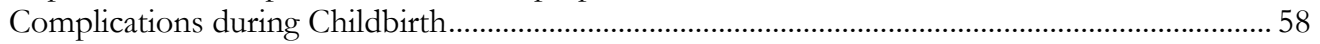

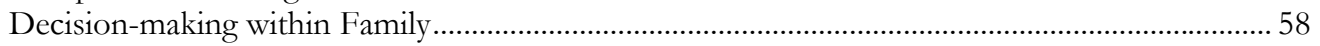

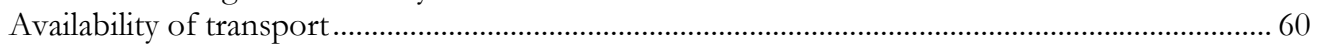

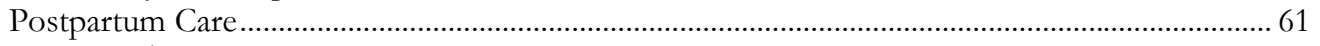

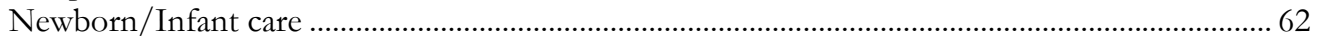

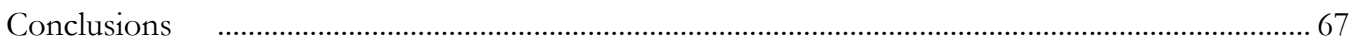

References

\section{List of Tables}

Table 1.1: Number of blocks/villages and households selected for the sample population .............. 2

Table 2.1: Interview completion status .............................................................................................. 7

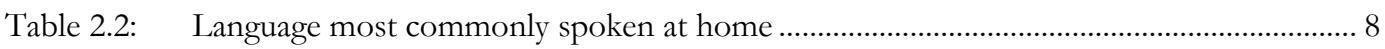

Table 2.3: Age-sex distribution of population .............................................................................. 9

Table 2.4: Household population by age (15 years and above), sex and marital status.................... 10

Table 2.5: Household population by age (10 years and above), sex and educational level.............. 11

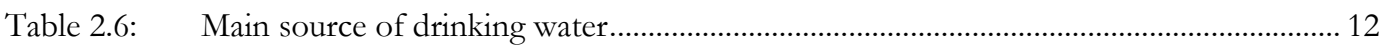

Table 2.7: Type of toilet facility used by household members …...................................................... 13

Table 2.8: Main type of fuel used for cooking.................................................................................... 13

Table 2.9: Number of rooms used for sleeping................................................................................. 14

Table 2.10: Ownership of household commodities / land .................................................................. 15

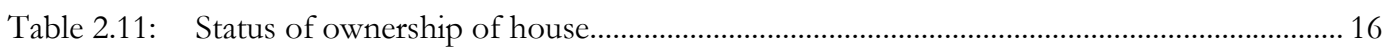

Table 3.1: Current age and age at marriage ........................................................................................... 18

Table 3.2: Education and literacy level of respondents and their husbands ..................................... 19

Table 3.3: Percentage distribution of married women by number of children ever born, mean number of children ever born, living children and age group, compared to the 1998 population census ............................................................................................................ 20

Table 3.4: Percentage distribution of married women by length of preceding birth interval........... 20

Table 3.5: Place where respondent usually watches television ........................................................ 23

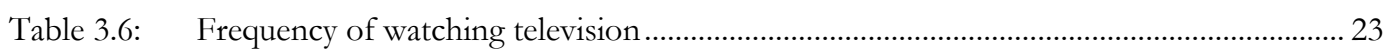

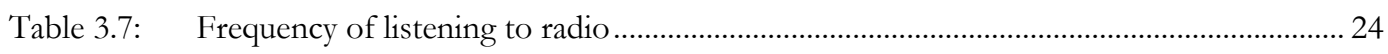

Table 3.8: $\quad$ Place where respondent listens to the radio........................................................................ 24

Table 4.1: Knowledge of existence and importance of transport, blood and finances by the community at the time of delivery ..................................................................................... 34

Table 5.1: Importance of antenatal check-ups ................................................................................ 36

Table 5.2: Month of pregnancy when women should go for antenatal care ................................... 36

Table 5.4: Respondents who believe that women should receive delivery services from health

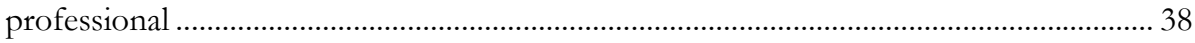

Table 5.5: Person who should make decisions regarding the health of a pregnant woman .............. 39

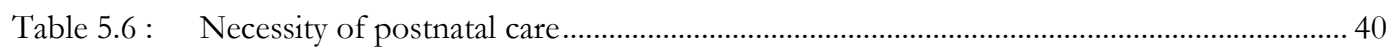

Table 5.7: Number of women who obtain postnatal care in the community ................................... 41 
Table 5.8: Presence of lady health worker in the community .......................................................... 41

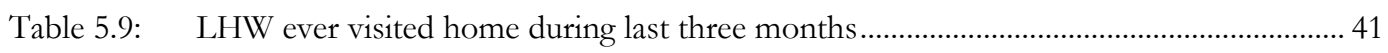

Table 6.1 : $\quad$ Ever use of specific contraceptive method ............................................................................. 44

Table 6.2: Current use of specific contraceptive method......................................................................... 45

Table 7.1: Pregnancy outcome by gestational age ............................................................................. 47

Table 7.2: Gestational age at first antenatal check-up/number of antenatal check-ups obtained ... 49

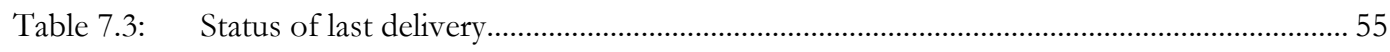

Table 7.4: Type of complications experienced during the last delivery............................................ 58

Table 7.5: Persons who made decision to seek health care/mode of transport used to reach health

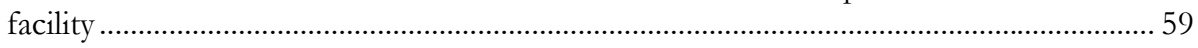

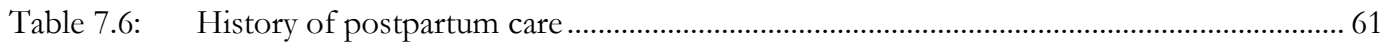

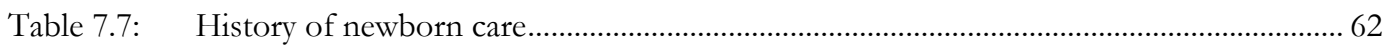

\section{List of figures}

Figure 2.1: Languages spoken in the households.............................................................................. 8

Figure 2.2: Material used for the construction of roof........................................................................ 14

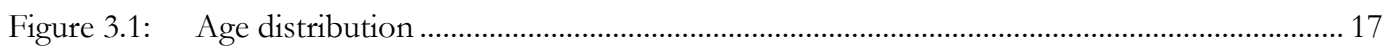

Figure 3.2: Exposure to mass media (radio, television or newspaper) ............................................... 21

Figure 3.3: Percentage of women who watch television or listen to radio.......................................... 22

Figure 3.4: Most trustworthy form of media ..................................................................................... 22

Figure 3.5: Influence of television programs on health behaviors of people...................................... 23

Figure 3.6: Influence of radio on the health behaviors ...................................................................... 25

Figure 3.7: Frequency of reading newspaper................................................................................... 25

Figure 3.8: Percentage of married women who had heard/read maternal and newborn messages during the last 3 months .................................................................................................... 26

Figure 4.1: Knowledge of danger signs during pregnancy, which require medical attention ............ 28

Figure 4.2: Percentage distribution of women by number of known danger signs during

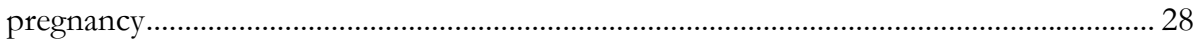

Figure 4.3: Distribution of respondents who had knowledge about complications during delivery 29

Figure 4.4: Percentage distribution of women by number of known danger signs during delivery30

Figure 4.5: Percentage of married women who had knowledge about complication during

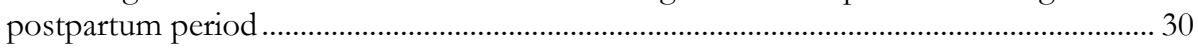

Figure 4.6: Percentage distribution of women by number of known danger signs during

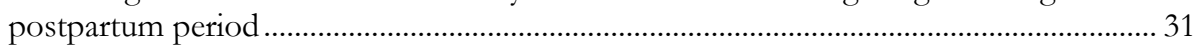

Figure 4.7: Percentage of married women by status of knowledge of danger signs in newborn ...... 32

Figure 4.8: Percentage distribution of women by number of known danger signs in the newborn33

Figure 4.9: Source of information regarding danger signs during pregnancy .................................... 33

Figure 5.1: Percentage of married women who thought it necessary to recieve T'T shots and take iron/folate tablets during pregnancy ................................................................................. 37

Figure 5.2: Respondents who believe women in their community obtain delivery services from

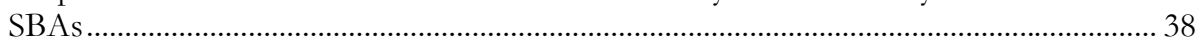

Figure 5.3: Percentage of women by their perception of where a delivery should take place ........... 39 
Figure 5.4: $\quad$ Percentage of married women by mode of transport they would use to reach a health facility

Figure 6.1: Percentage of married women by knowledge of specific contraceptive method - rural Jaffarabad.

Figure 6.2: $\quad$ Percentage of married women by knowledge of specific contraceptive method - urban

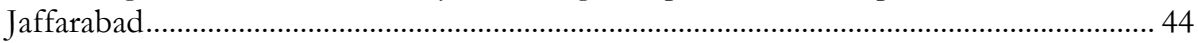

Figure 6.3: Percentage of married women by future intention to use contraceptives ....................... 46

Figure 7.1: Percentage of respondents who obtained antenatal care ................................................... 48

Figure 7.2: Persons accompanying pregnant women to antenatal check-ups..................................... 50

Figure 7.3: Services performed/asked during antenatal check-up................................................... 51

Figure 7.4: Percentage of pregnant women by issues discussed during antenatal check-up.............. 51

Figure 7.5: Percentage of married women by status of TT injections during the last pregnancy ..... 52

Figure 7.6: Percentage of married women by status of Iron/Folate tablets during the last pregnancy52

Figure 7.7: Percentage of married women who experienced complications during their last

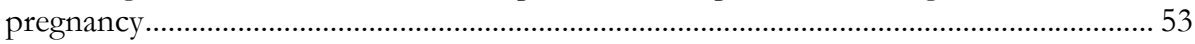

Figure 7.8: Percentage of married women who made arrangements for their last delivery ................54

Figure 7.9: Percentage of pregnancies by outcome ............................................................................. 55

Figure 7.10: Percentage of women by place of delivery......................................................................... 56

Figure 7.11: Percentage of married women who delivered their last child at home by type of delivery

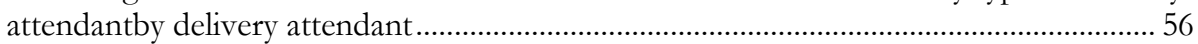

Figure 7.12: Main reason for choosing a TBA/dai to assist with the last delivery.............................. 57

Figure 7.13: Percentage of delivery attendants who reportedly washed hands before conducting the delivery and type of thread used to tie the cord ................................................................. 57

Figure 7.14: Percentage of delivery attendants who reported instruments for cutting the cord ......... 58

Figure 7.15: Time taken to reach the health facility for childbirth ......................................................... 60

Figure 7.16: Median time to get the transport, to reach the health facility and to obtain the treatment

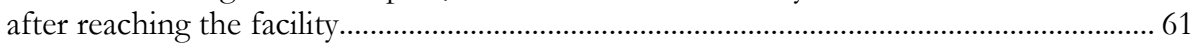

Figure 7.17: Percentage of newborns according to their size (small, normal and big) at birth............ 62

Figure 7.18: Duration between the time of birth and the first bath given to a newborn ..................... 63

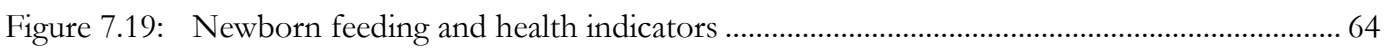

Figure 7.20: Percentage of newborns with danger signs/symptoms soon after deliver ...................... 64

Figure 7.22: Place where treatment was sought for newborn complications...................................... 65

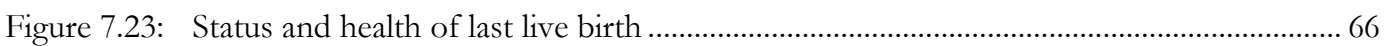




\section{Acknowledgments}

The PAIMAN Baseline Household Survey is a collaborative effort involving many partners, and will be the foundation of the PAIMAN project as a whole. Firstly, we would like to acknowledge our major partners. The United States Agency for International Development (USAID), in particular Mr. Chris McDermott, made funding available for this activity. Dr. Nabeela Ali, Chief of Party for PAIMAN, encouraged the study in general, and greatly facilitated the partnership between the Population Council and NIPS. The role of NIPS was supported under a separate agreement with PAIMAN. The comments, suggestions and feedback received from PAIMAN partners with regard to the design of this activity greatly contributed towards the success of the household survey.

The National Institute of Population Studies (NIPS) ably carried out the fieldwork for this study and was responsible for the completion of a clean dataset. We would like to appreciate the efforts of the Executive Director, Dr. Saeed Shafqat; and the Director Mr. Mahboob Sultan for the timely execution of the fieldwork; Computer Programmer, Mr. Fateh-ud-din, who managed the entry and cleaning of the data and the numerous NIPS staff members who carried out the study.

The Population Council was primarily responsible for designing the study, overseeing the data collection, analysis of data, and writing the reports. Dr. Arshad Mahmood, Director of Monitoring and Evaluation for PAIMAN, used his capable technical and managerial skills to oversee the entire study with enthusiasm and energy. Mr. Peter Miller, Deputy Country Director, contributed substantially in the design phase, and Dr. Sathar and Mr. Miller contributed towards the report preparation.

The essential work of the study was carried out by several Council staff members at all phases. During the design and pre-testing phases, we would particularly like to acknowledge Shagufta Naheed, Bushra Bano, Tayyaba Gul, and Saima Pervaiz for monitoring fieldwork and ensuring quality data collection in the field. Muhammad Ashraf and Saman Naz assisted in preparing graphs and tables as well as with the writing process. Dr. Arshad Mahmood and Reem Khan jointly prepared the first draft of the baseline survey report, which served as the template for all ten district reports. Shafique Arif, Azeema Faizunisa and Nadia Abid also contributed to the report writing and reviewing process. Reem Khan completed the initial editing of the baseline reports, Mehdi Ali Khan designed their layout, Ali Ammad was responsible for the formatting, and Ms. Mary DeSouza carried out the final proofreading of the district reports.

Finally, we must express our gratitude to the women of Jaffarabad, who gave their time freely and cooperated with us in order to make this study possible. We hope to repay them by using the information obtained from them to improve maternal and neonatal health services in the district of Jaffarabad. 



\section{Chapter}

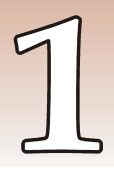

\section{Introduction}

\section{Background}

The Pakistan Initiative for Mothers and Newborns (PAIMAN) is a five-year project funded by the United States Agency for International Development (USAID). PAIMAN is committed to assisting the Government of Pakistan (GoP) in its attempt to implement the full spectrum of interventions necessary to address maternal and neonatal health $(\mathrm{MNH})$ issues.

The consortium is led by John Snow Incorporated (JSI), with partners from Pakistani and international organizations including Aga Khan University, Contech, Greenstar Social Marketing, Johns Hopkins University Center for Communication Program (JHU), PAVHNA, Population Council and Save the Children USA.

USAID has provided a grant to implement PAIMAN in 10 districts of Pakistan's four provinces. These districts are: Rawalpindi, Jhelum, Khanewal, and DG Khan in Punjab; Dadu and Sukkur in Sindh; Jaffarabad and Lasbela in Balochistan; and Upper Dir and Buner in the North West Frontier Province. The goal of the project is to reduce maternal, newborn and child mortality in Pakistan. The project is based on the "Pathway to Care and Survival" framework. The five major strategic objectives are to:

1) Increase awareness and promote positive maternal and neonatal health behaviors

2) Increase access (including essential obstetric care) to and community involvement in maternal and child health services, while ensuring that services are successfully delivered through health and ancillary health services

3) Improve service quality in both the public and private sectors, particularly related to the management of obstetrical complications

4) Increase the capacity of Maternal and Newborn Health (MNH) managers and care providers

5) Improve the management and integration of services at all levels

The PAIMAN Project will promote skilled attendants as the long-term goal for all deliveries in Pakistan while acknowledging that maternal and neonatal health outcomes are influenced by factors other than health care. The PAIMAN Project calls for a multi-pronged and integrated strategic approach combining individual health care with public health and community-based interventions. 
To ensure that the success of PAIMAN is properly attained and that the appropriate lessons are learned, PAIMAN has developed a Monitoring and Evaluation Plan. Included in this plan is the establishment of baseline measures for a set of indicators which will be used to evaluate the success of the project. This baseline report explores the level of knowledge of, as well as the attitudes and behaviors towards, maternal and newborn health in the Jaffarabad district. The specific objectives of the baseline survey were as follows:

\section{Objectives}

- To measure the Intermediate Result 7 indicators necessary as part of PAIMAN's obligation to USAID.

- $\quad$ To measure PAIMAN indicators for which household survey data are appropriate for measurement and for which sample sizes are feasible.

- To obtain information on maternal and neonatal health along with related issues, which may be of use to district Departments of Health for health management purposes.

- To obtain information needed for the detailed design of the PAIMAN project and, in particular, behavior change communication, public/private partnerships and health systems strengthening.

\section{Methodology}

\section{Study Population}

PAIMAN is primarily a district-level project, intended to improve the health of all pregnant women, women with neonatal children, as well as all neonates of the district over the course of the project. To this end, the study covers community residents - notably mothers and prospective mothers - in order to understand and measure general knowledge and practice in relation to pregnancy, delivery, obstetric and neonatal emergencies etc.

Hence, the study population for the baseline includes all currently married women of reproductive age (15-49 years) living in the selected districts. More specifically, it includes women who have experienced a pregnancy during the last three years.

\section{Sample Design}

The sampling design adopted for the survey is a stratified, systematic sample of households. The universe consists of all urban and rural areas of the district. The number of blocks selected in urban areas, along with the number of villages selected in rural areas, are presented in table 1.1. The selection procedure is described below:

Table 1.1:

Number of blocks/villages and households selected for the sample population

\begin{tabular}{|c|c|c|}
\hline Area & $\begin{array}{l}\text { Number of Sample } \\
\text { Blocks/Villages }\end{array}$ & $\begin{array}{l}\text { Number of Households } \\
\text { Selected }\end{array}$ \\
\hline Urban & 8 & 192 \\
\hline Rural & 30 & 720 \\
\hline Total & 38 & 912 \\
\hline
\end{tabular}




\section{Urban sample}

The "Enumeration Circle" was the smallest unit available in the 1998 Population District Census Reports as demarcated by the Population Census organizations. The required numbers of enumeration blocks were selected with probability proportional to size. The maps of these circles were obtained from the Population Census Organization.

The areas were already divided into blocks of approximately 250-300 households depending on the number of households in each circle. Later, blocks were randomly selected with probability proportional to size from the list of total blocks in that circle. The listing of each block was then updated by the enumeration teams before selecting the sampled households. A fixed number of 24 households have been drawn from each sample enumeration block by using systematic random technique.

\section{Rural Sample}

The 1998 Population Census list of villages was used as the sampling frame for the selection of the rural sample. Villages in rural areas have been treated as primary sampling units (PSU). Sample PSUs have been selected with probability proportional to size (number of households). Households within the sample PSUs were considered secondary sampling units. The enumeration teams then updated the listing of each village before selecting the sampled households. A fixed number of 24 households have been drawn from each sample enumeration village by the systematic random technique.

\section{Questionnaire Design}

The questionnaire has been developed by the Population Council based on a combination of current general Demographic and Health Survey methodologies and the questionnaire developed by the Population Council for the Safe Motherhood Applied Research and Training (SMART) Project. The questionnaires contain data sufficient to estimate all PAIMAN indicators.

Information on the following is included in the questionnaire:

- Households information

- Socio-economic status of women

- Fertility, pregnancy history and reproductive intentions

- Attitude towards, as well as knowledge and practice of, contraceptive methods

- Attitude towards pregnancy, delivery and the postpartum period

- Current birth preparedness/complications readiness (BP/CR) and knowledge of newborn care

- Current birth practices

- Health-seeking behaviors

- $\quad$ Future BP/CR intentions

- Personal beliefs regarding pregnancy, delivery and the postpartum period

- Common perceptions pertaining to women who are pregnant, delivering or in their postpartum period 
- Facilities regarding BP/CR available in the community

- Factors that facilitate or hinder behaviors related to BP/CR

- Media habits

\section{Pre-testing of Questionnaire}

The questionnaire was reviewed by the PAIMAN's M\&E thematic group and other interested stakeholders and was pre-tested in non-PAIMAN districts. The main objective of pre-testing was to examine the suitability and effectiveness of questions in eliciting adequate responses and to find out if there were any linguistic problems faced either by interviewers or by respondents.

Finally, the pre-testing also helped determine the approximate time required to complete a questionnaire. The pre-tests were carried out by the Population Council's female staff members who recorded their experiences with regard to each question. These records were then used to revise and finalize the questionnaire.

\section{Hiring of Interviewers and Supervisors}

Since the respondents in the baseline were to be MWRA and married men, it was decided that female interviewers would be used to interview women and male interviewers for men. Based on the constitution of each team, the required number of female interviewers were hired by the National Institute of Population Studies (NIPS) according to its own internal procedures.

\section{Training of Interviewers and Supervisors}

The quality of training received by interviewers is reflected in the quality of data they record. In order to ensure that interviews were of a high and uniform quality and that interviewers understood the definitions and concepts behind the language of the questions, training was conducted by the Population Council in collaboration with NIPS. The training took place in Islamabad over two weeks and interviewers were schooled in questionnaire and survey procedures. Interviewers visited 3-4 households to conduct practice interviews.

It was very important for the interviewers to thoroughly understand the methodology and statistical importance of the sampled households. Training regarding the importance of the criterion for the selection of primary sampling units, mapping and listing procedure, sample selection, field operation procedures, as well as the selection of the particular households and respondents was also provided by experts.

\section{Data Entry and Edit Procedures}

Data processing was started from the field level with the checking of the questionnaires. Each team leader completed on-the-spot checks and preliminary editing of questionnaires during the enumeration period. Editing instructions were provided to the team leaders and emphasis was laid on the importance of completing each questionnaire, correctly identifying each eligible respondent and the completeness of household composition. 


\section{Quality Assurance}

To ensure the quality of the data, Population Council staff monitored the fieldwork accompanying the field teams. While supervising the fieldwork, the Population Council supervisory staff was also available to provide on-the-spot guidance to interviewers in the event that any part of the questionnaire was unclear to them. This ensured the completeness and accuracy of each questionnaire. 



\section{Socio-Economic and Demographic Characteristics}

This chapter presents the demographic and socioeconomic characteristics of the population in the survey households of Jaffarabad. Information was collected on some demographic and socioeconomic characteristics such as the condition of the households, including the source of drinking water, sanitation facilities, building materials, and possession of household durable goods. This information on the characteristics of the households is essential for the interpretation of survey findings. The definition of the household used for the baseline survey was "a person or a group of persons, related or unrelated, who live together in the same dwelling unit and share a common source of food".

\section{Urban/Rural sample population}

A total of 912 households were selected in the district of Jaffarabad for the purpose of collecting baseline information. This included 720 households from rural areas and 192 from the urban areas of the district (Table 2.1)

Table 2.1: $\quad$ Interview completion status

\begin{tabular}{lrrrrrrr}
\multirow{2}{*}{ Result } & \multicolumn{2}{c}{ Rural } & \multicolumn{2}{c}{ Urban } & \multicolumn{2}{c}{ Total } \\
\cline { 2 - 7 } Completed & Percent & Number & Percent & Number & Percent & \multicolumn{1}{c}{ Number } \\
\hline Incomplete & 98.6 & 710 & 99.0 & 190 & 98.7 & 900 \\
\hline Refused & 0.1 & 1 & & & 0.1 & 1 \\
\hline Total & 1.3 & 9 & 1.0 & 2 & 1.2 & 11 \\
\hline
\end{tabular}




\section{Languages spoken}

An overall picture of the ethnic and linguistic makeup of the district becomes possible by determining the languages spoken in the households. According to table 2.2, Sindhi (28percent), Balochi (32 percent), Barahvi (21 percent) and Saraiki (18 percent) are the most commonly spoken local languages in the district. A majority of the urban population in Jaffarabad speaks Saraiki (35.8 percent) followed by Sindhi (33.2 percent). While in rural areas mainly spoken languages were Balochi and Sindhi 35.2 and 26.6 ) respectively.

Figure 2.1: Languages spoken in the households

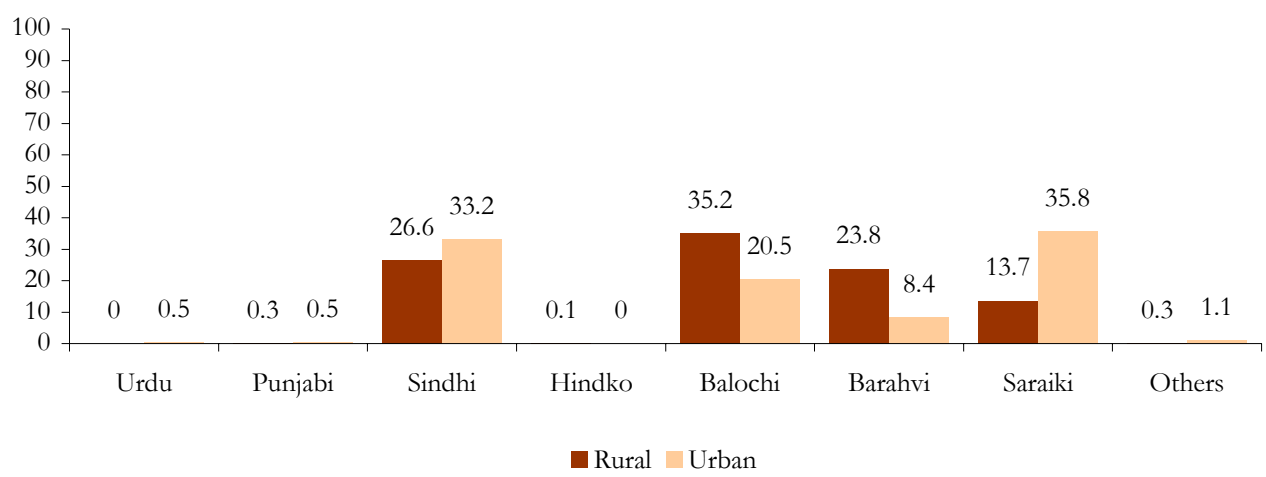

Table 2.2: $\quad$ Language most commonly spoken at home

\begin{tabular}{lrrrrrr}
\multicolumn{1}{c}{ Language } & \multicolumn{2}{c}{ Rural } & \multicolumn{2}{c}{ Urban } & \multicolumn{2}{c}{ Total } \\
\cline { 2 - 7 } Urdu & Percent & \multicolumn{1}{c}{ Number } & Percent & Number & Percent & Number \\
\hline Punjabi & & & 0.5 & 1 & 0.1 & 1 \\
\hline Sindhi & 0.3 & 2 & 0.5 & 1 & 0.3 & 3 \\
\hline Hindko & 26.6 & 189 & 33.2 & 63 & 28.0 & 252 \\
\hline Balochi & 0.1 & 1 & & & 0.1 & 1 \\
\hline Barahvi & 35.2 & 250 & 20.5 & 39 & 32.1 & 289 \\
\hline Saraiki & 23.8 & 169 & 8.4 & 16 & 20.6 & 185 \\
\hline Others & 13.7 & 97 & 35.8 & 68 & 18.3 & 165 \\
\hline Total & 0.3 & 2 & 1.1 & 2 & 0.4 & 4 \\
& 100.0 & 710 & 100.0 & 190 & 100.0 & 900
\end{tabular}




\section{Population composition}

Age and sex are important demographic variables and are the primary basis of demographic analysis.

These are also important variables in the study of reproductive health, mortality and fertility.

According to the table 2.3, men make up almost 51 percent of the population. Out of the total female population of the district, 40 percent fall in the reproductive age group of 15- 49 years. Table 2.3 gives a comparative distribution of the sample population of Jaffarabad according to their age and sex in selected age groups.

Table 2.3: $\quad$ Age-sex distribution of population

\begin{tabular}{|c|c|c|c|c|c|c|}
\hline \multirow[b]{2}{*}{ Age-group } & \multicolumn{2}{|c|}{ Males } & \multicolumn{2}{|c|}{ Females } & \multicolumn{2}{|c|}{ Both Sexes } \\
\hline & Number & Percent & Number & Percent & Number & Percent \\
\hline$<5$ & 895 & 18.1 & 863 & 18.4 & 1758 & 18.2 \\
\hline $5-9$ & 985 & 19.9 & 935 & 19.9 & 1920 & 19.9 \\
\hline $10-14$ & 643 & 13.0 & 538 & 11.5 & 1181 & 12.2 \\
\hline $15-19$ & 442 & 8.9 & 390 & 8.3 & 832 & 8.6 \\
\hline $20-24$ & 396 & 8.0 & 384 & 8.2 & 780 & 8.1 \\
\hline $25-29$ & 337 & 6.8 & 407 & 8.7 & 744 & 7.7 \\
\hline $30-34$ & 272 & 5.5 & 280 & 6.0 & 552 & 5.7 \\
\hline $35-39$ & 267 & 5.4 & 183 & 3.9 & 450 & 4.7 \\
\hline $40-44$ & 149 & 3.0 & 118 & 2.5 & 267 & 2.8 \\
\hline $45-49$ & 130 & 2.6 & 108 & 2.3 & 238 & 2.5 \\
\hline $50-54$ & 98 & 2.0 & 158 & 3.4 & 256 & 2.7 \\
\hline $55-59$ & 93 & 1.9 & 95 & 2.0 & 188 & 1.9 \\
\hline $60-64$ & 73 & 1.5 & 81 & 1.7 & 154 & 1.6 \\
\hline 65 and older & 175 & 3.5 & 154 & 3.3 & 329 & 3.4 \\
\hline Total & 4955 & 100.0 & 4694 & 100.0 & 9649 & 100.0 \\
\hline
\end{tabular}




\section{Marital status}

All individuals over the age of 15 years were asked about their marital status. High differences were noticed between the percentage of currently married males and females who fall in the same age bracket. A comparison of the baseline results with the results of the Population Census 1998, shows that there has been a decrease in the percentage of women getting married between 15-29 years of age. However, despite the fact that there has been a decline in early marriages for females, 60 percent of them were currently married at the time of the survey. Table 2.4 gives the percentage distribution of marital status by sex and age groups.

Table 2.4:

Household population by age (15 years and above), sex and marital status

\begin{tabular}{lcccccc} 
& \multicolumn{3}{c}{ Males } & \multicolumn{3}{c}{ Females } \\
\cline { 2 - 4 } Age & Never & Currently & Widow/ & Never & Currently & Widow/ \\
Group & Married & Married & Divorced & Married & Married & Divorced
\end{tabular}

PAIMAN Baseline 2005

\begin{tabular}{lrrrrrr}
\hline $15-19$ & 97.6 & 2.4 & 0.0 & 87.8 & 11.7 & 0.5 \\
\hline $20-24$ & 79.3 & 20.4 & 0.0 & 50.3 & 49.1 & 0.6 \\
\hline $25-29$ & 45.3 & 52.6 & 1.0 & 19.9 & 75.9 & 3.4 \\
\hline $30-34$ & 12.5 & 85.2 & 0.9 & 3.2 & 90.5 & 5.5 \\
\hline $35-39$ & 6.6 & 92.9 & 0.5 & 3.5 & 92.4 & 4.0 \\
\hline $40-44$ & 1.8 & 95.8 & 1.2 & 2.1 & 89.4 & 8.5 \\
\hline $45-49$ & 1.4 & 95.8 & 2.1 & 1.0 & 83.8 & 14.1 \\
\hline $50-54$ & 0.0 & 93.8 & 5.2 & 0.0 & 86.7 & 13.3 \\
\hline $55-59$ & 0.0 & 96.1 & 2.6 & 1.4 & 75.7 & 21.6 \\
\hline $60-64$ & 0.0 & 87.2 & 12.8 & 1.5 & 53.7 & 43.3 \\
\hline 65 and older & 2.3 & 71.0 & 26.0 & 2.0 & 33.7 & 64.3 \\
Total & 40.7 & 55.9 & 2.9 & 30.9 & 60.0 & 8.7
\end{tabular}

Population census 1998

\begin{tabular}{lrrrrrr}
\hline $15-19$ & 95.5 & 4.3 & 0.2 & 83.8 & 15.9 & 0.4 \\
\hline $20-24$ & 73.4 & 26.0 & 0.6 & 42.6 & 56.4 & 1.0 \\
\hline $25-29$ & 41.3 & 57.4 & 1.3 & 15.4 & 82.7 & 1.9 \\
\hline $30-34$ & 18.4 & 79.8 & 1.9 & 7.0 & 90.2 & 2.8 \\
\hline $35-39$ & 9.0 & 88.5 & 2.5 & 4.0 & 91.2 & 4.8 \\
\hline $40-44$ & 5.5 & 91.1 & 3.4 & 3.0 & 89.8 & 7.2 \\
\hline $45-49$ & 3.9 & 91.4 & 4.7 & 2.1 & 87.2 & 10.7 \\
\hline $50-54$ & 4.0 & 89.2 & 6.8 & 2.5 & 80.0 & 17.5 \\
\hline $55-59$ & 2.8 & 88.0 & 9.3 & 2.1 & 74.7 & 23.2 \\
\hline $60-64$ & 3.5 & 83.4 & 13.1 & 3.5 & 61.8 & 34.7 \\
\hline 65 and older & 3.8 & 71.6 & 24.6 & 5.0 & 41.5 & 53.5 \\
Total & 37.1 & 58.5 & 4.4 & 25.9 & 65.1 & 9.0
\end{tabular}




\section{Education Attainment}

The productivity and economic growth of any country depends upon the educational status of its people. The majority of female respondents in Jaffarabad (86 percent) have never attended school, compared to 55 percent of males. Furthermore, the findings indicate that out of those females who had attended school, only 5 percent had attained at least 6-10 years of education or above. An overall picture of Jaffarabad presents a low literacy level for the district with a higher educational status for men than women. Details are given in table 2.5 .

Table 2.5: $\quad$ Household population by age (10 years and above), sex and educational level

\begin{tabular}{|c|c|c|c|c|c|}
\hline $\begin{array}{c}\text { Age } \\
\text { Group }\end{array}$ & $\begin{array}{c}\text { No } \\
\text { Schooling }\end{array}$ & $\begin{array}{c}1-5 \\
\text { Years }\end{array}$ & $\begin{array}{l}6-10 \\
\text { Years }\end{array}$ & $\begin{array}{c}11 \text { and } \\
\text { More years }\end{array}$ & Total \\
\hline $10-14$ & 51.0 & 41.1 & 7.9 & 0.0 & 643 \\
\hline $15-19$ & 41.2 & 17.4 & 38.0 & 3.4 & 442 \\
\hline $20-24$ & 41.2 & 12.4 & 40.4 & 6.1 & 396 \\
\hline $25-29$ & 43.9 & 7.1 & 34.1 & 14.8 & 337 \\
\hline $30-34$ & 49.6 & 7.4 & 26.8 & 16.2 & 272 \\
\hline $35-39$ & 59.9 & 6.0 & 19.9 & 14.2 & 267 \\
\hline $40-44$ & 71.8 & 8.1 & 10.7 & 9.4 & 149 \\
\hline $45-49$ & 71.5 & 13.1 & 9.2 & 6.2 & 130 \\
\hline $50-54$ & 73.5 & 10.2 & 10.2 & 6.1 & 98 \\
\hline $55-59$ & 80.6 & 15.1 & 2.2 & 2.2 & 93 \\
\hline $60-64$ & 90.4 & 6.8 & 2.7 & 0.0 & 73 \\
\hline 65 and older & 91.4 & 4.6 & 2.9 & 1.1 & 175 \\
\hline Total & 54.9 & 16.8 & 21.7 & 6.6 & 3075 \\
\hline \multicolumn{6}{|l|}{ Females } \\
\hline $10-14$ & 74.2 & 22.3 & 3.5 & 0.0 & 538 \\
\hline $15-19$ & 72.6 & 15.1 & 10.5 & 1.8 & 390 \\
\hline $20-24$ & 78.4 & 10.9 & 7.3 & 3.4 & 384 \\
\hline $25-29$ & 88.2 & 6.4 & 3.2 & 2.2 & 407 \\
\hline $30-34$ & 94.3 & 3.6 & 1.8 & 0.4 & 280 \\
\hline $35-39$ & 96.2 & 1.6 & 1.1 & 1.1 & 183 \\
\hline $40-44$ & 94.1 & 5.1 & 0.8 & 0.0 & 118 \\
\hline $45-49$ & 97.2 & 0.9 & 1.9 & 0.0 & 108 \\
\hline $50-54$ & 98.7 & 0.6 & 0.6 & 0.0 & 158 \\
\hline $55-59$ & 100.0 & 0.0 & 0.0 & 0.0 & 95 \\
\hline $60-64$ & 100.0 & 0.0 & 0.0 & 0.0 & 81 \\
\hline 65 and older & 99.4 & 0.6 & 0.0 & 0.0 & 154 \\
\hline Total & 85.7 & 9.3 & 3.9 & 1.1 & 2896 \\
\hline
\end{tabular}




\section{Housing characteristics}

\section{Source of drinking water}

In order to assess the basic housing characteristics of the district, respondents were asked to indicate the main source of drinking water available to them. A quarter of the sample population in Jaffarabad (25 percent) indicated that they obtain their drinking water from rivers, canals, streams or ponds.

One-tenth of the population has motorized hand pumps inside their homes both in rural and urban Jaffarabad. More than 70 percent of urban population has access to govt. supply tap water inside their home, whereas only about 3 percent in rural areas have the same privilege. Table 2.6 gives details of rural urban differentials for sources of drinking water.

Table 2.6: $\quad$ Main source of drinking water

\begin{tabular}{lrrrrrrr} 
& \multicolumn{2}{c}{ Rural } & \multicolumn{2}{c}{ Urban } & \multicolumn{2}{c}{ Total } \\
& \multicolumn{1}{c}{ Source } & Percent & Number & Percent & Number & Percent & Number \\
\hline Govt. supply (tap water inside) & 2.7 & 19 & 70.5 & 134 & 17.0 & 153 \\
\hline Govt. supply (communal) & 3.8 & 27 & 14.7 & 28 & 6.1 & 55 \\
\hline Motorized/hand pump (inside) & 9.7 & 69 & 8.9 & 17 & 9.6 & 86 \\
\hline Motorized/hand pump (outside) & 16.5 & 117 & 5.8 & 11 & 14.2 & 128 \\
\hline Well (inside) & 0.1 & 1 & & & 0.1 & 1 \\
\hline Well (outside) & 1.4 & 10 & & & 1.1 & 10 \\
\hline Tube-well & 0.1 & 1 & & & 0.1 & 1 \\
\hline River/canal/stream & 32.3 & 229 & & & 25.4 & 229 \\
\hline Others & 33.0 & 234 & & & 26.0 & 234 \\
\hline Govt. supply (tap water inside) & 0.4 & 3 & & & 0.3 & 3 \\
\hline Total & 100.0 & 710 & 100.0 & 190 & 100.0 & 900
\end{tabular}

\section{Toilet facilities}

Along with the source of drinking water, toilet facilities are a major indicator of a household's socioeconomic status, and therefore the level of hygiene, sanitation and comfort available to an expectant or new mother and her newborn children. The type of toilet facility a household has access to directly reflects the quality of sanitation, which has a more direct affect on mortality than does socioeconomic status (Martin et al, 1983). Households lacking hygienic toilet facilities have a higher risk of disease and infection, which in turn endangers the health of newborn children and their mothers.

In response to a question on the type of toilet facility used in the household, more than three quarters of the rural ( 80 percent) respondents reported using the fields. In the urban parts of the district, a pit latrine was used by almost 59 percent of the respondents. The results indicate the low socio-economic status of the population residing in the district. 
Table 2.7:

Type of toilet facility used by household members

\begin{tabular}{lrrrrrrr}
\multirow{2}{*}{ Toilet facility } & \multicolumn{2}{c}{ Rural } & \multicolumn{2}{c}{ Urban } & \multicolumn{2}{c}{ Total } \\
\cline { 2 - 7 } Flush to sewerage & Percent & Number & Percent & Number & Percent & Number \\
\hline Flush connected to septic tank & & & 0.5 & 1 & 0.1 & 1 \\
\hline Flush connected to open drain & 3.0 & 21 & 24.2 & 46 & 7.4 & 67 \\
\hline Raised latrine & 1.1 & 8 & 7.9 & 15 & 2.6 & 23 \\
\hline Pit latrine & 6.3 & 45 & 7.4 & 14 & 6.6 & 59 \\
\hline In fields & 9.3 & 66 & 58.9 & 112 & 19.8 & 178 \\
\hline Others & 80.1 & 569 & 1.1 & 2 & 63.4 & 571 \\
\hline Total & 0.1 & 1 & & & 0.1 & 1 \\
\hline
\end{tabular}

\section{Fuel used for cooking}

Fossil fuel is hazardous for health and is an important source of environment pollution. Substantial differences have been noted in the type of fuel used for cooking in urban and rural areas. Dry dung remains to be the most common type of fuel used by 62 percent of the rural respondents, and 25 percent of the urban respondents. On the other hand, natural gas is used by more than 55 percent of the respondents in urban areas as compared to only 5 percent in rural areas. Fire wood was reported as a fuel for cooking by one-third (32 percent) of rural and 19 percent of urban population.

Table 2.8: $\quad$ Main type of fuel used for cooking

\begin{tabular}{lrrrrrrr}
\multirow{2}{*}{\multicolumn{1}{c}{ Type of fuel }} & \multicolumn{2}{c}{ Rural } & \multicolumn{2}{c}{ Urban } & \multicolumn{2}{c}{ Total } \\
\cline { 2 - 7 } & Percent & Number & Percent & Number & Percent & Number \\
\hline Fire wood & 32.0 & 227 & 18.9 & 36 & 29.2 & 263 \\
\hline Kerosene oil & 0.1 & 1 & & & 0.1 & 1 \\
\hline Gas cylinder & 0.3 & 2 & 1.1 & 2 & 0.4 & 4 \\
\hline Natural gas (Sui gas) & 4.9 & 35 & 54.7 & 104 & 15.4 & 139 \\
\hline Dry dung & 62.3 & 442 & 25.3 & 48 & 54.4 & 490 \\
\hline Charcoal/coal & 0.1 & 1 & & & 0.1 & 1 \\
\hline Others & 0.3 & 2 & & & 0.2 & 2 \\
\hline Total & 100.0 & 710 & 100.0 & 190 & 100.0 & 900
\end{tabular}

\section{Materials used for the House Roof}

The materials used for the roof and walls of a household are major indicators of the socio-economic status of that household, as well as the living standards of the people residing in them. The more secure the materials, the higher the level of comfort and living standard for residents, and the lower the risk of disease and infection. Nearly three quarters of the rural respondents (71 percent) reported roofs made of wood and mud followed by a quarter (23 percent) who had roofs made of girder and T-iron. Girder and T-iron were the most commonly reported materials used for roofs by 63 percent of urban respondents. It may be noted that only 5 percent in rural areas and 2 percent in urban areas had concrete roofs. 
Figure 2.2: $\quad$ Material used for the construction of roof

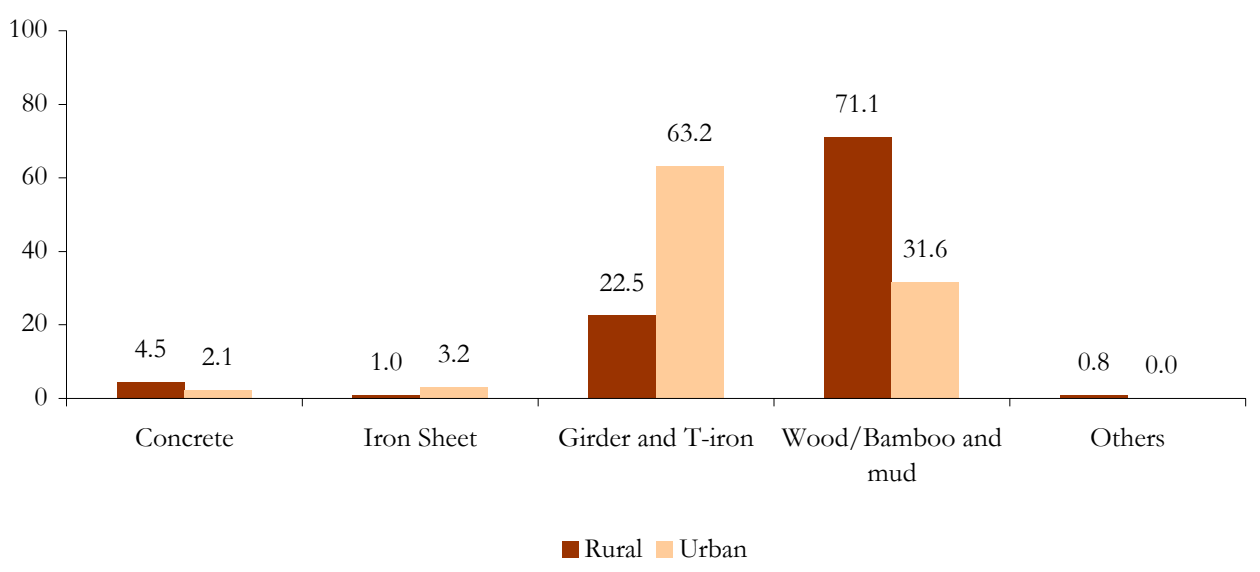

\section{Number of Rooms for Sleeping}

The number of separate rooms available for sleeping in each household is an important indicator of sanitation and hygiene levels. Overcrowding in households may lead to the spread of infection and diseases, which puts the lives of expectant/young mothers and their newborn children at risk. According to table 2.9, the majority of the respondents (42 percent) reported having a single room, followed by 32 percent who had two rooms available to them for the purpose of sleeping. In urban areas there was an average of 4.9 persons per room, compared to 6.3 persons per room in rural areas.

Table 2.9: $\quad$ Number of rooms used for sleeping

\begin{tabular}{lrrrrrr}
\multirow{2}{*}{ Number of rooms } & \multicolumn{2}{c}{ Rural } & \multicolumn{2}{c}{ Urban } & \multicolumn{2}{c}{ Total } \\
\cline { 2 - 8 } 0.00 & Percent & \multicolumn{1}{c}{ Number } & Percent & Number & Percent & Number \\
\hline 1 & 0.1 & 1 & & & 0.1 & 1 \\
\hline 2 & 46.6 & 331 & 23.7 & 45 & 41.8 & 376 \\
\hline 3 & 30.1 & 214 & 38.9 & 74 & 32.0 & 288 \\
\hline 4 & 13.4 & 95 & 22.6 & 43 & 15.3 & 138 \\
\hline $5+$ & 6.6 & 47 & 12.1 & 23 & 7.8 & 70 \\
\hline Total & 3.1 & 22 & 2.6 & 5 & 3.0 & 27 \\
& 100.0 & 710 & 100.0 & 190 & 100.0 & 900
\end{tabular}




\section{Household Possessions}

Household possessions are perhaps one of the most effective ways of determining socio-economic success in a household. Often, it is easier to obtain information on household possessions than to ask for details about the household income, which respondents may be less willing to provide for various reasons.

The presence of durable goods in the household, such as radio, television, telephone, refrigerator, motorcycle, and private car, is another indicator of the household's socio-economic status. Moreover, particular goods have specific benefits such as, ownership of a radio or television is a measure of access to mass media and exposure to innovative ideas; telephone ownership measures access to an efficient means of communication; refrigerator ownership prolongs the wholesomeness of foods and ownership of private transport allows greater access to many services away from the local area.

Table 2.10 presents the details of household possessions reported by respondents in Jaffarabad. Commodities such as an electric fan, electric iron, radio cassette player, and television were reported to be possessed by a high majority of the population in Jaffarabad.

Table 2.10 : Ownership of household commodities/land

\begin{tabular}{|c|c|c|c|c|}
\hline \multirow{2}{*}{ Household items } & \multirow{2}{*}{ Rural } & \multirow{2}{*}{ Urban } & \multicolumn{2}{|c|}{ Total } \\
\hline & & & Percentage & Number \\
\hline Electric iron & 37.6 & 75.3 & 45.6 & 410 \\
\hline Electric fan & 81.7 & 97.9 & 85.1 & 766 \\
\hline Sewing machine & 33.1 & 60.0 & 38.8 & 349 \\
\hline Radio or cassette player & 45.5 & 52.6 & 47.0 & 423 \\
\hline Chair/table & 8.3 & 24.7 & 11.8 & 106 \\
\hline Television & 38.0 & 68.4 & 44.4 & 400 \\
\hline Telephone & 14.5 & 26.8 & 17.1 & 154 \\
\hline Watch/clock & 44.1 & 74.7 & 50.6 & 455 \\
\hline VCR/VCP/VCD/CD player & 16.5 & 18.9 & 17.0 & 153 \\
\hline Refrigerator/deep freezer & 16.8 & 24.2 & 18.3 & 165 \\
\hline Air cooler & 6.9 & 23.7 & 10.4 & 94 \\
\hline Air conditioner & 3.0 & 7.4 & 3.9 & 35 \\
\hline Computer & 2.7 & 5.8 & 3.3 & 30 \\
\hline Bicycle & 38.2 & 24.2 & 35.2 & 317 \\
\hline Motorcycle & 15.2 & 16.3 & 15.4 & 139 \\
\hline Car/jeep & 5.5 & 2.1 & 4.8 & 43 \\
\hline Tractor/truck & 11.0 & 2.1 & 9.1 & 82 \\
\hline Ownership of agriculture land by $\mathrm{HH}$ & 36.9 & 7.4 & 30.7 & 276 \\
\hline Agriculture major source of livelihood & 35.6 & 6.3 & 29.4 & 265 \\
\hline
\end{tabular}




\section{Ownership of the House}

Table 2.11 reflects ownership of the house. Nearly 92 percent of the respondents in urban areas and 44 percent in rural parts of Jaffarabad own the house in which they reside. A high percentage of respondents in rural area (52 percent) live in rent-free accommodations.

Table 2.11: $\quad$ Status of ownership of house

\begin{tabular}{l|rrrrrr}
\multirow{2}{*}{\multicolumn{1}{c}{ Status }} & \multicolumn{2}{c}{ Rural } & \multicolumn{2}{c}{ Urban } & \multicolumn{2}{c}{ Total } \\
\cline { 2 - 7 } & Percent & Number & Percent & Number & Percent & Number \\
\hline Owner occupied & 43.8 & 311 & 91.6 & 174 & 53.9 & 485 \\
\hline Rented & 1.4 & 10 & 5.8 & 11 & 2.3 & 21 \\
\hline Rent free & 52.1 & 370 & 2.6 & 5 & 41.7 & 375 \\
\hline Others & 2.7 & 19 & & & 2.1 & 19 \\
Total & 100.0 & 710 & 100.0 & 190 & 100.0 & 900
\end{tabular}




\section{Chapter \\ 5}

\section{Background Characteristics of Married Women of Reproductive Age}

Information regarding the basic background characteristics of respondents is essential for the interpretation of survey findings. This chapter describes the basic background characteristics including age, education level, and place of residence of the respondents. It also describes detailed information on the educational status of respondents and their husbands, literacy levels, and exposure to mass media. Only currently married women aged 15-49 were interviewed for this portion of the survey.

\section{Women's Characteristics}

\section{Age Distribution of Married Women}

Table 3.1 indicates the number of married women of reproductive age in each age group for the households surveyed. The results show that the majority of the respondents $(87.5$ percent) in Jaffarabad fall in the various reproductive age groups between 20 to 44 years of age.

The majority of rural (64 percent) and urban (65 percent) respondents reported getting married between the ages of 15-19 years. Only 1 percent in rural areas and nearly 2 percent in urban areas got married at the age of 25 years or over. It is clear that girls tend to get married at a younger age in the district of Jaffarabad. Overall, the mean age of respondents in Jaffarabad is estimated to be 31.6 years. The mean age at marriage for women in Jaffarabad is 16.1 years. Table 3.1 gives the details of age distribution of women and their age at marriage.

Figure 3.1: $\quad$ Age distribution

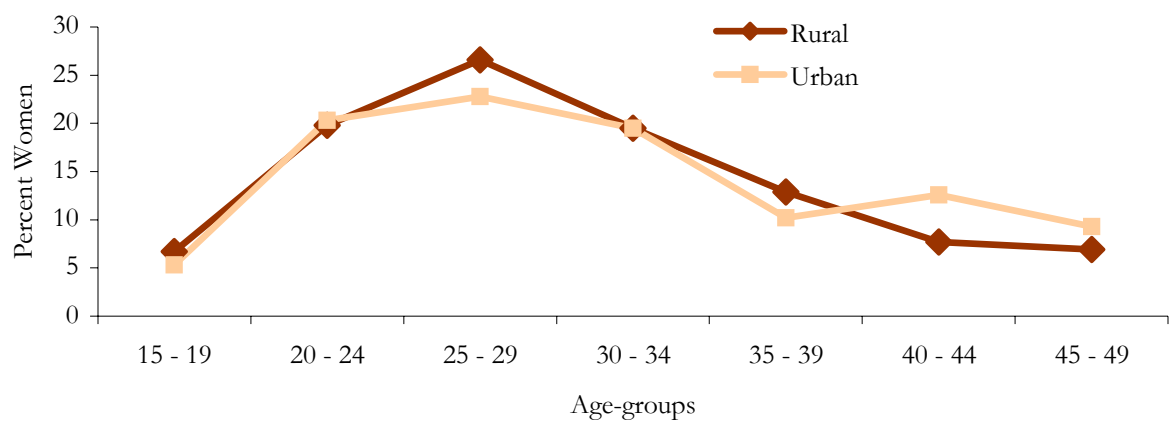


Table 3.1: $\quad$ Current age and age at marriage

\begin{tabular}{|c|c|c|c|c|c|c|c|}
\hline \multirow{2}{*}{\multicolumn{2}{|c|}{ Background profile }} & \multicolumn{2}{|c|}{ Rural } & \multicolumn{2}{|c|}{ Urban } & \multicolumn{2}{|c|}{ Total } \\
\hline & & Percent & Number & Percent & Number & Percent & Number \\
\hline \multirow{7}{*}{ Age of respondent } & $15-19$ & 6.7 & 65 & 5.3 & 13 & 6.4 & 78 \\
\hline & $20-24$ & 19.8 & 193 & 20.3 & 50 & 19.9 & 243 \\
\hline & $25-29$ & 26.6 & 260 & 22.8 & 56 & 25.9 & 316 \\
\hline & $30-34$ & 19.5 & 190 & 19.5 & 48 & 19.5 & 238 \\
\hline & $35-39$ & 12.9 & 126 & 10.2 & 25 & 12.4 & 151 \\
\hline & $40-44$ & 7.7 & 75 & 12.6 & 31 & 8.7 & 106 \\
\hline & $45-49$ & 6.9 & 67 & 9.3 & 23 & 7.4 & 90 \\
\hline \multirow{4}{*}{ Age at marriage } & $<15$ & 21.9 & 214 & 24.4 & 60 & 22.4 & 274 \\
\hline & $15-19$ & 63.9 & 624 & 65.0 & 160 & 64.2 & 784 \\
\hline & $20-24$ & 13.1 & 128 & 8.9 & 22 & 12.3 & 150 \\
\hline & $25+$ & 1.0 & 10 & 1.6 & 4 & 1.1 & 14 \\
\hline
\end{tabular}

\section{Education/literacy level}

The level of education obtained by a woman can be a good indicator of her status in society as well as the independent decision-making power available to her. It is presumed that the higher the level of education obtained by a woman, the more say she has in matters concerning her health and that of her children. With regard to maternal health, a higher literacy rate in women can result in an increased use of contraceptives, higher awareness of complications during and after pregnancy, a strong understanding of neonatal and newborn health, and finally, a more complete understanding of safe birth practices.

It has also been shown that the mortality rates among children with mothers who have six or more years of education are considerably lower than the mortality rates among children with uneducated mothers (Martin, 1983). Educated women are more likely to recognize signs of illness in their children, actively seek assistance from a doctor and administer the treatment in the manner required. Educated women are also more likely to return to a doctor in the event that the treatment administered failed to take effect. Therefore, the proactive nature of educated women with regard to the health of their children lowers the morbidity and mortality rates of infants and young children (Caldwell, 1986).

Out of the total woman interviewed, 92 percent were illiterate. When asked about the educational status of the husbands, 57 percent of the women reported that their husbands were also illiterate. Among the 8 percent of the respondents who were educated, 6 percent went up to the primary level only. Table 3.2 gives details of the education and literacy levels of respondents and their husbands. 
Table 3.2:

Education and literacy level of respondents and their husbands

\begin{tabular}{|c|c|c|c|c|c|c|c|}
\hline \multirow{2}{*}{\multicolumn{2}{|c|}{ Background profile }} & \multicolumn{2}{|c|}{ Rural } & \multicolumn{2}{|c|}{ Urban } & \multicolumn{2}{|c|}{ Total } \\
\hline & & Percent & Number & Percent & Number & Percent & Number \\
\hline \multirow{5}{*}{$\begin{array}{l}\text { Level of } \\
\text { education }\end{array}$} & No education & 92.8 & 906 & 83.3 & 205 & 90.9 & 1,111 \\
\hline & Up to primary & 4.7 & 46 & 10.6 & 26 & 5.9 & 72 \\
\hline & Up to middle & 0.5 & 5 & 1.6 & 4 & 0.7 & 9 \\
\hline & Up to secondary & 1.4 & 14 & 3.3 & 8 & 1.8 & 22 \\
\hline & Secondary + & 0.5 & 5 & 1.2 & 3 & 0.7 & 8 \\
\hline \multirow{2}{*}{$\begin{array}{l}\text { Respondent's } \\
\text { literacy }\end{array}$} & Literate & 7.3 & 71 & 13.0 & 32 & 8.4 & 103 \\
\hline & Illiterate & 92.7 & 905 & 87.0 & 214 & 91.6 & 1,119 \\
\hline \multirow{6}{*}{$\begin{array}{l}\text { Husband's Level } \\
\text { of education }\end{array}$} & No education & 60.9 & 594 & 43.5 & 107 & 57.4 & 701 \\
\hline & Up to primary & 8.2 & 80 & 11.0 & 27 & 8.8 & 107 \\
\hline & Up to middle & 6.0 & 59 & 8.1 & 20 & 6.5 & 79 \\
\hline & Up to secondary & 15.4 & 150 & 19.9 & 49 & 16.3 & 199 \\
\hline & Secondary + & 9.4 & 92 & 17.5 & 43 & 11.0 & 135 \\
\hline & Don't know & 0.1 & 1 & & & 0.1 & 1 \\
\hline \multirow{2}{*}{$\begin{array}{l}\text { Husband's } \\
\text { literacy }\end{array}$} & Literate & 39.0 & 381 & 56.5 & 139 & 42.6 & 520 \\
\hline & Illiterate & 61.0 & 595 & 43.5 & 107 & 57.4 & 702 \\
\hline
\end{tabular}

The level of education of fathers also affects the mortality rates amongst children. This is partly an indication of socio-economic level, as typically the more education the father of a child has, the higher his socio-economic status and standard of living are likely to be. However, the effect educated fathers have on the mortality rates of children is lower than the effect an educated mothers have. (Mahmood, 1992).

The ability to read is an important personal asset allowing women and their husbands increased access to various opportunities. By gathering information regarding the distribution of literacy among the respondents surveyed, maternal and newborn health communicators are better able to reach their target population with their messages.

\section{Children Ever Born and Living}

The mean number of children ever born in Jaffarabad is 4.3 , while the mean number of children still living is 3.7. Out of a total of 1,222 women interviewed, 44 percent reported giving birth to five or more children. It may be noted that 29 percent of the women who reported giving birth to five or more children were between the ages of 25-29 years. About 44 percent of the women in the 15-19 year age group reported giving birth to 1-2 children at the time of the baseline survey. 
Table 3.3: $\quad$ Percentage distribution of married women by number of children ever born, mean number of children ever born, living children and age group, compared to the 1998 population census

\begin{tabular}{|c|c|c|c|c|c|c|c|c|}
\hline \multirow{3}{*}{$\begin{array}{l}\text { Age } \\
\text { Group }\end{array}$} & \multicolumn{5}{|c|}{ Number of Children Ever Born } & \multirow{3}{*}{$\begin{array}{l}\text { No. of } \\
\text { Women }\end{array}$} & \multirow{2}{*}{\multicolumn{2}{|c|}{$\begin{array}{c}\text { Mean Number of Children } \\
\text { Baseline }\end{array}$}} \\
\hline & \multirow[t]{2}{*}{0} & \multirow[t]{2}{*}{$1-2$} & \multirow[t]{2}{*}{$3-4$} & \multirow{2}{*}{$\begin{array}{l}5 \text { or } \\
\text { more }\end{array}$} & \multirow[t]{2}{*}{ Total } & & & \\
\hline & & & & & & & Ever born & Living \\
\hline $15-19$ & 53.8 & 43.6 & 2.6 & 0.0 & 100 & 78 & 0.6 & 0.5 \\
\hline $20-24$ & 18.9 & 51.9 & 22.2 & 7.0 & 100 & 243 & 1.9 & 1.7 \\
\hline $25-29$ & 4.1 & 27.5 & 39.2 & 29.1 & 100 & 316 & 3.4 & 3.0 \\
\hline $30-34$ & 3.4 & 10.9 & 26.5 & 59.2 & 100 & 238 & 5.1 & 4.3 \\
\hline $35-39$ & 2.6 & 6.6 & 12.6 & 78.1 & 100 & 151 & 6.5 & 5.5 \\
\hline $40-44$ & 4.7 & 2.8 & 9.4 & 83.0 & 100 & 106 & 7.2 & 6.1 \\
\hline $45-49$ & 1.1 & 3.3 & 2.2 & 93.3 & 100 & 90 & 8.1 & 6.9 \\
\hline Total & 9.7 & 23.6 & 22.4 & 44.2 & 100 & 1222 & 4.3 & 3.7 \\
\hline
\end{tabular}

\section{Preceding Birth Interval}

The length of the preceding birth interval is very important as it directly affects the health and mortality of both mother and child. A mother with repeated pregnancies, especially at short intervals, does not have sufficient time for recovery both physically and nutritionally and is therefore more likely to have pregnancy losses and babies of a lower birth weight. Table 3.4 shows that almost 18.9 percent of the last births occurred after an interval of less than 19 months, 25.3 percent after an interval of 19-24 months, while 27.8 percent had a 25-36 month interval between their last two births.

Table 3.4: $\quad$ Percentage distribution of married women by length of preceding birth interval

\begin{tabular}{lrr} 
Length of Preceding Birth Interval & Number & Percent \\
Less than 12 Months & 25 & 3.5 \\
\hline 13-18 Months & 111 & 15.4 \\
\hline 19-24 Months & 182 & 25.3 \\
\hline $25-36$ Months & 200 & 27.8 \\
\hline More than 36 Months & 202 & 28.1 \\
\hline Total & 720 & 100
\end{tabular}




\section{Access to Information}

In the baseline survey, respondents were asked several questions regarding access and exposure to television, radio and newspapers. One of the main objectives of the baseline was to determine the knowledge of married women on different maternal and newborn health issues and the source of that knowledge. This information is useful in determining which media channels should be employed in the dissemination of maternal and newborn health information to target audiences. Moreover, it is important to measure the likelihood of reaching target audiences as well as to determine which media channels are most effective when it comes to reaching those target audiences.

\section{Access to Media (Television, Radio and newspaper)}

Mass media is regularly used to campaign on various issues, including those relating to the health of mothers and newborns. In the past, radio was the most popular form of communication (Syed, 1979). In recent decades however, television has become a more popular source of information.

As seen in figure 3.2, almost 77 percent of the respondents in urban Jaffarabad and 47 percent in rural Jaffarabad had exposure to some form of media, whether it was television, radio or newspaper.

Figure 3.2: $\quad$ Exposure to mass media (radio, television or newspaper)

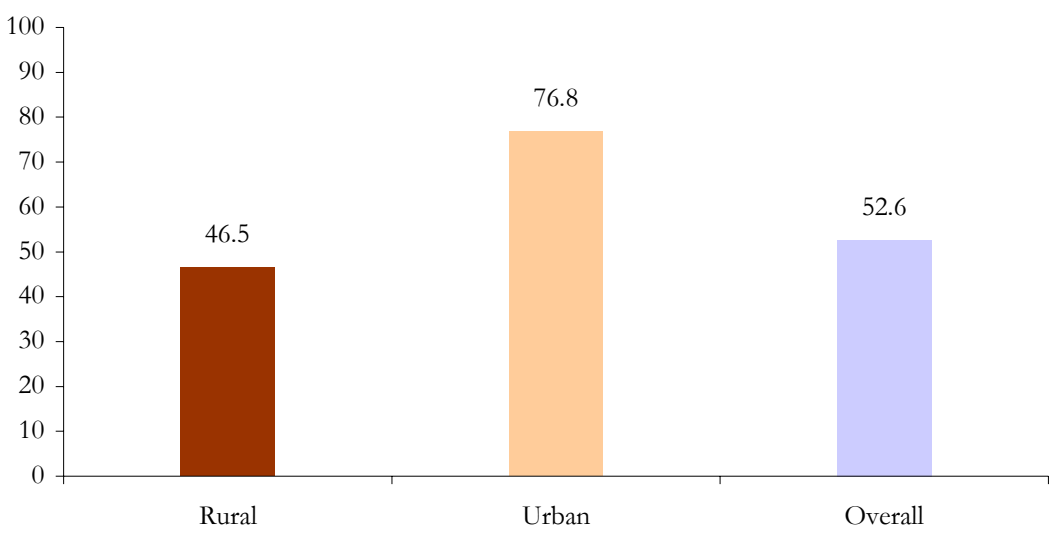

Respondents were asked whether they watched television and listened to the radio. According to figure 3.3, nearly 48 percent of the respondents in Jaffarabad reported watching television and around 7 percent listened to the radio. It may be noted that the percentage of television viewers was higher in urban parts of the district. 
Figure 3.3: $\quad$ Percentage of women who watch television or listen to radio

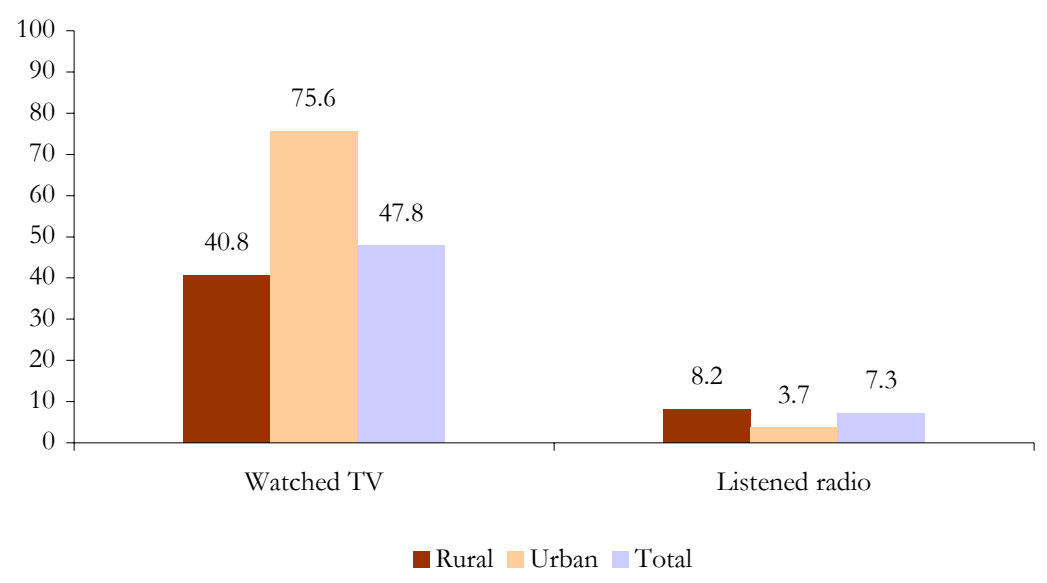

When respondents were asked to give their opinion regarding the trustworthiness of the various sources of media, nearly 55 percent in urban areas and 35 percent in rural areas said they considered TV to be the most trustworthy source, while a high percentage of women in both rural and urban parts remained unsure. Figure 3.7 gives details regarding the trustworthiness of various sources of mass media as perceived by respondents in both urban and rural areas.

Figure 3.4: $\quad$ Most trustworthy form of media

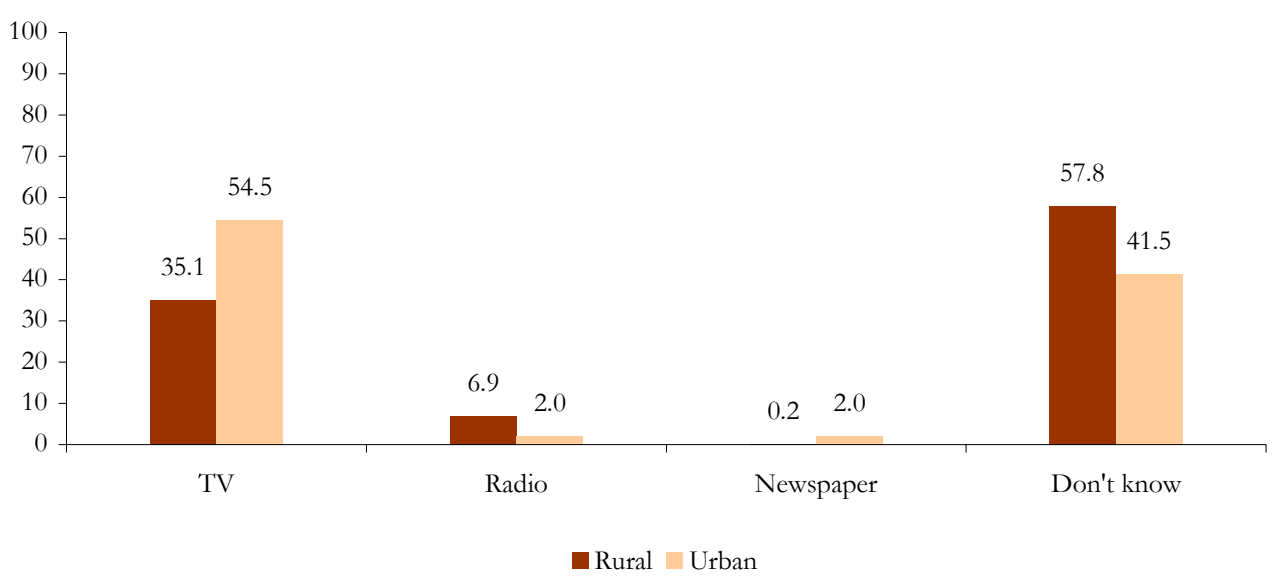

\section{Television}

About 75 percent of the respondents in urban areas and nearly 41 percent in rural areas reported having access to television. Since rural areas are typically poorer than urban centers, the percentage of women who indicated that they did not watch television was much higher in rural settings.

Out of the total TV viewers, 80 percent women in Jaffarabad reported watching TV at home, nearly 18 percent did so at a relative's house, and 2 percent at a neighbor's house (Table 3.5). 
Table 3.5:

Place where respondent usually watches television

\begin{tabular}{lrrrrrrr}
\multirow{2}{*}{ Place } & \multicolumn{2}{c}{ Rural } & \multicolumn{2}{c}{ Urban } & \multicolumn{2}{c}{ Total } \\
\cline { 2 - 7 } & Percent & Number & Percent & Number & Percent & Number \\
\hline At home & 75.9 & 302 & 89.2 & 166 & 80.1 & 468 \\
\hline At relative's house & 20.9 & 83 & 10.8 & 20 & 17.6 & 103 \\
\hline At neighbor's house & 2.8 & 11 & & & 1.9 & 11 \\
\hline Others & 0.5 & 2 & & & 0.3 & 2 \\
\hline Total & 100.0 & 398 & 100.0 & 186 & 100.0 & 584
\end{tabular}

According to table 3.6, about 60 percent of the respondents in rural areas and 76 percent in urban areas reported watching television on a daily basis

Table 3.6: $\quad$ Frequency of watching television

\begin{tabular}{lrrrrrr}
\multirow{2}{*}{ Frequency } & \multicolumn{2}{c}{ Rural } & \multicolumn{2}{c}{ Urban } & \multicolumn{2}{c}{ Total } \\
\cline { 2 - 7 } Almost daily & Percent & Number & Percent & Number & Percent & Number \\
\hline At least once a week & 59.5 & 237 & 75.8 & 141 & 64.7 & 378 \\
\hline At least once a month & 6.3 & 25 & 3.8 & 7 & 5.5 & 32 \\
\hline Rarely & 0.5 & 2 & & & 0.3 & 2 \\
\hline Total & 33.7 & 134 & 20.4 & 38 & 29.5 & 172 \\
\hline
\end{tabular}

Furthermore, 25 percent of the respondents in rural areas, along with 21 percent in urban Jaffarabad believed that television had a great deal of influence on people's health behaviors. Figure 3.5 illustrates the various responses received from respondents.

Figure 3.5: $\quad$ Influence of television programs on health behaviors of people

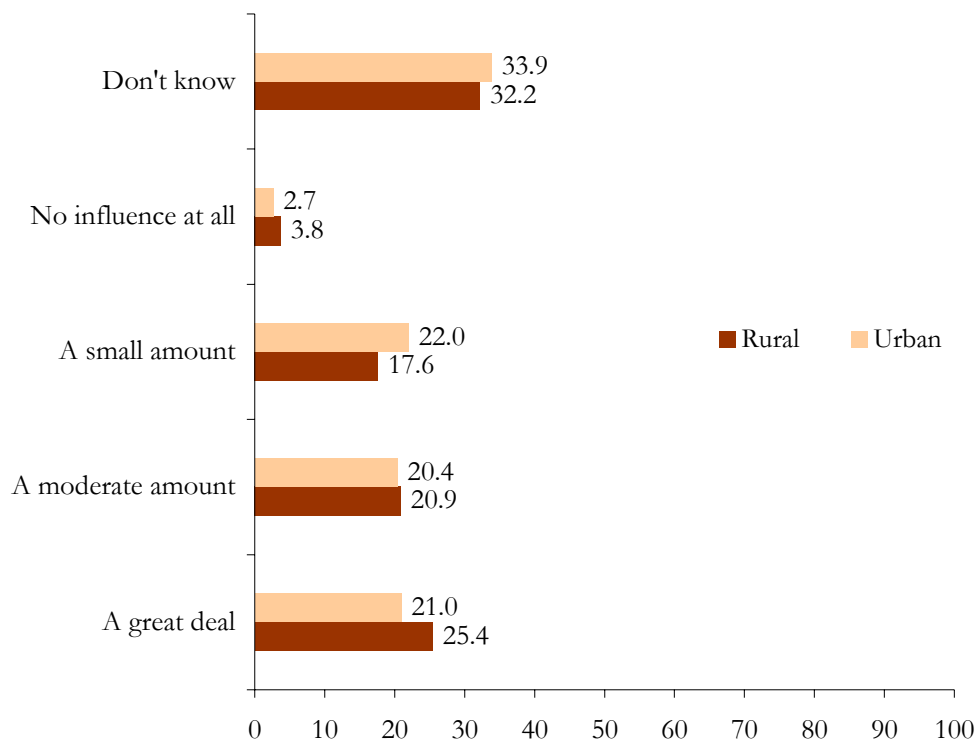




\section{Radio}

Much like television, radio is also a tool through which messages may be relayed to a relatively large audience. However, as already discussed, a majority of the respondents from both rural and urban areas do not listen to the radio. This seems to suggest that radio is not the most effective way of communicating information about health and neonatal care to the target audiences.

Table 3.7 :

Frequency of listening to radio

\begin{tabular}{lrrrrrr} 
& \multicolumn{2}{c}{ Rural } & \multicolumn{2}{c}{ Urban } & \multicolumn{2}{c}{ Total } \\
\cline { 2 - 7 } \multicolumn{1}{c}{ Frequency } & Percent & Number & Percent & Number & Percent & Number \\
\hline Almost daily & 31.3 & 25 & 44.4 & 4 & 32.6 & 29 \\
\hline Alt least once a week & 8.8 & 7 & & & 7.9 & 7 \\
\hline At least once a month & 1.3 & 1 & & 5 & 57.3 & 51 \\
\hline Rarely & 57.5 & 46 & 55.6 & 5 & 1.1 & 1 \\
\hline Others & 1.3 & 1 & & & 100.0 & 89
\end{tabular}

Out of those who were radio listeners, only 33 percent listened to it on daily basis (44 percent in urban areas and 31 percent in rural areas). The majority of radio listeners ( 85 percent) said that they listened to the radio at home. Tables 3.7 provides the details about the frequency of listening to the radio, while table 3.8 outlines the place at which respondents most often listen to the radio.

Table 3.8: $\quad$ Place where respondent listens to the radio

\begin{tabular}{lrrrrrr} 
& \multicolumn{2}{c}{ Rural } & \multicolumn{2}{c}{ Urban } & \multicolumn{2}{c}{ Total } \\
\cline { 2 - 7 } \multicolumn{1}{c}{ Place } & Percent & Number & Percent & Number & Percent & Number \\
\cline { 2 - 7 } At home & 87.5 & 70 & 66.7 & 6 & 85.4 & 76 \\
\hline At work place & 2.5 & 2 & & 3 & 11.2 & 10 \\
\hline At relative's house & 8.8 & 7 & 33.3 & & 1.1 & 1 \\
\hline At neighbor's house & 1.3 & 1 & & & 100.0 & 89 \\
\hline Total & 100.0 & 80 & 100.0 & 9 & 100 & 2 \\
\hline
\end{tabular}

A majority of the radio listeners in both rural (45 percent) and urban (33 percent) areas of Jaffarabad did not know whether or not radio programs had any influence on people's health behaviors. Another 33 percent in the urban areas and 23 percent in rural parts believed radio had a small amount of influence, while only 11 percent in rural and urban Jaffarabad indicated that radio had a great deal of influence on their behaviors. 
Figure 3.6:

Influence of radio on the bealth behaviors

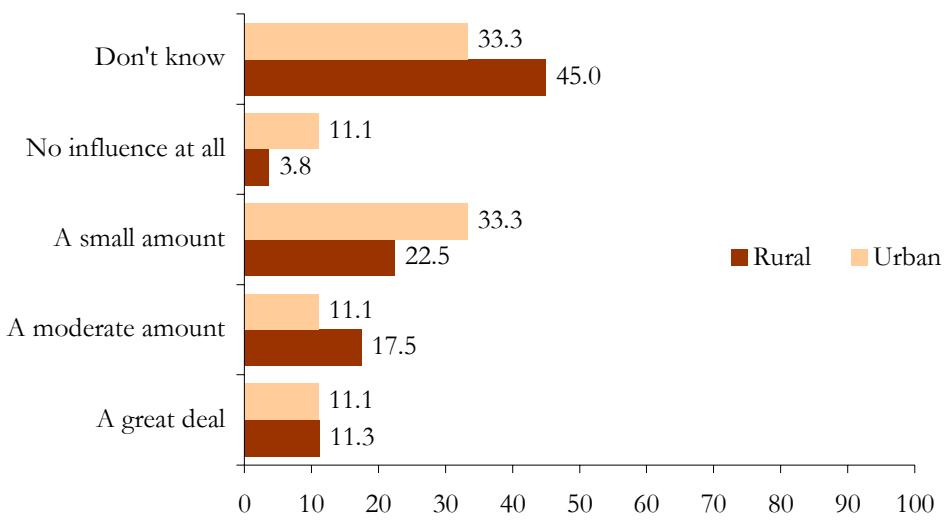

\section{Newspapers}

According to figure 3.7, 90 percent and 93 percent of the respondents in urban and rural Jaffarabad respectively do not read newspapers. Only about 2.4 percent and 0.4 percent in urban and rural areas respectively read the newspaper on a daily basis, while 4 percent in rural areas and 5 percent in urban areas rarely read them. It is observed that newspapers like the radio may not be a very efficient means of communication for the PAIMAN target population in Jaffarabad because of high illiteracy rates.

Figure 3.7: $\quad$ Frequency of reading newspaper

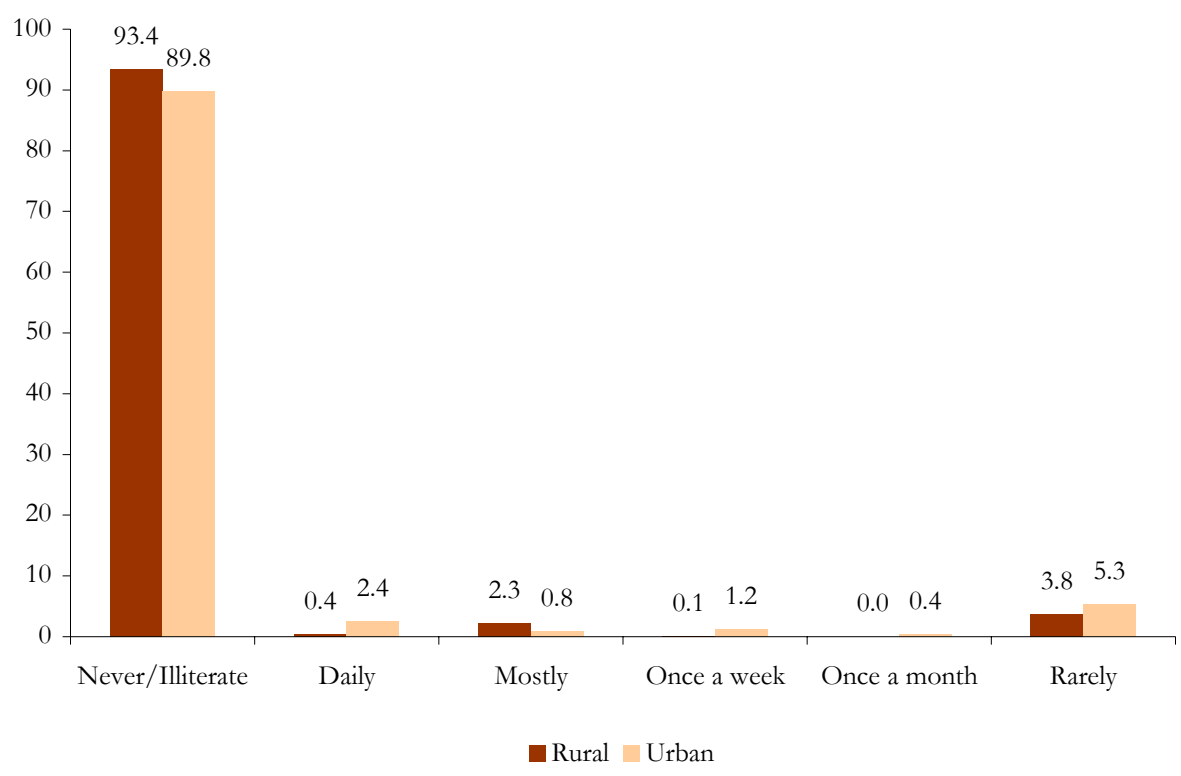

These results concerning mass media access and its popularity in Jaffarabad indicate that TV, as in many other parts of Pakistan, remains the most popular source of information. 


\section{Information/Education through Media}

Before moving on to questions regarding attitudes towards pregnancy, delivery and postpartum, respondents were asked to comment on whether or not they had heard or read anything about maternal and newborn mortality within the three months preceding the baseline survey.

As seen in figure 3.8, one-fourth (25.2 percent) of the women in urban Jaffarabad had heard or read something regarding maternal health within the last three months. More than 11 percent said the same thing in rural Jaffarabad. Overall, a very large portion of the women (85.7 percent) indicated that they had not heard of anything regarding maternal health over the past three months.

Similarly, the married women were also asked if they had heard or read anything regarding newborn health within the last three months. Once again, the figures were quite low. Only 22 percent of the urban respondents stated that they had in fact heard/read about newborn health, whereas less than 12 percent of the women in rural areas stated the same thing. However, 86 percent of the total women indicated that they had heard/read nothing about newborn health over the past three months. This data clearly indicates a lack of access to information in the district of Jaffarabad

Figure 3.8: $\quad$ Percentage of married women who had heard/ read maternal and newborn messages during the last 3 months

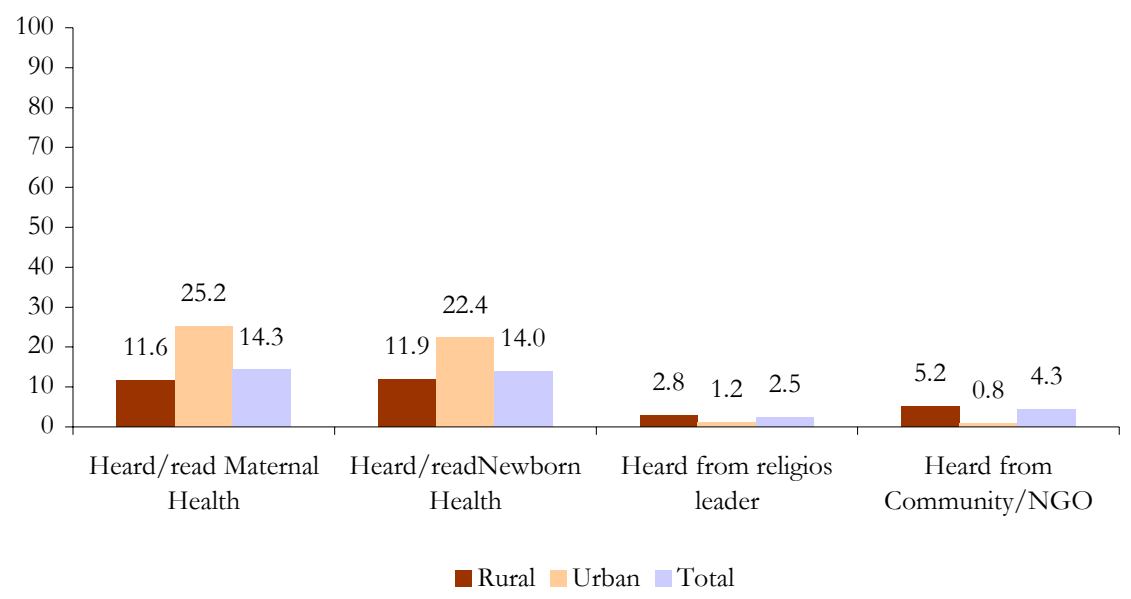

Respondents were then asked to indicate if they had heard a religious leader or community/NGO worker speak about health care within the last three months. In rural areas, just under 3 percent of the respondents interviewed indicated that they had heard a community/NGO worker speak about health care, while 5.2 percent stated that they had heard religious leaders speak about the same topic. The numbers were even lower for urban areas. About one percent stated that they had heard a community/NGO worker or religious leader speak about health care within the last three months.

Upon reflection of the data provided above, it becomes quite evident that the percentages of married women who had heard anything about maternal or newborn health are very low for both urban and rural areas, indicating the absence of proactive education and awareness in many areas of Jaffarabad. Hence, it would be a challenge for the PAIMAN team to reach these women in both urban and rural areas, and convey messages regarding maternal and newborn health. 


\section{Chapter 4}

\section{Knowledge of Safe Motherhood, Birth Preparedness and Community Resources}

This chapter explores the level of understanding women have of safe motherhood practices, birth preparedness and the use of community resources. It examines the level of health awareness women in the district possess and thus provides an explanation for the maternal and newborn mortality rates. Respondents were asked questions regarding knowledge of complications during pregnancy, delivery, the postpartum period and newborn health. They were also asked about the community resources available to them within the community. The findings of those responses are presented in this chapter

\section{Knowledge of Danger Signs}

In this section of the survey, respondents were asked about the various danger signs that could arise during pregnancy, delivery, the postpartum period, and in the newborn soon after birth.

Danger signs include any vaginal bleeding, severe headache, dizziness or blurred vision, generalized edema, convulsions, breathlessness and tiredness, labor pains for more than 12 hours, excessive bleeding in labor or after delivery, ruptured membranes and fever.

\section{Knowledge of Danger Signs during Pregnancy}

Respondents were asked whether they knew about the various danger signs during pregnancy.

According to figure 4.1, heavy vaginal bleeding, sever abdominal pain, severe vomiting, high fever with or without rigors and jaundice were some of the most commonly reported signs of danger during pregnancy for which medical treatment was considered necessary. The majority of the respondents in urban (39 percent) and rural (42 percent) areas reported severe abdominal pain as the danger sign in pregnancy for which immediate medical attention was necessary. 
Figure 4.1: $\quad$ Knowledge of danger signs during pregnancy, which require medical attention

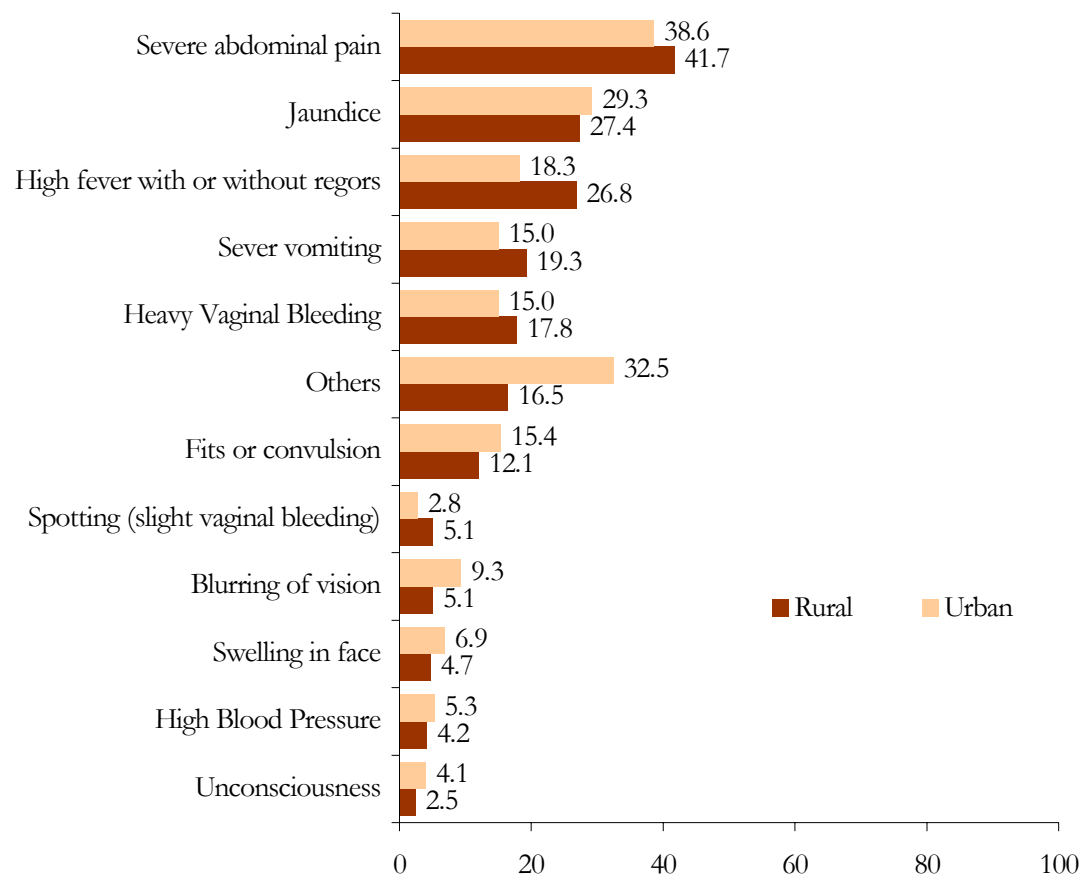

A quarter of the respondents ( 25 percent) in both rural and urban parts knew at least three danger signs that could arise during pregnancy. However, 29 percent of the respondents in urban areas and around 26 percent in rural areas of Jaffarabad had no knowledge about the danger signs during pregnancy. Overall results presented in figure 4.2 indicate that knowledge of danger signs during pregnancy is quite low among the women in Jaffarabad.

Figure 4.2: $\quad$ Percentage distribution of women by number of known danger signs during pregnancy

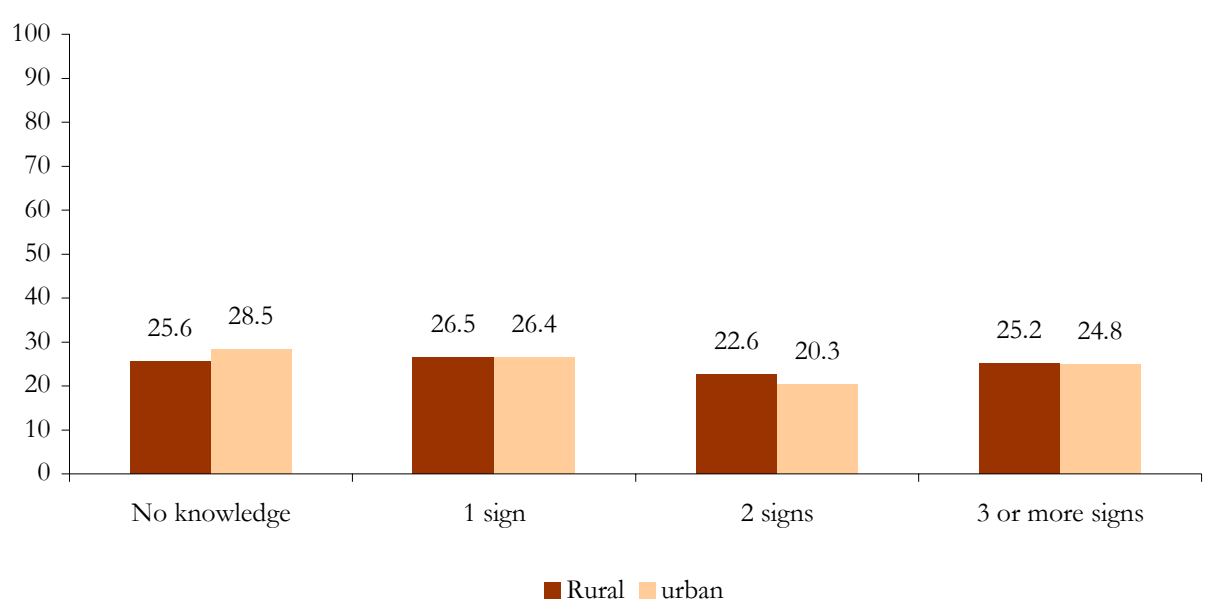




\section{Knowledge of danger signs during childbirth/delivery}

As in the case of pregnancy, many women are not aware of the complications that may arise during delivery. This lack of knowledge may eventually result in women not being taken to a hospital in the event that such a complication should occur. Deliveries can only be made safer if married women are educated regarding the danger signs that could arise during delivery, so that they are able to decide when to seek medical treatment. Even under normal circumstances, some 15 percent of pregnant women require emergency obstetric care to avoid maternal and newborn deaths.

More than three-quarters of the respondents did not recognize the danger signs that can have severe consequences. According to figure 4.3 a very high percentage in rural (27percent) and urban (19 percent) Jaffarabad reported "retained placenta/delay in delivery of placenta" as a danger sign during childbirth/delivery. Other danger signs identified and reported by respondents included malpositioning, excessive vaginal bleeding, bleeding before labor begun, and prolonged labor.

Figure 4.3: $\quad$ Distribution of respondents who had knowledge about complications during delivery

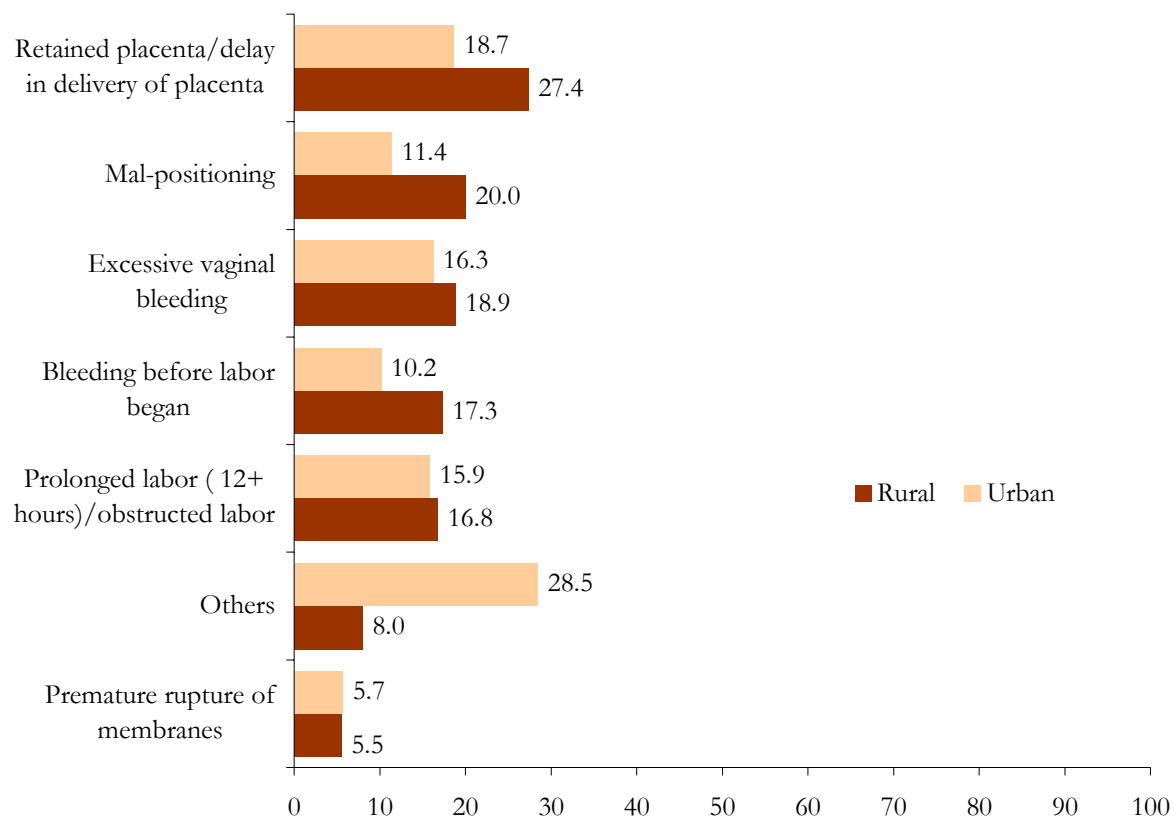

Knowledge about the danger signs during delivery was far lower when compared with knowledge of danger signs during pregnancy. Nearly 47 percent of the respondents in urban parts and around 31 percent in rural areas had no knowledge at all. About 42 percent of respondents in rural areas and 35 percent in urban areas knew just one danger sign. The percentage of respondents who were aware of at least three danger signs during delivery was very low (figure 4.4). 
Figure 4.4: $\quad$ Percentage distribution of women by number of known danger signs during delivery

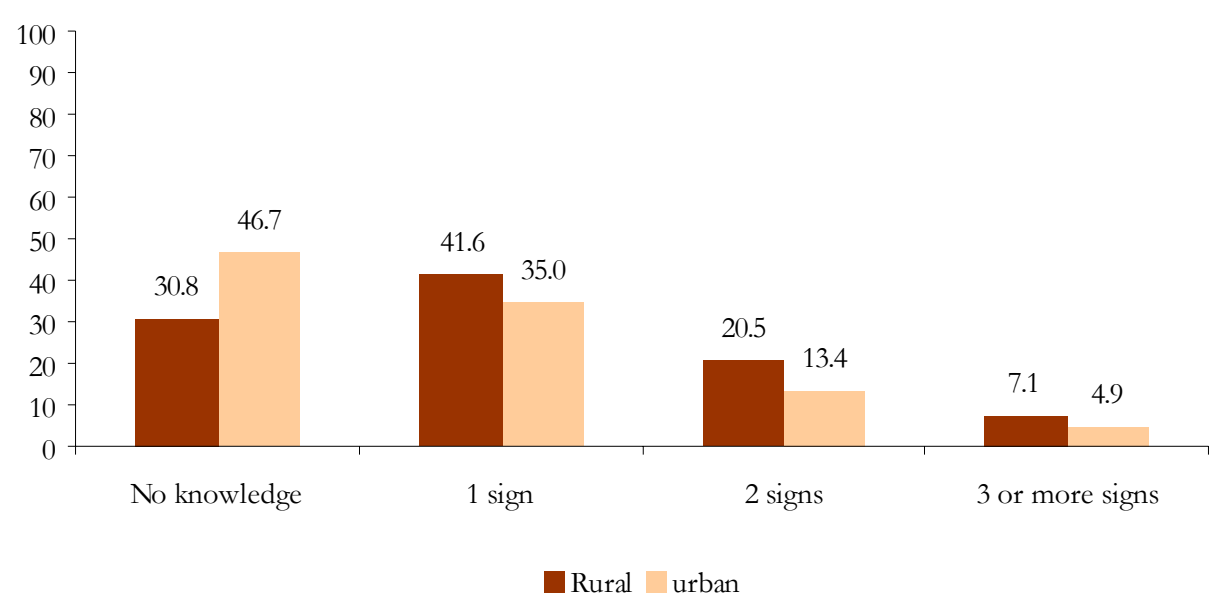

\section{Knowledge of Danger Signs during the Postpartum Period}

Postpartum hemorrhage is the most significant cause of maternal mortality in developing countries. In the baseline survey, the postpartum period is defined as the 40 days following childbirth. Although baseline survey findings indicate that excessive vaginal bleeding is the most known danger sign during the postpartum period, not all women are aware of this fact. If mothers are not medically fit during the postpartum period they cannot take adequate care of their newborns.

According to the findings, excessive vaginal bleeding was the most widely reported danger sign during the postpartum period by both urban (46 percent) and rural (55 percent) respondents in Jaffarabad (figure 4.5).

Figure 4.5: $\quad$ Percentage of married women who had knowledge about complication during postpartum period

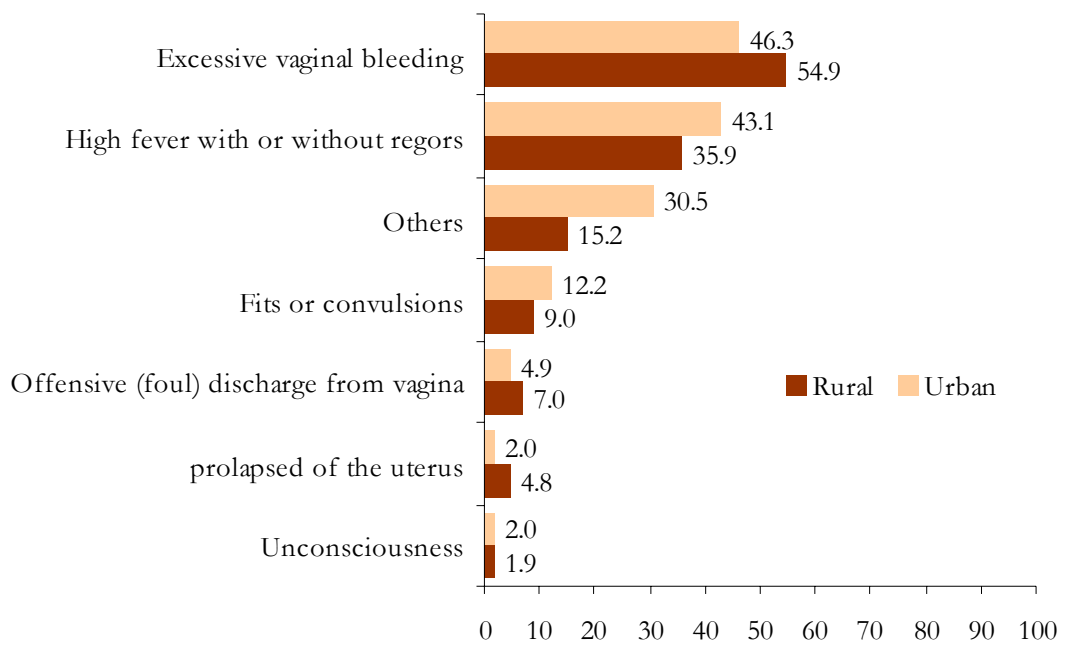


Nearly half of the respondents in urban areas (47 percent) and rural areas (46 percent) were able to name only one danger sign. Only 7 percent and 5 percent of the rural and urban respondents respectively were able to name three or more danger signs during the postpartum period.

Figure 4.6: $\quad$ Percentage distribution of women by number of known danger signs during postpartum period

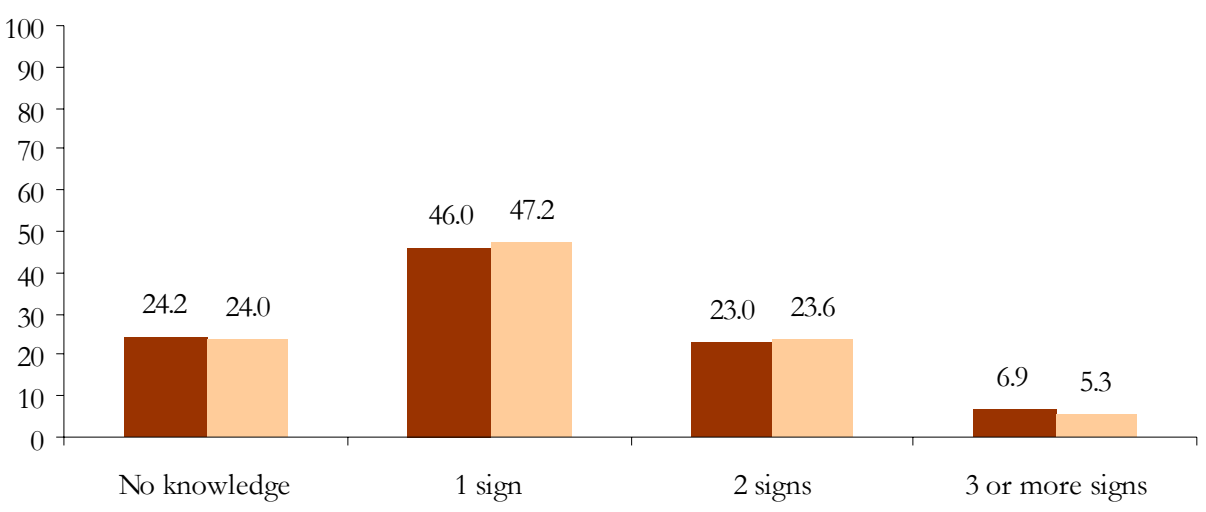

Rural urban 


\section{Knowledge of Danger Signs in the Newborn}

The newborn period is defined as the first four weeks after birth. Unfortunately, many women are also unaware of the danger signs that may appear in newborns, especially in the first seven days after the childbirth.

Fits/abnormal jerky movements were widely cited as being danger signs in newborns by 56 percent and 41 percent of the urban and rural respondents respectively. Fever with or without rigors was recognized as being a danger sign by 37 percent of the urban respondents and 35 percent of the rural respondents in Jaffarabad. Other danger signs included cold/shivering, red swollen eyes, difficult breathing, and poor suckling (Figure 4.7).

Figure 4.7: $\quad$ Percentage of married women by status of knowledge of danger signs in newborn

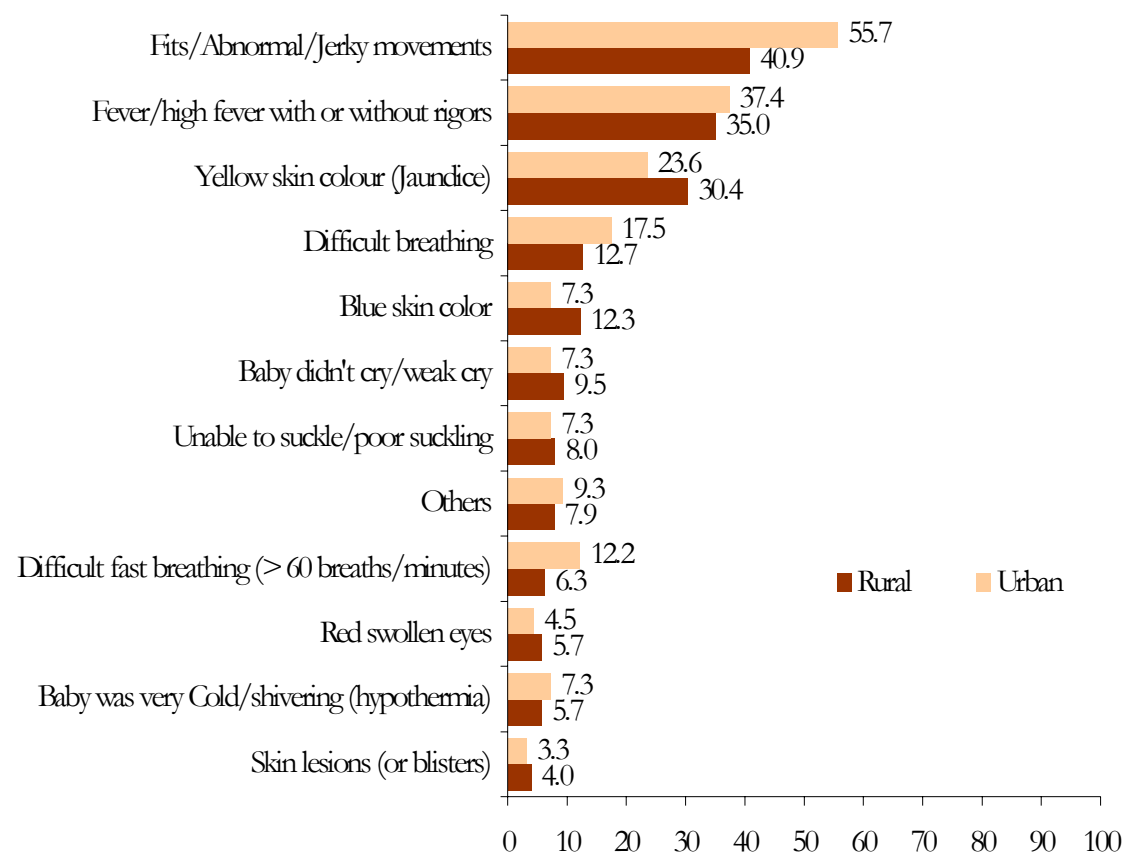

It can be noted that 27 percent of the respondents in urban and rural Jaffarabad knew at least three danger signs in newborns. About 24 percent and 15 percent in rural and urban Jaffarabad respectively were unable to name a single danger sign which may appear in newborns. 
Figure 4.8: $\quad$ Percentage distribution of women by number of known danger signs in the newborn

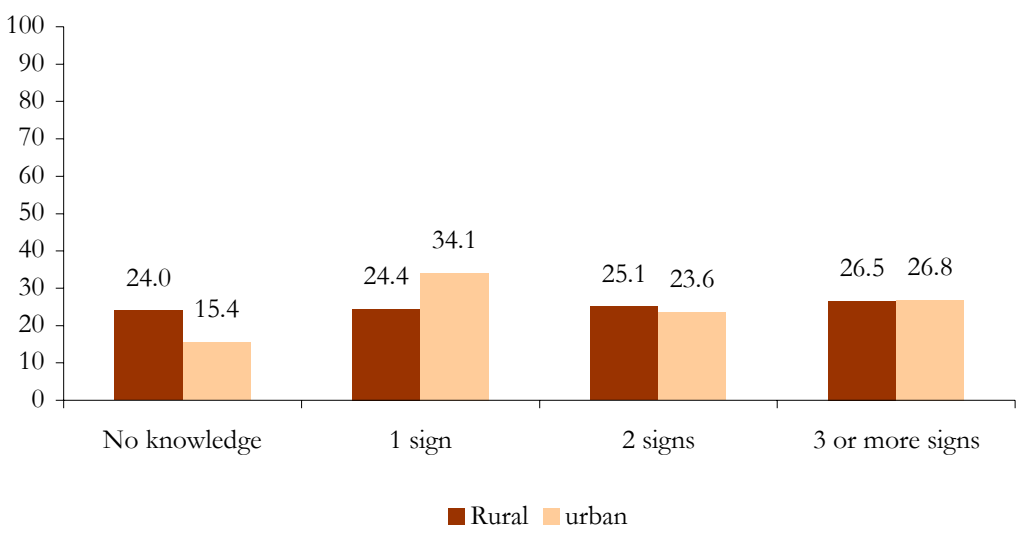

\section{Source of information regarding danger signs}

Finally, respondents were asked to state the source of their information regarding complications during pregnancy, delivery and the postpartum period. According to figure 4.9, friends, neighbors and relatives were the most common source of information reported by 60 percent of respondents in urban Jaffarabad and 55 percent in rural Jaffarabad.

Among the various health care providers, TBAs/Dais were the most common source of information for by 26 percent of rural respondents and nearly 13 percent of the urban respondents. Overall results indicate that family, in-laws and friends are the most popular sources of information for the people of the district.

Figure 4.9: $\quad$ Source of information regarding danger signs during pregnancy

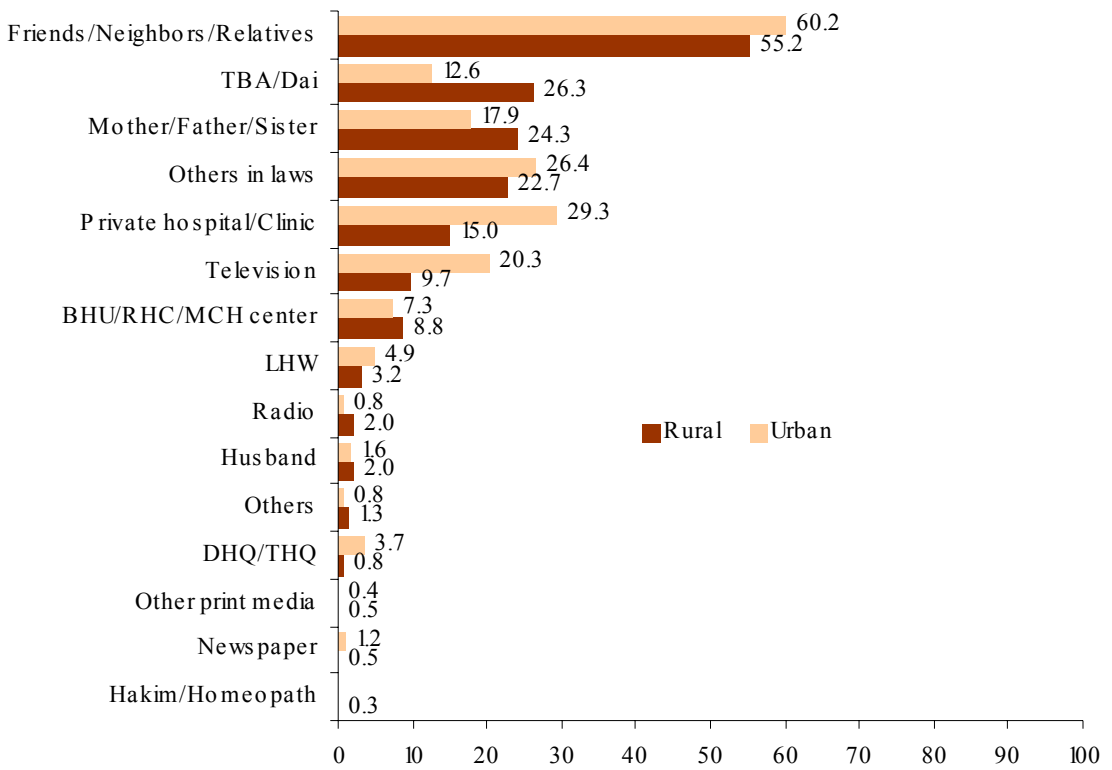




\section{Knowledge of Community Schemes for the Welfare of Women and Newborns}

Respondents were asked whether they were aware of any existing schemes in their respective communities designed to help women have a safe childbirth. The baseline focused on schemes pertaining to transportation, blood arrangements and funding; all of which help ensure that there are no delays at the time of delivery. Arrangement of transport to a health facility is a major cause of delay which can lead to maternal and newborn mortality, and therefore the arrangement of transport ahead of time is necessary to eliminate that delay. Unfortunately, many households lack transport facilities.

Even though all of the respondents surveyed in Jaffarabad believed in the importance of communitybased transport, blood and money facilities for emergencies, less than 1 percent of the respondents actually knew of the existence of such facilities in their respective communities.

Table 4.1: $\quad$ Knowledge of existence and importance of transport, blood and finances by the community at the time of delivery

\begin{tabular}{lcccccc}
\multicolumn{1}{c}{ Community Services } & \multicolumn{2}{c}{ Rural } & \multicolumn{2}{c}{ Urban } & \multicolumn{2}{c}{ Total } \\
\cline { 2 - 7 } & Percent & Number & Percent & Number & Percent & Number \\
\hline $\begin{array}{l}\text { Existence of transport by the } \\
\text { community at delivery }\end{array}$ & 0.2 & 2 & 0.4 & 1 & 0.2 & 3 \\
\hline $\begin{array}{l}\text { Important to have community } \\
\text { provided transport facility }\end{array}$ & 99.4 & 970 & 98.4 & 242 & 99.2 & 1,212 \\
\hline $\begin{array}{l}\text { Existence of blood by the } \\
\text { community at time of delivery }\end{array}$ & 0.1 & 1 & & & 0.1 & 1 \\
\hline $\begin{array}{l}\text { Important to have community } \\
\text { provided blood facility }\end{array}$ & 98.7 & 963 & 100.0 & 246 & 98.9 & 1,209 \\
\hline $\begin{array}{l}\text { Existence of money by community } \\
\text { at the time of delivery }\end{array}$ & 0.2 & 2 & & & 0.2 & 2 \\
\hline $\begin{array}{l}\text { Important to have community } \\
\text { provided money facility }\end{array}$ & 99.4 & 970 & 100.0 & 246 & 99.5 & 1,216 \\
\hline
\end{tabular}




\section{Chapter}

\section{Attitudes Towards Pregnancy, Delivery and the Postpartum Period}

This chapter explores the attitudes of married women towards pregnancy, delivery and the postpartum period. Determining these attitudes and beliefs is important for designing strategies that bring about a change in traditional thinking.

\section{Attitudes Towards Age at Marriage}

Respondents were asked if they thought a woman should get married soon after puberty. More than 61 percent of rural respondents and 41 percent of urban respondents were of the opinion that women should get married soon after puberty. A deeper look into this issue shows that many families do not value girls' education, and place greater emphasis on marriage. As a result, women are married at an early age, and often do not have the opportunity to obtain any education whatsoever. There is also a link between the years of education obtained by women and the fertility rate of a country (Sathar et al, 1988). The younger the age at marriage, the greater the exposure to childbearing. Therefore, in order to lower the fertility rate, it is important to delay the age at marriage for women.

\section{Attitudes Towards Antenatal Care}

Women in both urban and rural areas of Rawalpindi were then asked if they believed pregnant women needed to have antenatal check-ups. Overall, prenatal care provides an opportunity to offer preventive care that will benefit the newborn as well as the mother. Prenatal care also allows women to learn about hygiene, the benefits of breastfeeding, nutrition and general health (Mahmood, 2002). An encouraging finding was that a very high percentage of respondents in both rural (70 percent) and urban (91 percent) areas considered an antenatal check-up to be important for pregnant women (Table 5.1). 
Table 5.1:

Importance of antenatal check-ups

\begin{tabular}{lrrrrrrr}
\multirow{2}{*}{ Should have antenatal check-up } & \multicolumn{2}{c}{ Rural } & \multicolumn{2}{c}{ Urban } & \multicolumn{2}{c}{ Total } \\
\cline { 2 - 7 } & Percent & Number & Percent & Number & Percent & Number \\
\hline Yes & 69.5 & 676 & 91.1 & 224 & 73.8 & 900 \\
\hline No & 21.5 & 209 & 6.1 & 15 & 18.4 & 224 \\
\hline Don't know & 9.0 & 88 & 2.8 & 7 & 7.8 & 95 \\
Total & 100.0 & 973 & 100.0 & 246 & 100.0 & 1,219
\end{tabular}

Though a high number of women understood the necessity of antenatal care, most of them (46 percent) believed that antenatal care should be sought only when necessary. Very few women said that an antenatal checkup should be conducted in the initial months of the pregnancy, while only 4 percent said that a woman should seek care as soon as possible after becoming pregnant (Table 5.2).

Table 5.2: $\quad$ Month of pregnancy when women should go for antenatal care

\begin{tabular}{lrrrrrr} 
& \multicolumn{2}{c}{ Rural } & \multicolumn{2}{c}{ Urban } & \multicolumn{2}{c}{ Total } \\
\cline { 2 - 7 } & Percent & Number & Percent & Number & Percent & Number \\
\hline & 1.6 & 11 & 4.9 & 11 & 2.4 & 22 \\
\hline 2 & 3.0 & 20 & 5.8 & 13 & 3.7 & 33 \\
\hline 3 & 9.2 & 62 & 10.7 & 24 & 9.6 & 86 \\
\hline 4 & 5.2 & 35 & 3.1 & 7 & 4.7 & 42 \\
\hline 5 & 11.2 & 76 & 12.1 & 27 & 11.4 & 103 \\
\hline 6 & 5.3 & 36 & 2.7 & 6 & 4.7 & 42 \\
\hline 7 & 6.7 & 45 & 2.7 & 6 & 5.7 & 51 \\
\hline 8 & 3.8 & 26 & 1.8 & 4 & 3.3 & 30 \\
\hline 9 & 2.7 & 18 & 0.9 & 2 & 2.2 & 20 \\
\hline $\begin{array}{l}\text { As soon as possible after } \\
\text { pregnancy }\end{array}$ & 3.6 & 24 & 3.6 & 8 & 3.6 & 32 \\
\hline When check-up is needed & 44.8 & 303 & 51.3 & 115 & 46.4 & 418 \\
\hline Don't know & 3.0 & 20 & 0.4 & 1 & 2.3 & 21 \\
\hline Total & 100.0 & 676 & 100.0 & 224 & 100.0 & 900
\end{tabular}

Respondents were asked indicate the ideal number of antenatal check-ups a pregnant woman should receive. A majority (55 percent) considered an antenatal check-up important onlywhen needed. Only 1.1 percent said that a woman should have at least 9 or more antenatal checkups during her pregnancy (Table 5.3). 
Table 5.3: $\quad$ Number of antenatal visits considered necessary

\begin{tabular}{|c|c|c|c|c|c|c|}
\hline \multirow{2}{*}{ Number } & \multicolumn{2}{|c|}{ Rural } & \multicolumn{2}{|c|}{ Urban } & \multicolumn{2}{|c|}{ Total } \\
\hline & Percent & Number & Percent & Number & Percent & Number \\
\hline 1 & 6.8 & 46 & 1.8 & 4 & 5.6 & 50 \\
\hline 2 & 14.8 & 100 & 8.5 & 19 & 13.2 & 119 \\
\hline 3 & 12.4 & 84 & 14.3 & 32 & 12.9 & 116 \\
\hline 4 & 3.9 & 26 & 4.5 & 10 & 4.0 & 36 \\
\hline 5 & 2.5 & 17 & 6.3 & 14 & 3.4 & 31 \\
\hline 6 & 1.0 & 7 & 2.2 & 5 & 1.3 & 12 \\
\hline 7 & 0.6 & 4 & 0.4 & 1 & 0.6 & 5 \\
\hline 8 & 0.3 & 2 & 0.4 & 1 & 0.3 & 3 \\
\hline 9 & 0.9 & 6 & 0.4 & 1 & 0.8 & 7 \\
\hline 11 & & & 0.4 & 1 & 0.1 & 1 \\
\hline 12 & 0.1 & 1 & & & 0.1 & 1 \\
\hline 20 & 0.1 & 1 & & & 0.1 & 1 \\
\hline $\begin{array}{l}\text { When check-up is } \\
\text { needed }\end{array}$ & 53.9 & 364 & 59.8 & 134 & 55.4 & 498 \\
\hline Don't know & 2.5 & 17 & 0.9 & 2 & 2.1 & 19 \\
\hline Total & 100.0 & 675 & 100.0 & 224 & 100.0 & 899 \\
\hline
\end{tabular}

More than three quarters of the respondents (80 percent) in Jaffarabad knew the importance of Tetanus Toxoid (TT) shots during pregnancy. About 86 percent in urban areas and 53 percent in rural areas said that it was important to take iron/folate supplements during pregnancy (Figure 5.1).

Figure 5.1: $\quad$ Percentage of married women who thought it necessary to recieve TT shots and take iron/folate tablets during pregnancy

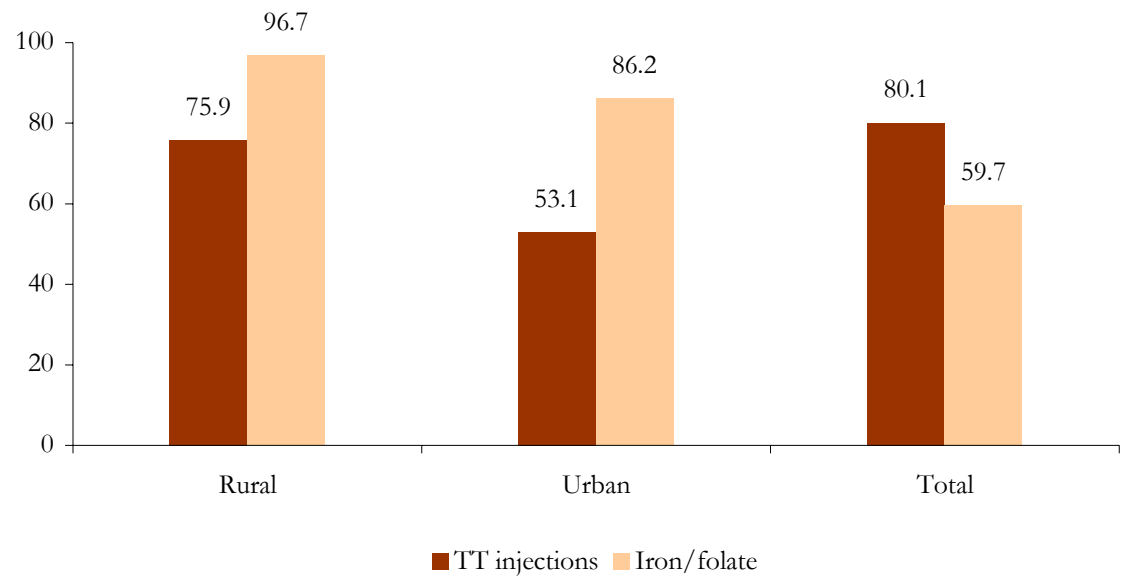




\section{Attitudes Towards Delivery}

Many families prefer the traditional practice of employing Traditional Birth Attendants (TBAs) or Dais to assist with deliveries. These TBAs/Dais have vast experience but no formal training and therefore do not qualify as skilled birth attendants. However, many families do not realize the impact a lack of training can have on childbirth, and chose to opt for TBAs over health professionals. When asked if women should receive delivery services from a Skilled Birth Attendant (SBA), 80 percent of respondents in Jaffarabad responded in the affirmative (Table 5.4).

Table 5.4: Respondents who believe that women should receive delivery services from bealth professional

\begin{tabular}{lrrrrrr}
\multirow{2}{*}{ Number } & \multicolumn{2}{c}{ Rural } & \multicolumn{2}{c}{ Urban } & \multicolumn{2}{c}{ Total } \\
\cline { 2 - 7 } Yes & Percent & Number & Percent & Number & Percent & Number \\
\hline No & 76.5 & 746 & 95.1 & 234 & 80.3 & 980 \\
\hline Don't know & 5.7 & 56 & & & 4.6 & 56 \\
\hline Total & 17.7 & 173 & 4.9 & 12 & 15.2 & 185 \\
\hline
\end{tabular}

An almost equal percentage of respondents in urban and rural Jaffarabad said that only some of the women in their respective communities received delivery services from SBAs. Only 1 percent believed that all the women in their area received delivery services from a SBA (Figure 5.2).

Figure 5.2: $\quad$ Respondents who believe women in their community obtain delivery services from SBAs

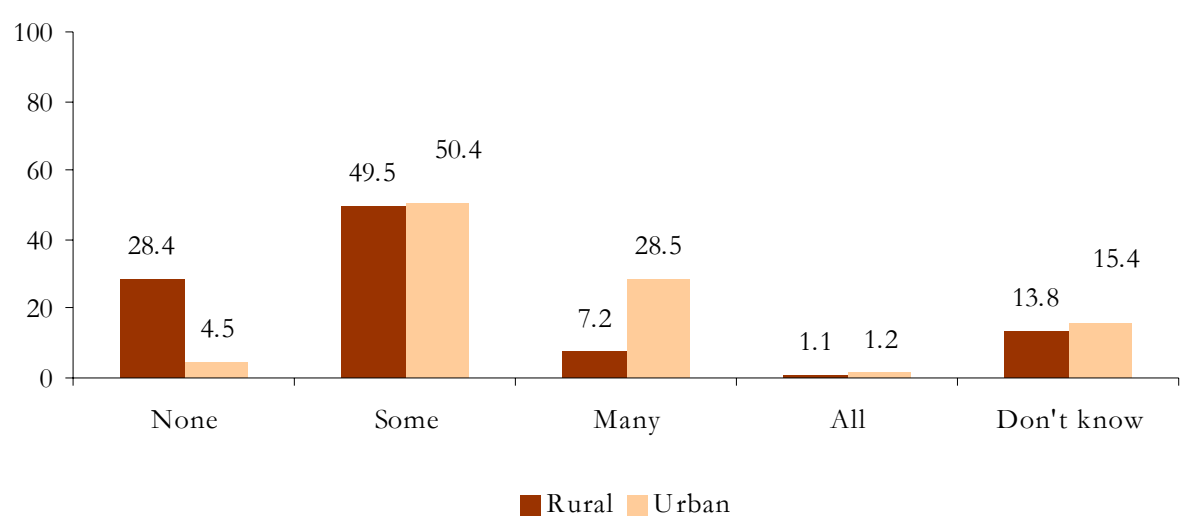

When asked whether a woman should deliver in hospital or at home the majority in rural areas (72 percent) favored delivery being conducted at home. More than half of the urban respondents (55 percent) considered a hospital to be the most appropriate place for delivery.

It may be noted that even though a very high percentage ( 77 percent) of rural respondents want to receive the services of a trained health provider, most end up delivering at home (figure 5.3). 
Figure 5.3: $\quad$ Percentage of women by their perception of where a delivery should take place

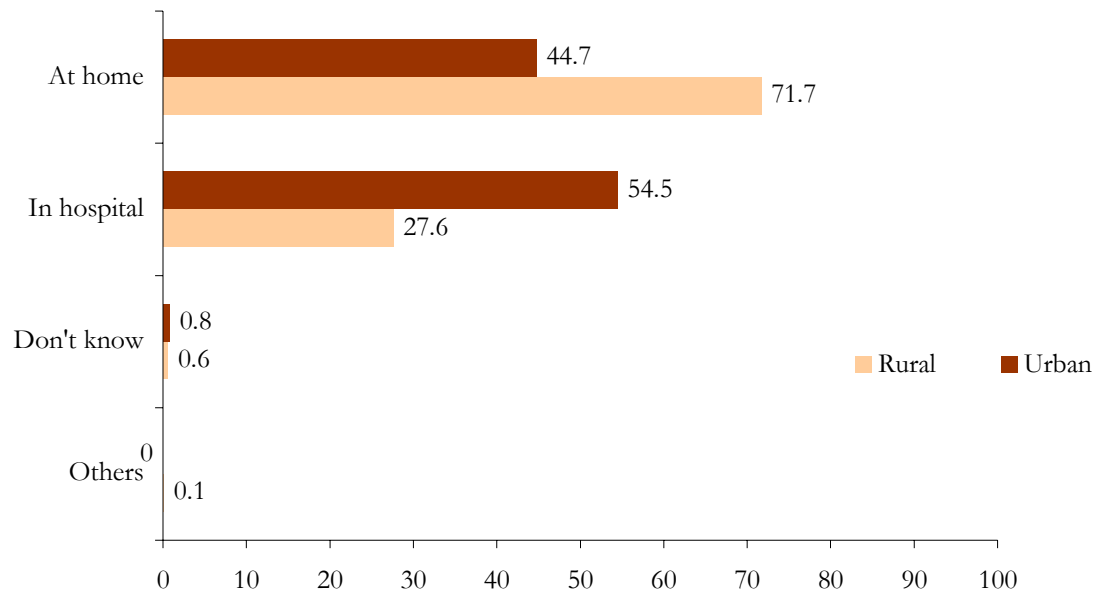

About 46 percent of the respondents in Jaffarabad believed that the decision to seek treatment in the event of a complication should be taken by the husband of a pregnant woman. Only 3 percent of respondents in rural areas and 18 percent in urban parts of the district said that the pregnant woman should take the decision herself. About 39 percent of the respondents left the decision to their family members. Table 5.5 presents detailed information on the various responses received with regards to taking care of the pregnant women at a time of complication.

Table 5.5: $\quad$ Person who should make decisions regarding the health of a pregnant woman

\begin{tabular}{lrrrrrrr}
\multirow{2}{*}{\multicolumn{1}{c}{ Person }} & \multicolumn{2}{c}{ Rural } & \multicolumn{2}{c}{ Urban } & \multicolumn{2}{c}{ Total } \\
\cline { 2 - 7 } & Percent & Number & Percent & Number & Percent & Number \\
\hline Pregnant woman & 3.3 & 32 & 18.3 & 45 & 6.3 & 77 \\
\hline Husband & 43.5 & 424 & 57.7 & 142 & 46.4 & 566 \\
\hline Other family members & 43.2 & 421 & 23.2 & 57 & 39.1 & 478 \\
\hline TBA/Dai & 8.3 & 81 & 0.8 & 2 & 6.8 & 83 \\
\hline Others & 0.4 & 4 & & & 0.3 & 4 \\
\hline Don't know & 1.3 & 13 & & & 1.1 & 13 \\
\hline Total & 100.0 & 975 & 100.0 & 246 & 100.0 & 1,221
\end{tabular}

Respondents were asked to indicate the mode of transportation they would use to reach a health facility. A very high percentage in rural areas ( 67 percent) as well as urban areas (72 percent) planned to use private transport at the time of delivery (Figure 5.4). 
Figure 5.4: $\quad$ Percentage of married women by mode of transport they would use to reach a bealth facility

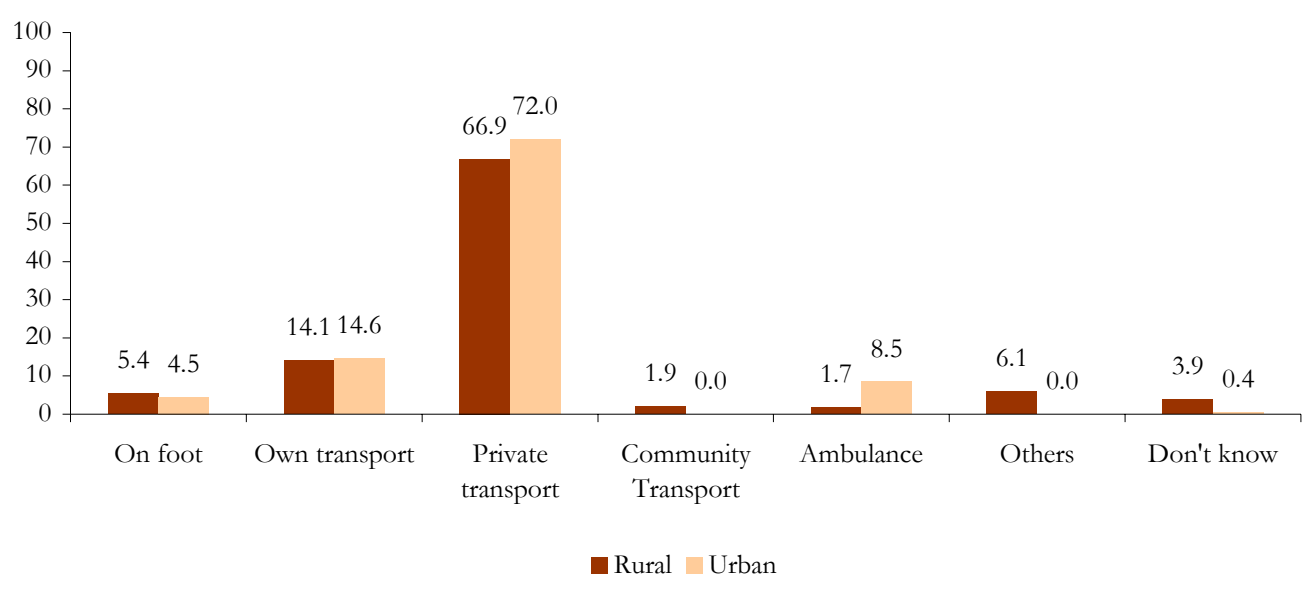

\section{Attitudes Towards Postpartum and Neonatal Care}

The importance of postnatal care is often undervalued. Postnatal care ensures that both mother and newborn are in good health, and monitors the recovery process of new mothers.

Postpartum is defined as the period occurring immediately after childbirth. According to table 5.6, when asked if a woman requires a postnatal check-up or not, 43 percent in urban as well as rural areas did not consider it important.

Table 5.6: $\quad$ Necessity of postnatal care

\begin{tabular}{lrrrrrrr}
\multirow{2}{*}{ Need postnatal care } & \multicolumn{2}{c}{ Rural } & \multicolumn{2}{c}{ Urban } & \multicolumn{2}{c}{ Total } \\
\cline { 2 - 7 } Yes & Percent & Number & Percent & Number & Percent & Number \\
\hline No & 49.2 & 351 & 51.1 & 70 & 49.5 & 421 \\
\hline Don't know & 43.0 & 307 & 43.1 & 59 & 43.0 & 366 \\
\hline Total & 7.8 & 56 & 5.8 & 8 & 7.5 & 64 \\
\hline
\end{tabular}

In Jaffarabad, the percentage of respondents who believed that only some of the women in their community had received postnatal care was 38 percent. About 48 percent in rural areas and 24 percent in urban areas said that none of the women in their community received any antenatal care (Table 5.7). 
Table 5.7: $\quad$ Number of women who obtain postnatal care in the community

\begin{tabular}{lrrrrrr}
\multirow{2}{*}{ Number of visits } & \multicolumn{2}{c}{ Rural } & \multicolumn{2}{c}{ Urban } & \multicolumn{2}{c}{ Total } \\
\cline { 2 - 7 } None & Percent & Number & Percent & Number & Percent & Number \\
\hline Some & 47.6 & 464 & 24.4 & 60 & 42.9 & 524 \\
\hline Most & 36.5 & 356 & 43.5 & 107 & 37.9 & 463 \\
\hline All & 1.7 & 17 & 14.2 & 35 & 4.3 & 52 \\
\hline Don't know & 0.2 & 2 & & & 0.2 & 2 \\
\hline Total & 13.9 & 136 & 17.9 & 44 & 14.7 & 180 \\
\hline
\end{tabular}

\section{Coverage of Lady Health Workers}

Women were asked about the presence of Lady Health Workers (LHW) in their community. About 77 percent of the respondents in rural areas and 28 percent in urban Jaffarabad said that there was no LHW in their respective communities. Table 5.8 indicated that the presence of Lady Health Workers in urban parts was reported by 63 percent of the respondents compared to 18 percent in rural.

Table 5.8: $\quad$ Presence of lady bealth worker in the community

\begin{tabular}{lrrrrrrr}
\multirow{2}{*}{ Has LHW in the area } & \multicolumn{2}{c}{ Rural } & \multicolumn{2}{c}{ Urban } & \multicolumn{2}{c}{ Total } \\
\cline { 2 - 7 } & Percent & Number & Percent & Number & Percent & Number \\
Yes & 17.9 & 175 & 63.4 & 156 & 27.1 & 331 \\
\hline No & 76.5 & 747 & 28.0 & 69 & 66.8 & 816 \\
\hline Respondent herself is LHW & 0.5 & 5 & & & 0.4 & 5 \\
\hline Don't know & 5.0 & 49 & 8.5 & 21 & 5.7 & 70 \\
Total & 100.0 & 976 & 100.0 & 246 & 100.0 & 1,222
\end{tabular}

About 84 percent of the urban respondents and 77 percent of the rural respondents indicated that a LHW had visited their home within the three months preceding the survey (Table 5.9).

Table 5.9:

LHW ever visited home during last three months

\begin{tabular}{lrrrrrrr} 
& \multicolumn{2}{c}{ Rural } & \multicolumn{2}{c}{ Urban } & \multicolumn{2}{c}{ Total } \\
\cline { 2 - 7 } Ever visited & Percent & Number & Percent & Number & Percent & Number \\
\hline Yes & 76.6 & 134 & 84.0 & 131 & 80.1 & 265 \\
\hline No & 23.4 & 41 & 16.0 & 25 & 19.9 & 66 \\
Total & 100.0 & 175 & 100.0 & 156 & 100.0 & 331
\end{tabular}





\section{Chapter}

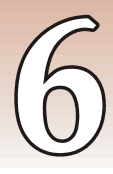

\section{Contraceptive Knowledge and Use}

Respondents were asked to name the ways in which a couple could delay or avoid a pregnancy. If the respondent did not spontaneously mention a particular method, the interviewer described different methods and asked the respondent to indicate if she recognized them. In the questionnaire, descriptions were included for six modern contraceptive methods and two traditional methods.

\section{Knowledge of Contraceptive Methods}

Many women are unaware of the different types of contraceptives that may be used to either delay or prevent pregnancy. Knowledge of contraception is an important step towards reproductive choice. Respondents were if they knew or had heard of any family planning methods. According to Figure 6.1, the most widely known methods in rural Jaffarabad were pills (76 percent), injection (72 percent), IUD (48 percent), female sterilization (27 percent) and condoms (10 percent). Very few women knew about male sterilization ( 3 percent), withdrawal ( 2 percent) and the rhythm method (3percent). It may be noted that 80 percent of the respondents in rural Jaffarabad did not recognize male sterilization as a form of birth control even after it was described to them.

Figure 6.1: $\quad$ Percentage of married women by knowledge of specific contraceptive method - rural Jaffarabad

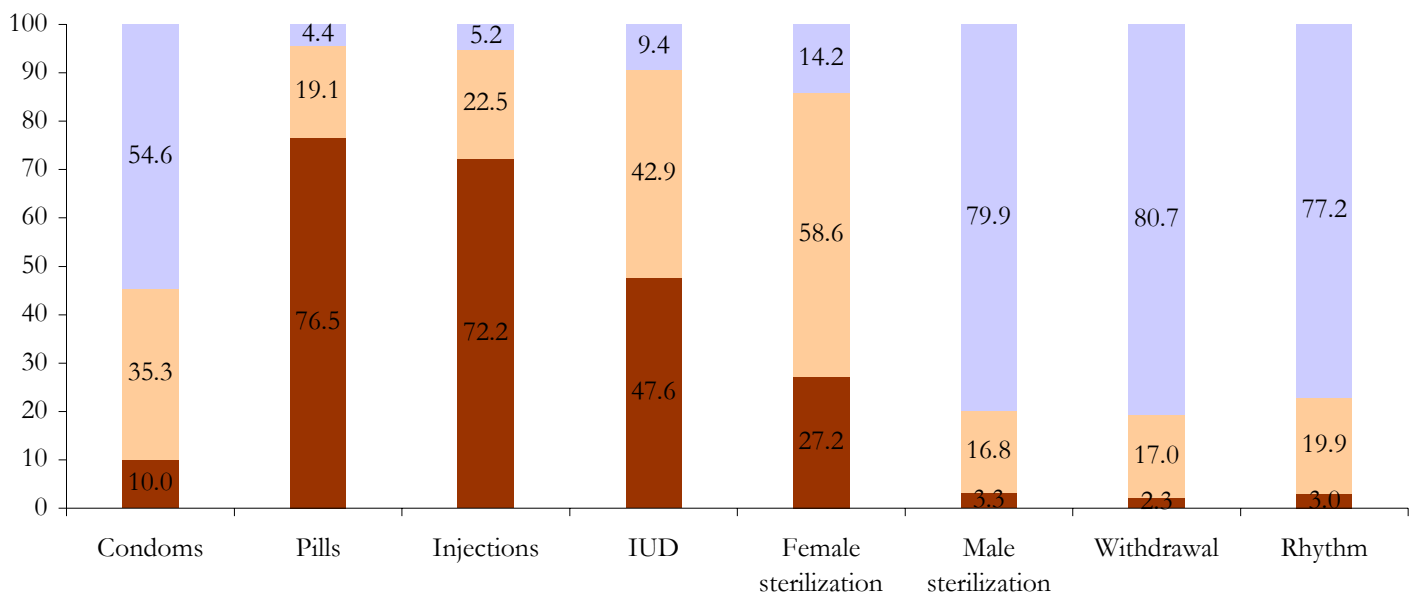

apontaneous $\square$ Prompted $\square$ No Knowledge 
Knowledge about various contraceptive methods was slightly higher in urban areas than rural ones. For example, 76 percent of respondents in urban areas had knowledge of pills, 72 percent of injections, 48 percent of IUDs and 27 percent knew about female sterilization. Male sterilization and traditional contraceptive methods like withdrawal and rhythm were not very well known in the urban parts of the district.

Figure 6.2: $\quad$ Percentage of married women by knowledge of specific contraceptive method-urban Jaffarabad

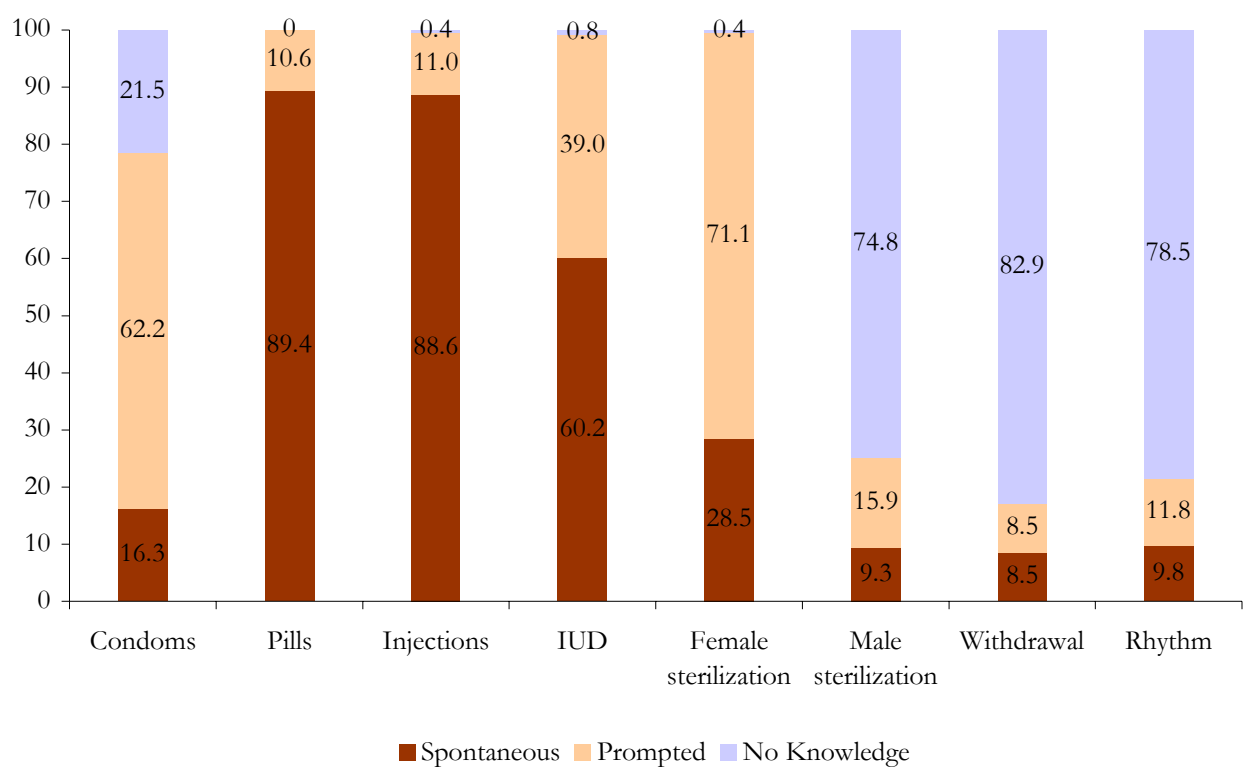

\section{Ever Use of Contraception}

When asked if they had ever used any form of contraception, nearly three quarters ( 76 percent) of the respondents said no. The most widely used contraceptives were injections (8 percent), pills ( 7 percent), and IUDs ( 5 percent). Table 6.1 presents details of various family planning methods used by the urban and rural population in Jaffarabad.

Table 6.1: $\quad$ Ever use of specific contraceptive method

\begin{tabular}{lrrrr}
\multicolumn{1}{c}{ Contraceptive method } & \multicolumn{2}{c}{ Place of residence } & \multicolumn{2}{c}{ Total } \\
\cline { 2 - 5 } Any method & \multicolumn{1}{c}{ Rural } & Urban & Percentage & \multicolumn{1}{c}{ Number } \\
\hline Condoms & 16.2 & 26.0 & 18.2 & 222 \\
\hline Pills & 1.2 & 1.2 & 1.2 & 15 \\
\hline Injections & 5.6 & 11.0 & 6.7 & 82 \\
\hline IUD & 7.3 & 9.3 & 7.7 & 94 \\
\hline Female sterilization & 4.0 & 8.5 & 4.9 & 60 \\
\hline Male sterilization & 1.6 & 2.4 & 1.8 & 24 \\
\hline Withdrawal & & & & 6 \\
\hline Rhythm & 0.5 & 0.4 & 0.5 & 6 \\
\hline
\end{tabular}




\section{Current Use of Contraceptive Methods}

Contraceptive prevalence is defined as the proportion of currently married women age 15-49 using some method of family planning at the time of the survey. When asked about the type of family planning method being used currently, 92 percent indicated that they do not use contraception.

Among those who were using any contraceptive method at the time of the survey, a majority reported using modern methods (7.4 percent), while the rest used traditional methods, such as withdrawal and rhythm. Among the users of modern methods, injections (1.8 percent), female sterilization (1.8 percent), pills (1.7 percent) and IUD (1.6 percent) were most common. Table 6.2 shows the percentage distribution of married women using a specific family planning method at the time of the survey.

Table 6.2: $\quad$ Current use of specific contraceptive method

\begin{tabular}{lccc}
\multicolumn{1}{c}{ Contraceptive Method } & Rural & Urban & All \\
Any method & 7.3 & 9.8 & 7.8 \\
\hline Any modern method & 6.9 & 9.8 & 7.4 \\
\hline Any traditional method & 0.3 & 0.0 & 0.2 \\
\hline Condom & 0.6 & & 0.5 \\
\hline Pill & 1.6 & 2.0 & 1.7 \\
\hline Injectables & 1.7 & 2.0 & 1.8 \\
\hline IUD & 1.2 & 3.3 & 1.6 \\
\hline Female sterilization & 1.6 & 2.4 & 1.8 \\
\hline Withdrawal & 0.1 & & 0.1 \\
\hline Rhythm & 0.2 & & 0.2 \\
\hline Other & 0.1 & & 0.1 \\
\hline Not currently using & 92.7 & 90.2 & 92.2 \\
\hline Number & 976 & 246 & 1,222
\end{tabular}




\section{Source of Contraceptive Supplies}

Private clinics and hospitals were reported as the most common source of contraceptive supplies for 52 percent of the rural and 54 percent of the urban respondents. It was discovered that the majority of respondents in Jaffarabad rely on hospitals (mostly private) and BHU/RHC/MCH centers for contraceptives (Table 6.3).

Table 6.3: $\quad$ Distribution of contraceptive users by source of supply

\begin{tabular}{lrrrrrrr}
\multirow{2}{*}{ Source/Place } & \multicolumn{2}{c}{ Rural } & \multicolumn{2}{c}{ Urban } & \multicolumn{2}{c}{ Total } \\
\cline { 2 - 7 } LHW & Percent & Number & Percent & Number & Percent & Number \\
\hline BHU/RHC/MCH center & 9.0 & 6 & & & & 6.6 & 6 \\
\hline DHQ/THQ & 11.9 & 8 & 16.7 & 4 & 13.2 & 12 \\
\hline Private clinic/hospital & 9.0 & 6 & 8.3 & 2 & 8.8 & 8 \\
\hline FWC/RHSA & 52.2 & 35 & 54.2 & 13 & 52.7 & 48 \\
\hline Medical store & & & 4.2 & 1 & 1.1 & 1 \\
\hline General store/shop & 6.0 & 4 & 8.3 & 2 & 6.6 & 6 \\
\hline Others & 7.5 & 5 & 4.2 & 1 & 6.6 & 6 \\
\hline Total & 4.5 & 3 & 4.2 & 1 & 4.4 & 4 \\
\hline
\end{tabular}

\section{Intentions of Future Use}

The non-users of family planning methods were then asked if they had any intentions of using family planning methods in the future. About 37 percent in rural areas and nearly 40 percent in urban areas said they did not plan to use contraception. A very high percentage in urban (44 percent) and rural (43 percent) areas remained uncertain regarding future use of contraception. Only 19 percent in rural areas and 17 percent in urban areas had intentions to use contraceptives in future (figure 6.3).

Figure 6.3: $\quad$ Percentage of married women by future intention to use contraceptives

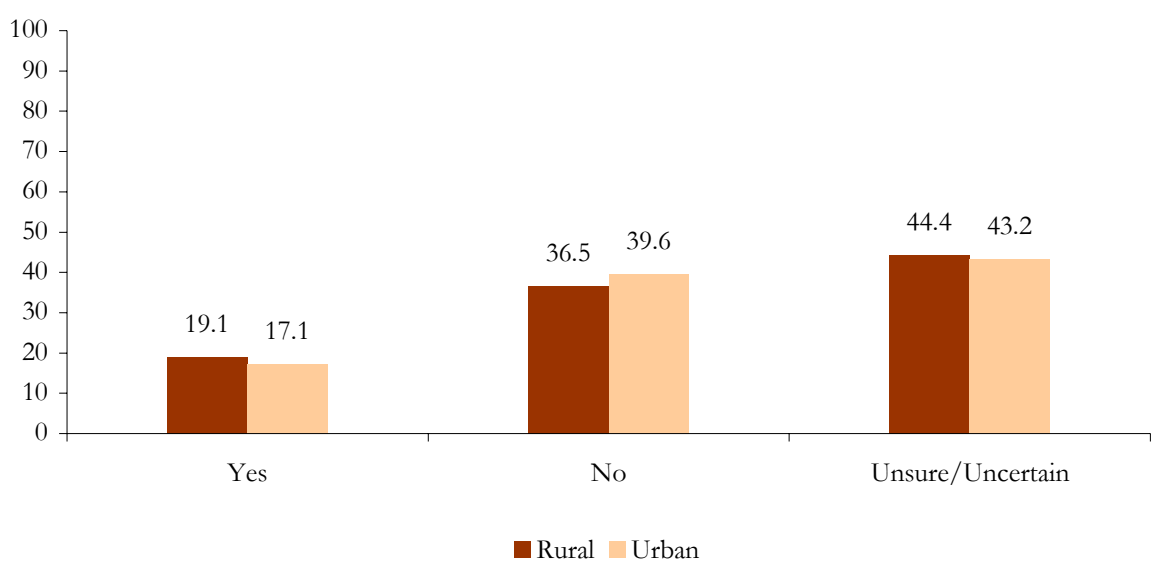




\title{
Chapter
}

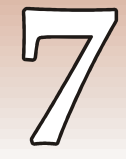

\section{Behavior Regarding Maternal and Newborn Health}

\begin{abstract}
Many of the women who were interviewed were currently pregnant. However, some women, especially those in the early stages of pregnancy, had not yet experienced the full range of events that take place over the nine-month gestational period. Women who had recently given birth were able to provide a full range of information on these events and thus constitute an important part of the sample population in terms of understanding attitudes and behaviors concerning maternal and newborn health. This chapter pertains to the respondents' last pregnancy, given that it was within the past three years. Respondents were asked several questions regarding their experience during their last pregnancy including antenatal and delivery care, complications during pregnancy and delivery, postnatal care and problems in accessing health care.

Information on antenatal care, delivery services and postnatal care is of great value in identifying segments of married women who do not utilize such services and is useful in planning for future improvements in services. Delivery services are described according to the person assisting the delivery and the rate of caesarean section. Information on postnatal care was collected for women who did not give birth in a health facility, and it describes the time since delivery when care was received, as well as the type of caregiver.
\end{abstract}

\section{Gestational Age}

The married women were asked to indicate gestational age at which their last pregnancy ended. Table 7.1 shows that of those pregnancies that ended in live births, almost two-thirds were completed after a nine month gestational period, whereas 30.5 percent of the pregnancies ended after a ten month gestational period. Stillbirths occurred in the third trimester while abortions, both induced and spontaneous, occured in the first and second trimesters.

Table 7.1: $\quad$ Pregnancy outcome by gestational age

\begin{tabular}{lrrrr}
$\begin{array}{l}\text { Gestational age when } \\
\text { Pregnancy ended }\end{array}$ & Live Birth & Still birth & $\begin{array}{c}\text { Spontaneous } \\
\text { Abortions }\end{array}$ & $\begin{array}{c}\text { Induced } \\
\text { Abortions }\end{array}$ \\
\hline First trimester & & & 44.2 & \\
\hline Second trimester & 0.5 & 13.5 & 55.8 & 100.0 \\
\hline 7 & 2.5 & 4.5 & & \\
\hline 8 & 66.5 & 63.8 & & \\
\hline 9 & 30.5 & 18.2 & & 100.0 \\
\hline 10 & 100.0 & 100.0 & 100.0 & 2 \\
\hline Total & 757 & 22 & 43 & \\
\hline Number of pregnancies & & & & \\
\hline
\end{tabular}




\section{Antenatal Care}

In the baseline survey, antenatal care was defined according to the type of provider, the number of visits made, and the stage of pregnancy at the time of the first visit, including whether or not tetanus toxoid injection and iron/folate tablets were received. The baseline survey also included questions regarding the antenatal care received by the respondent during the last pregnancy.

Figure 7.1: $\quad$ Percentage of respondents who obtained antenatal care

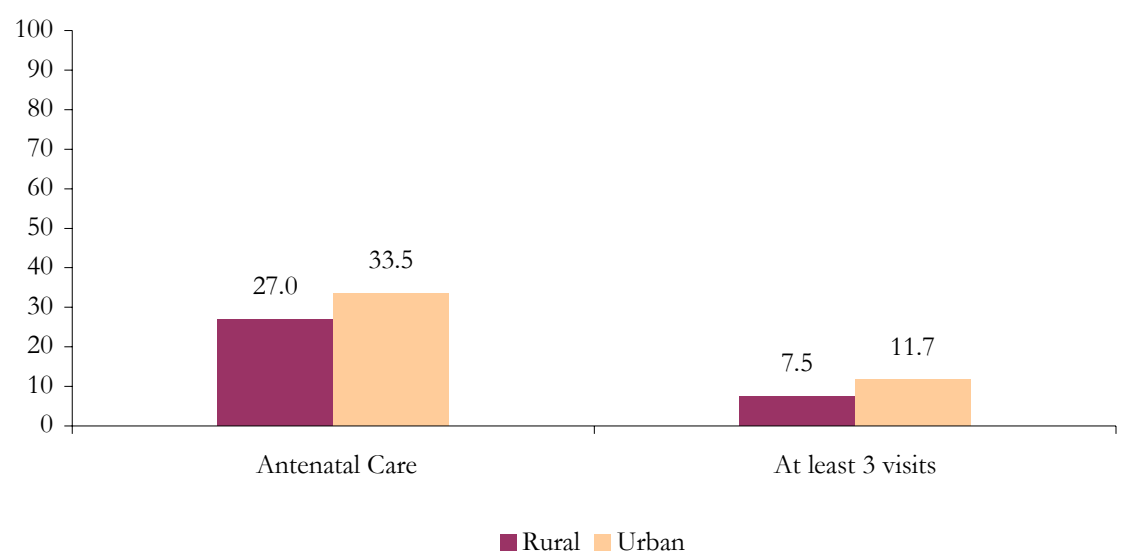

According to figure 7.1 about one third of respondents in urban areas and only 27 percent in rural areas received antenatal care during their last pregnancy. The majority of pregnant women both in urban and rural areas did not receive antenatal care during their last pregnancy. Only 12 percent of the pregnant women in urban areas and 8 percent in rural areas had three or more ANC visits during their last pregnancy.

According to table 7.2, about 44 percent of the respondents in rural areas had their first antenatal check-up during the third trimester, 32.5 percent during the second trimester and the remaining women in the first trimester. In urban areas, 32 percent of the respondents had their first antenatal check-up in the first trimester, 44 percent in the second trimester and 22 percent in the third trimester.

About four out of five women had one to three antenatal check-ups during their last pregnancy. Only 9 percent of the respondents went five or more antenatal check-ups. 
Table 7.2 :

Gestational age at first antenatal check-up/number of antenatal check-ups obtained

\begin{tabular}{|c|c|c|c|c|c|c|c|}
\hline \multirow{2}{*}{\multicolumn{2}{|c|}{ Check-ups }} & \multicolumn{2}{|c|}{ Rural } & \multicolumn{2}{|c|}{ Urban } & \multicolumn{2}{|c|}{ Total } \\
\hline & & Percent & Number & Percent & Number & Percent & Number \\
\hline \multirow{10}{*}{$\begin{array}{l}\text { Gestational } \\
\text { age at first } \\
\text { antenatal } \\
\text { check-up }\end{array}$} & 1 & 2.2 & 4 & 7.3 & 4 & 3.4 & 8 \\
\hline & 2 & 3.9 & 7 & 9.1 & 5 & 5.2 & 12 \\
\hline & 3 & 12.4 & 22 & 14.5 & 8 & 12.9 & 30 \\
\hline & 4 & 11.2 & 20 & 7.3 & 4 & 10.3 & 24 \\
\hline & 5 & 10.1 & 18 & 16.4 & 9 & 11.6 & 27 \\
\hline & 6 & 11.2 & 20 & 20.0 & 11 & 13.3 & 31 \\
\hline & 7 & 18.0 & 32 & 10.9 & 6 & 16.3 & 38 \\
\hline & 8 & 15.7 & 28 & 3.6 & 2 & 12.9 & 30 \\
\hline & 9 & 11.8 & 21 & 7.3 & 4 & 10.7 & 25 \\
\hline & Don't know & 3.4 & 6 & 3.6 & 2 & 3.4 & 8 \\
\hline \multirow{11}{*}{$\begin{array}{l}\text { No. of times } \\
\text { have antenatal } \\
\text { check-ups }\end{array}$} & 0 & 0.6 & 1 & & & 0.4 & 1 \\
\hline & 1 & 40.4 & 72 & 30.9 & 17 & 38.2 & 89 \\
\hline & 2 & 29.8 & 53 & 30.9 & 17 & 30.0 & 70 \\
\hline & 3 & 11.8 & 21 & 9.1 & 5 & 11.2 & 26 \\
\hline & 4 & 8.4 & 15 & 9.1 & 5 & 8.6 & 20 \\
\hline & 5 & 3.4 & 6 & 5.5 & 3 & 3.9 & 9 \\
\hline & 6 & 1.7 & 3 & 1.8 & 1 & 1.7 & 4 \\
\hline & 7 & 1.7 & 3 & 5.5 & 3 & 2.6 & 6 \\
\hline & 8 & & & 1.8 & 1 & 0.4 & 1 \\
\hline & 9 & 0.6 & 1 & 1.8 & 1 & 0.8 & 2 \\
\hline & Don't know & 1.7 & 3 & 3.6 & 2 & 2.1 & 5 \\
\hline \multicolumn{2}{|l|}{ Total } & 100.0 & 178 & 100.0 & 55 & 100.0 & 233 \\
\hline
\end{tabular}

Figure 7.2 presents the percentage distribution of married women by the person who accompanied them to their antenatal check-ups. About one-third of women said their husbands accompanied them, another one third were accompanied by family members, while 23 percent went with their mothers in law. 
Figure 7.2:

Persons accompanying pregnant women to antenatal check-ups

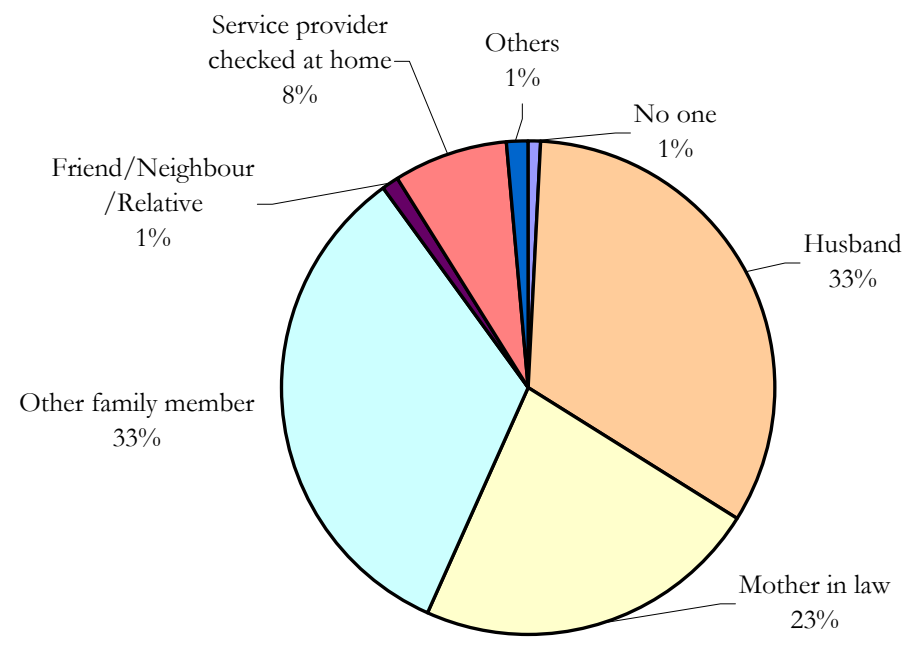

\section{Components of antenatal care}

In Pakistan, it is recommended that every pregnant woman receive the following services: height and weight measurements, blood pressure measurement, tetanus toxoid immunization and an abdominal examination. In any antenatal care visit, a woman should be informed of the danger signs of pregnancy, have her weight measured, and provide blood and urine samples for testing. Antenatal care can improve certain outcomes through timely detection and management of possible complications. Antenatal care may improve birth weight and can also prevent, identify and treat iron deficiency and anemia in pregnant mothers.

Figure 7.3 shows the percentage distribution of services received by pregnant women during antenatal check-ups. About 73 percent of the women in urban areas and 60 percent of the women in rural areas had their blood pressure measured during their antenatal check-ups. Three-quarters of women in urban areas and more than half in rural areas were asked about their last menses period. Only 64 percent of women in urban areas and 48 percent in rural areas were asked for their obstetric history. More than half of the women were referred for ultrasound both in urban and rural areas. About two thirds of pregnant women in urban areas and 44 percent in rural areas were tested for anemia. More than one-third in urban areas and 31 percent in rural areas were encouraged to have blood tests, while over 29 percent respondents in urban and 24 percent in rural areas were referred for a urine test. 
Figure 7.3: $\quad$ Services performed/asked during antenatal check-up

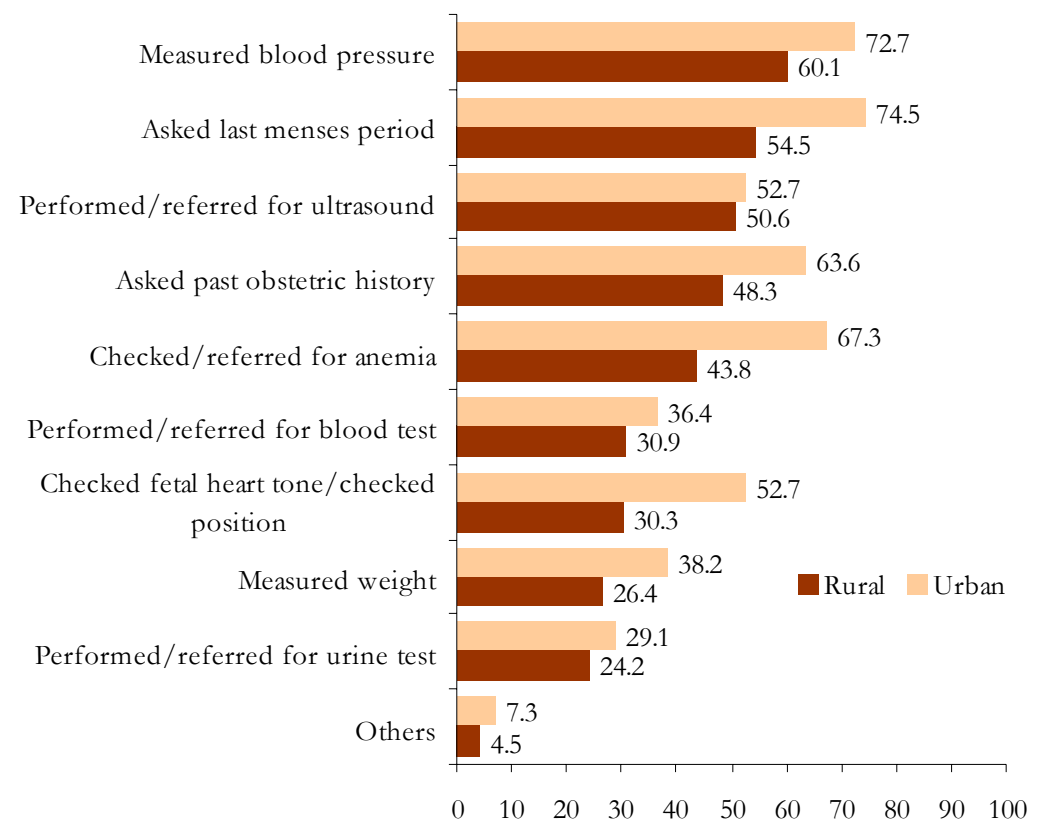

According to figure 7.4, about 83.6 percent of the urban respondents, along with 65.7 percent of their rural counterparts had a health professional discuss nutrition with them during their antenatal visit. Only 78 percent and 65 percent of the urban and rural women were informed of the importance of TT shots during pregnancy. Some very important issues such as birth preparedness, danger signs during pregnancy and breast-feeding were addressed during antenatal check-ups with only 20 percent of women in rural areas and only 30 percent in urban areas.

Figure 7.4: $\quad$ Percentage of pregnant women by issues discussed during antenatal check-up

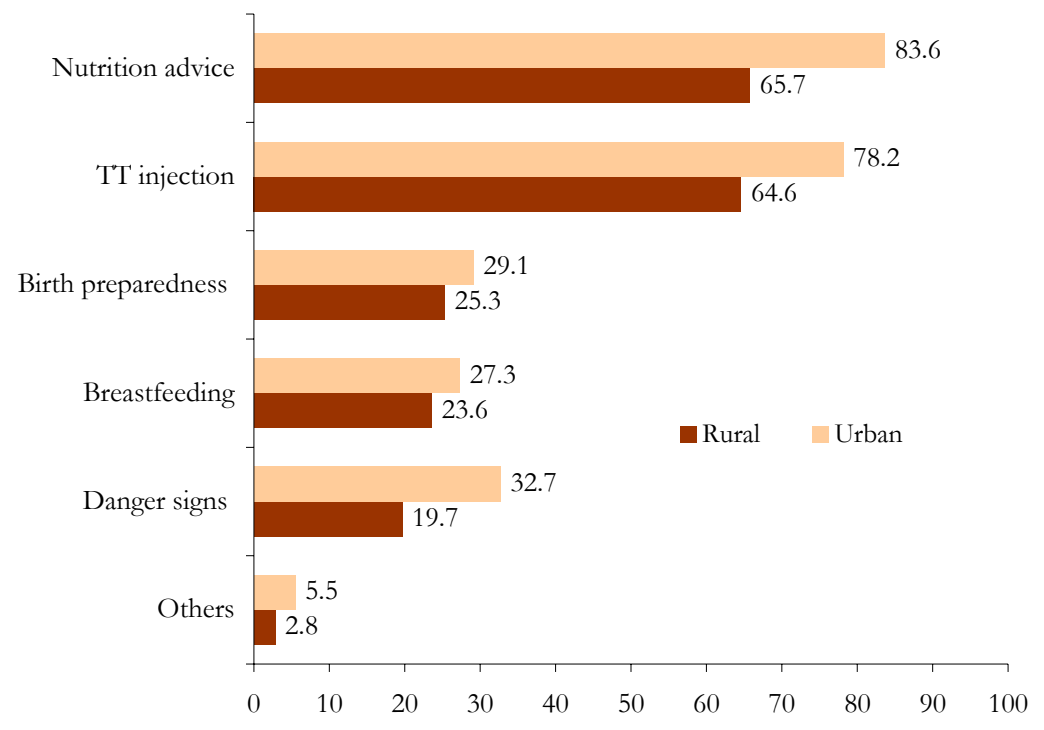




\section{T'T injections and Iron/Folate tablets}

Respondents were also asked to state whether they took iron and folate supplements and received TT shots during their last pregnancy. The immunization of pregnant women is enforced by a program coordinated by the Expanded Program on Immunization (EPI) and the Maternal and Child Health Care $(\mathrm{MCH})$ departments at the district level. The program recommends that women should receive two tetanus toxoid (TT) injections during their first pregnancy. Booster injections are given once during each subsequent pregnancy to maintain full protection. In recent years, TT immunization has also been given to women before marriage, so that any pregnancy occurring within three years of their marriage would be protected against tetanus.

Figure 7.5 shows that in rural areas, 31 percent of the women received TT shots during their last pregnancy, while 69 percent did not. In urban areas, almost 49.4 percent received TT shots, while about half of the respondents did not. Figure 7.5 also shows that only 24 percent of the rural respondents and 41 percent of the urban respondents received at least 2 TT shots.

Figure 7.6 indicates that in rural areas, 15 percent of the respondents took iron/folate supplements, while 85 percent did not use them during their last pregnancy. In urban areas, 46 percent of the respondents used iron/folate supplements while the remaining 54 percent did not.

Women may not have the decision-making power to obtain these supplements and vaccinations and may be dependent upon husbands or family members/in-laws to make important decisions for them.

Figure 7.5: $\quad$ Percentage of married women by status of TT injections during the last pregnancy

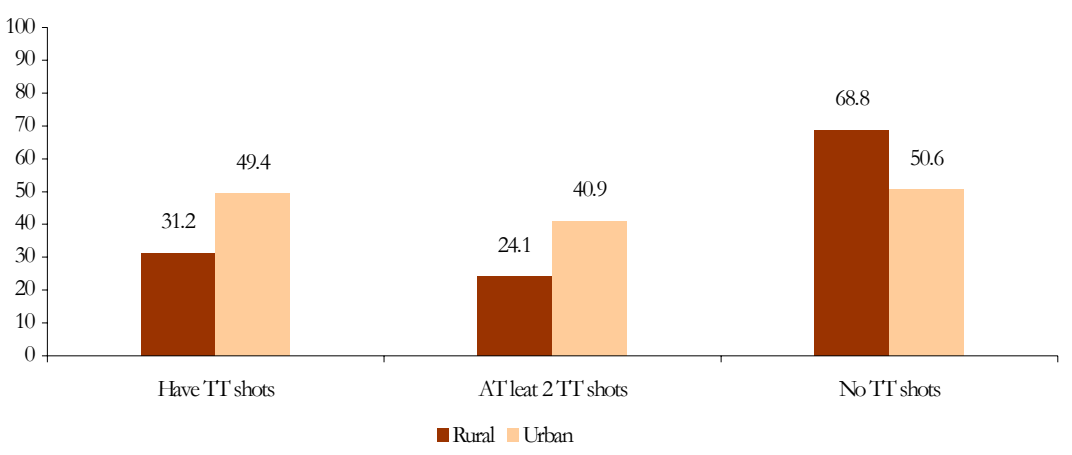

Figure 7.6: $\quad$ Percentage of married women by status of Iron/Folate tablets during the last pregnancy

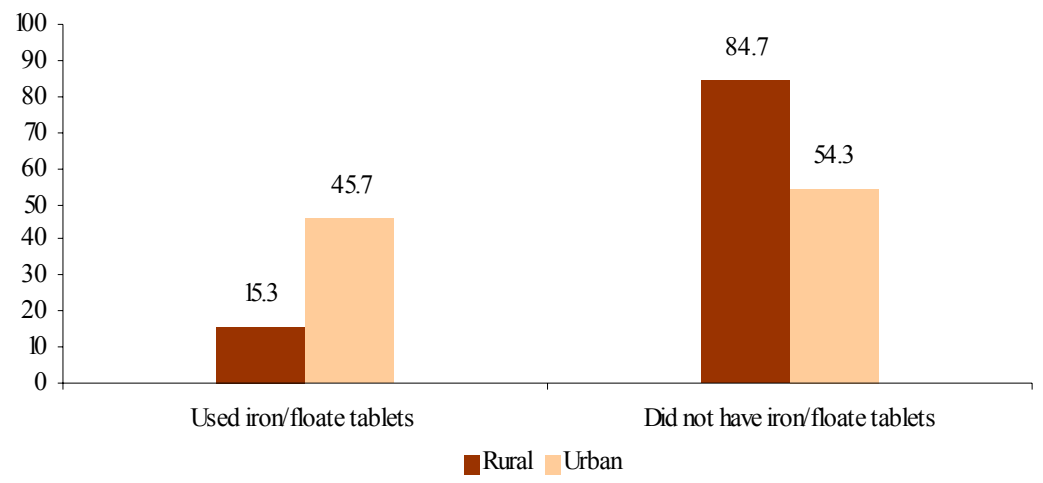




\section{Experience of complications and birth preparedness}

\section{Complications during pregnancy}

To identify complications associated with pregnancy, women were asked about certain signs and symptoms that they had experienced during their last pregnancy within the past three years. In rural areas almost three out of five pregnant women a indicated that they experienced some type of complication during their last pregnancy, while three-quarters stated the same thing in urban areas of Jaffarabad.

Figure 7.7 shows that more complications were reported by respondents in urban areas as compared to rural areas of Jaffarabad. In urban areas, 57.3 percent had severe headaches, 57 percent had shortness of breath and 52 percent had severe lower abdominal pain. In rural areas, 40 percent had severe lower abdominal pains, 37 percent had severe headache and 30 percent had shortness of breath.

Around 8 percent of women in both areas had heavy vaginal bleeding during their last pregnancy. It is possible that women perceive bleeding during pregnancy to be a normal symptom, and may therefore fail to report it as a complication.

Figure 7.7: $\quad$ Percentage of married women who experienced complications during their last pregnancy

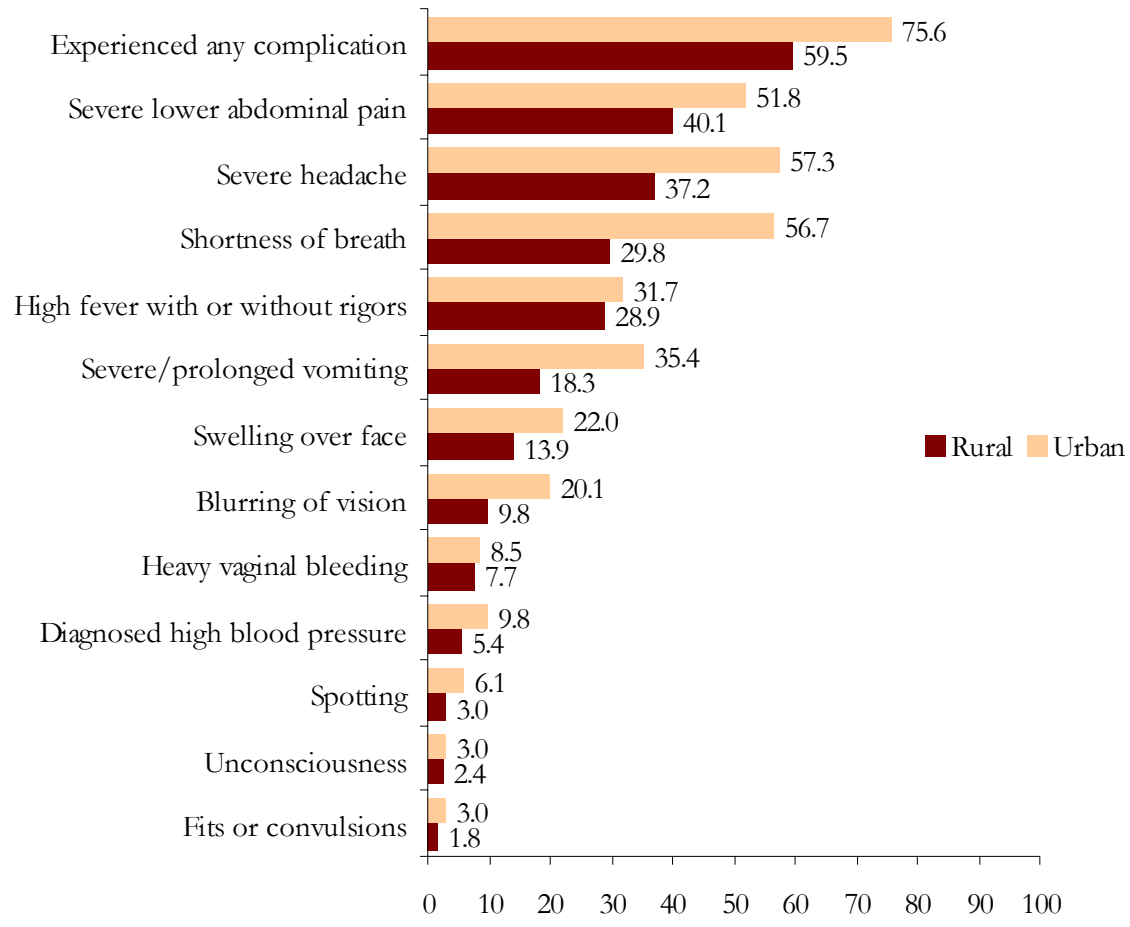




\section{Preparedness for Childbirth}

To ensure the safety of the mother and newborn at the time of delivery, certain preparations need to be made. These include deciding who is going to assist with the delivery, where the delivery is going to take place, how the woman is going to get to the place of delivery, and how much the delivery is going to cost. Delivery services, especially emergency obstetric care, are critical for pregnant women. Emergency care is important in the event that a pregnant mother experiences obstructed labor, pregnancy-induced hypertension, eclampsia or severe untreated anemia. Obstructed or prolonged labor is one of the more serious complications that can cause maternal death. Obstetric care can also prevent or treat complications that affect the neonate, such as birth asphyxia.

Figure 7.8 shows that more than 90 percent of women in urban areas of Jaffarabad prepared clothes for their babies, while 72 percent of their counterparts in rural areas did the same. More than half of the population in urban areas and only one third in rural areas arranged money for an emergency. Three out of five women in urban areas, and half of the women in rural areas arranged money for a normal delivery. About three-quarters of women in urban and one third in rural areas knew the location of a nearby hospital. In addition, 62 percent of women in urban areas and 42 percent in rural areas talked to a service provider about assisting the delivery. Transport arrangements were made by 42 percent respondents in urban and only 19 percent in rural areas.

Figure 7.8: $\quad$ Percentage of married women who made arrangements for their last delivery

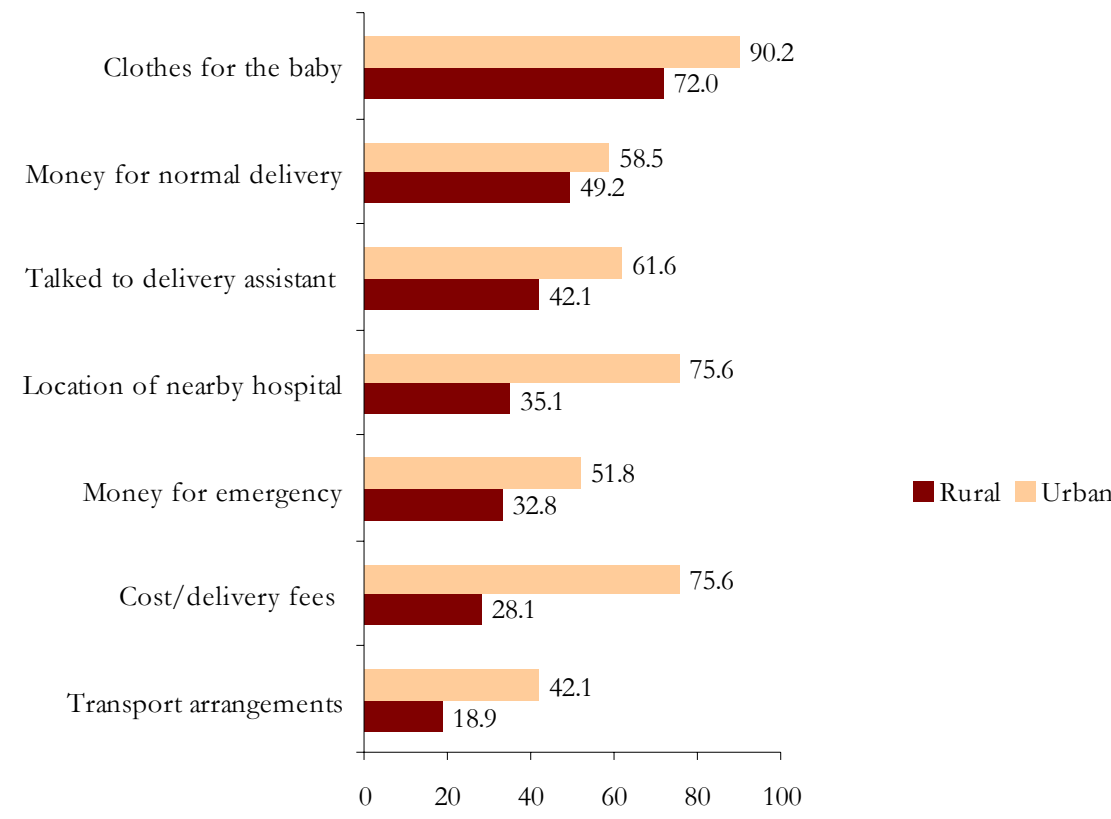




\section{Delivery Characteristics}

Table 7.3 shows the status of the last delivery of respondents. More than 90 percent of respondents in both urban and rural areas said that they had a normal vaginal delivery. The percentages of Caesarean and assisted vaginal deliveries in rural areas were only 1 percent and 3 percent respectively. In urban areas, the percentages of Caesarean and assisted vaginal deliveries were 2.4 percent and 1.2 percent respectively. Spontaneous abortions were reported by 5.5 percent and 6.1 percent of the rural and urban respondents. One case of induced abortion was reported in rural while none were reported in urban Jaffarabad.

Table 7.3: $\quad$ Status of last delivery

\begin{tabular}{lrrrrrr}
\multirow{2}{*}{ Status } & \multicolumn{2}{c}{ Rural } & \multicolumn{2}{c}{ Urban } & \multicolumn{2}{c}{ Total } \\
\cline { 2 - 7 } & Percent & Number & Percent & Number & Percent & Number \\
\hline Normal vaginal delivery & 90.8 & 599 & 90.2 & 148 & 90.7 & 747 \\
\hline Assisted vaginal delivery & 2.7 & 18 & 1.2 & 2 & 2.4 & 20 \\
\hline Caesarean section & 0.9 & 6 & 2.4 & 4 & 1.2 & 10 \\
\hline Spontaneous abortion & 5.5 & 36 & 6.1 & 10 & 5.6 & 46 \\
\hline Induced abortion & 0.2 & 1 & & & 0.1 & 1 \\
Total & 100.0 & 660 & 100.0 & 164 & 100.0 & 824
\end{tabular}

Figure 7.9 indicates the outcome of the last delivery. It shows that 92 percent of the pregnancies ended in live births, 3 percent in still births and more than 5 percent in abortions.

Figure 7.9: $\quad$ Percentage of pregnancies by outcome

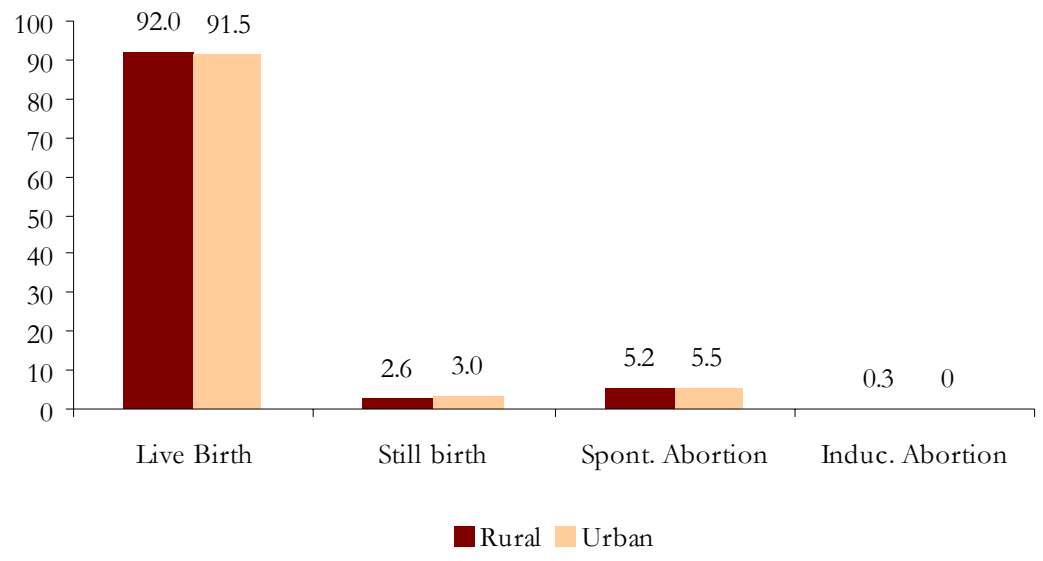




\section{Place of Delivery}

Four out of five women in rural areas indicated that they delivered their babies at home. Only 3 percent of rural women delivered their babies at government facilities and 17 percent at private hospitals. In urban areas, more than half of the women reported that they delivered their babies at home, about 42 percent did so at private hospitals/clinics. Only 2 percent of the urban respondents availed government health facilities in urban areas. This indicated that the use of government health facilities is very low in Jaffarabad. This may be due to a lack of trust in government health facilities, and a belief that the private sector has a better level of services.

Figure 7.10: $\quad$ Percentage of women by place of delivery

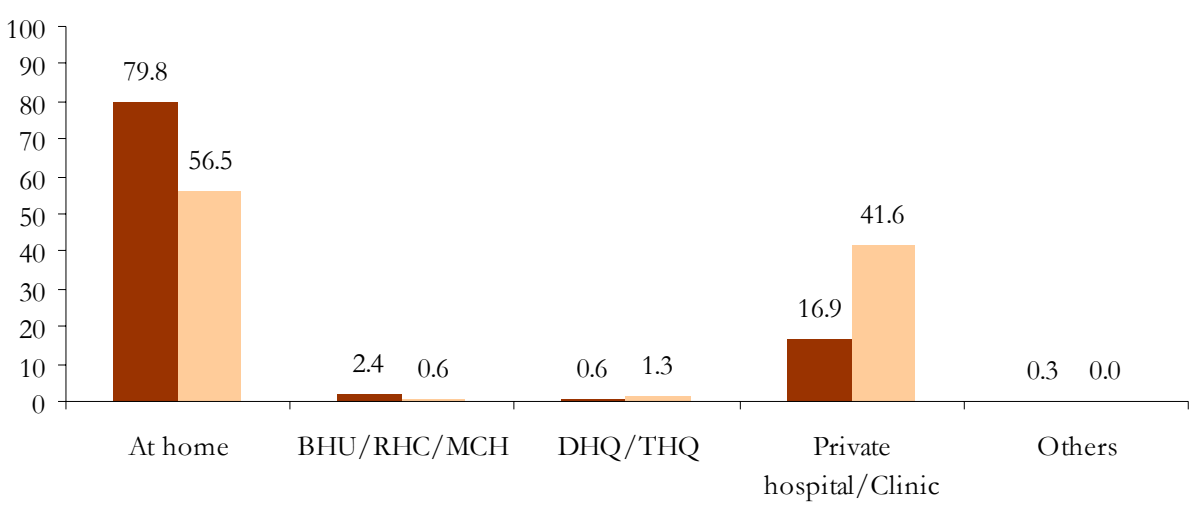

Rural Urban

\section{Assistance during Delivery}

Traditional Birth Attendants (TBAs) or Dais assisted at more than 95 percent of the home deliveries. Female relatives assisted only 3 percent of the respondents during their last delivery. A very low percentage of women were assisted by a nurse/LHW in both urban and rural areas of Jaffarabad.

Figure 7.11: $\quad$ Percentage of married women who delivered their last child at home by type of delivery attendantby delivery attendant

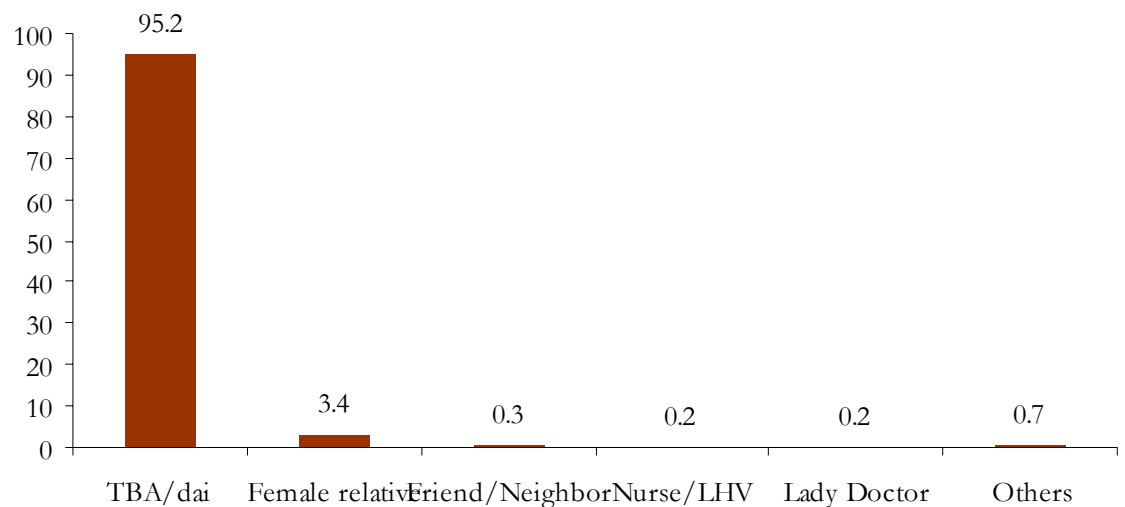


Figure 7.12 shows the main reason for choosing a TBA or Dai to assist with delivery. Overall in both rural and urban areas, 36 percent of the married women reported that it was their family to choose TBA for delivery. More than a quarter said that they had used the TBA for earlier deliveries while 19 percent of respondents cited geographical proximity as a main reason for choosing a TBA. About 11 percent indicated cost as being a reason, while more than 4 percent of women believed that TBAs were more knowledgeable than health professionals.

Figure 7.12: $\quad$ Main reason for choosing a TB $A$ / dai to assist with the last delivery

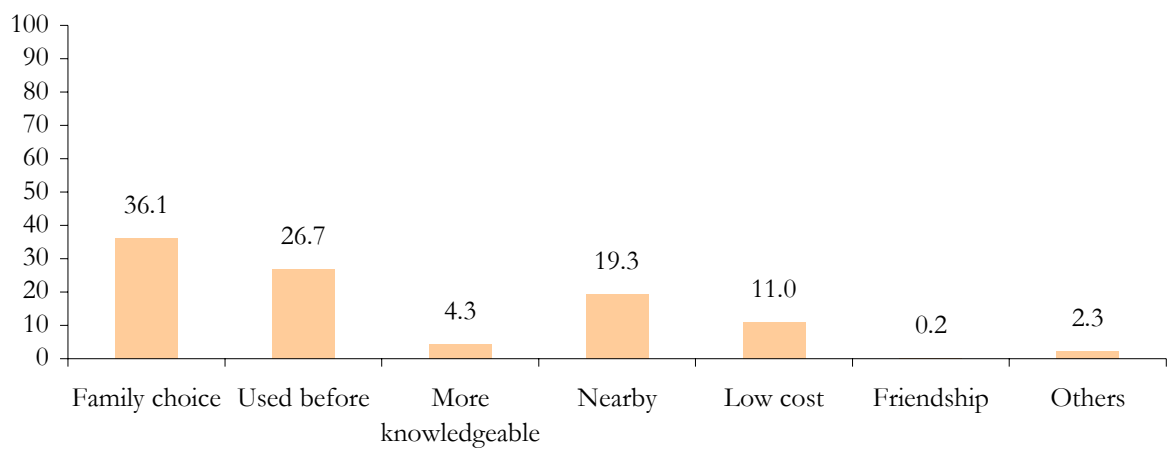

\section{Clean Delivery Practices}

Respondents were asked to state if their TBAs followed safe health practices such as washing their hands with soap prior to deliveries and using clean delivery kits. Figure 7.13 shows that about 75 percent of women in rural and more than 89 percent of women in urban areas reported that their delivery assistant washed her hands with soap. Figure 7.14 shows the type of instrument used to cut the cord during delivery. About 8 percent in rural areas and more than 4 percent of the respondents in urban areas reported that their TBAs did not use a new blade to cut the cord.

Figure 7.13: $\quad$ Percentage of delivery attendants who reportedly washed hands before conducting the delivery and type of thread used to tie the cord

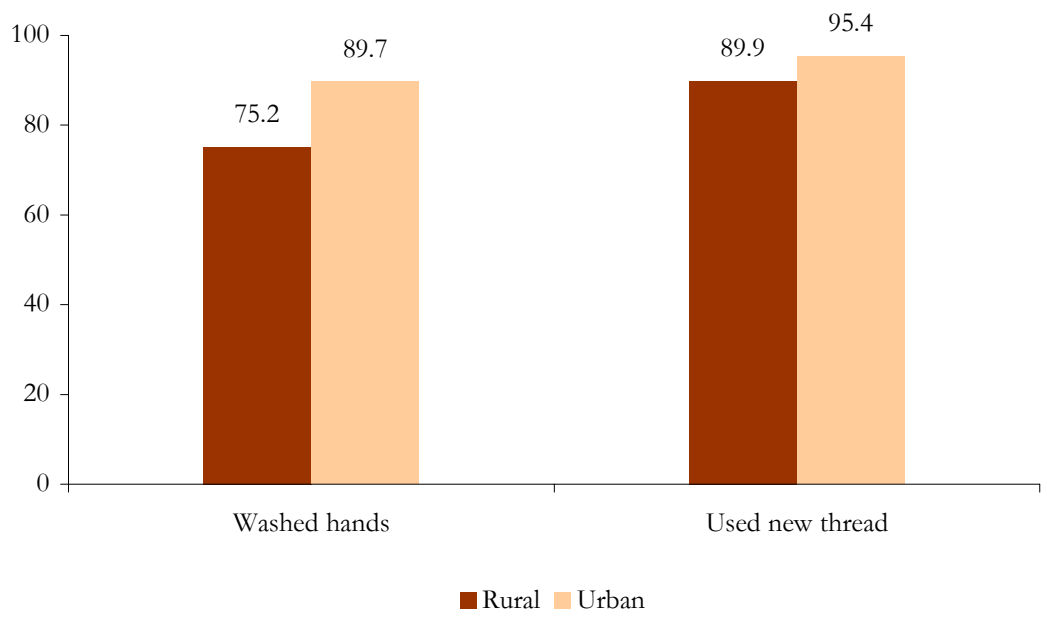


Figure 7.14: $\quad$ Percentage of delivery attendants who reported instruments for cutting the cord

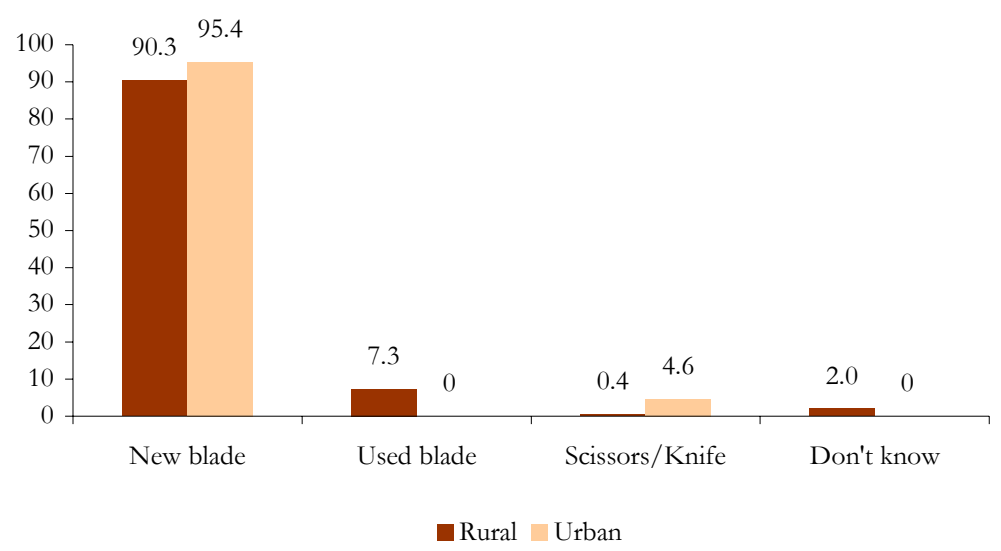

\section{Complications during Childbirth}

Table 7.4 indicates the percentage of severe complications experienced by respondents during childbirth. More than 29 percent of the respondents in rural areas indicated that they experienced excruciatingly abnormal pain during their last delivery, whereas more than 40 percent in urban areas reported the same thing. Prolonged labor, premature ruptures of membranes and excessive bleeding were also reported by the respondents.

Table 7.4: $\quad$ Type of complications experienced during the last delivery

\begin{tabular}{lrrrr}
\multicolumn{1}{c}{ Complications } & Rural & Urban & \multicolumn{2}{c}{ Total } \\
\cline { 2 - 4 } Prolonged/obstructed labor & 13.2 & 18.3 & 14.2 & 117 \\
\hline Bleeding before labor began & 5.4 & 4.9 & 5.3 & 44 \\
\hline Excruciating abnormal pain & 29.7 & 40.2 & 31.8 & 262 \\
\hline Premature rupture of membranes & 7.9 & 11.6 & 8.6 & 71 \\
\hline $\begin{array}{l}\text { Delay in delivery of placenta/retained placenta } \\
\text { Excessively postpartum bleeding on day of } \\
\text { deli./abort. }\end{array}$ & 5.6 & 4.9 & 5.5 & 45 \\
\hline Tear in vagina, cervix or uterus & 6.4 & 15.2 & 8.1 & 67 \\
\hline Prolapse of the uterus & 2.3 & 1.8 & 2.2 & 18 \\
\hline Fever & 2.1 & 3.7 & 2.4 & 20 \\
\hline Abnormal position fetus & 14.4 & 15.2 & 14.5 & 120 \\
\hline
\end{tabular}

\section{Decision-making within Family}

Delays in seeking care, in reaching adequate health facilities and in receiving appropriate care upon arrival at a health facilities are recognized barriers to care for pregnant women, and these factors may 
be especially pronounced for young and old pregnant mothers. Timely and appropriate care provides an opportunity to prevent or manage the direct causes of maternal mortality such as hemorrhage, obstructed labor, infection and hypertensive disorders. It also reduces fetal and neonatal deaths related to obstetric complications.

Table 7.5 shows that in rural areas, only 20 percent of the respondents indicated that they themselves had the freedom to decide that they needed medical attention compared to 14 percent of the urban respondents. Two out of five women (39 percent) in rural and one out of five women in urban areas indicated that their husbands made decisions regarding medical treatment in the event of a complication. In urban areas more than one third (34 percent) of respondents indicated that it was the TBA/dai to make such decisions.

Table 7.5 :

Persons who made decision to seek health care/ mode of transport used to reach health facility

\begin{tabular}{|c|c|c|c|c|c|c|c|}
\hline \multirow{2}{*}{\multicolumn{2}{|c|}{ Measures taken }} & \multicolumn{2}{|c|}{ Rural } & \multicolumn{2}{|c|}{ Urban } & \multicolumn{2}{|c|}{ Total } \\
\hline & & Percent & Number & Percent & Number & Percent & Number \\
\hline \multirow{6}{*}{$\begin{array}{l}\text { Person who made } \\
\text { decision to seek } \\
\text { health care }\end{array}$} & Self & 19.6 & 35 & 14.3 & 10 & 18.1 & 45 \\
\hline & Husband & 39.1 & 70 & 20.0 & 14 & 33.7 & 84 \\
\hline & Mother in law & 6.1 & 11 & 12.9 & 9 & 8.0 & 20 \\
\hline & $\begin{array}{l}\text { Other family } \\
\text { member }\end{array}$ & 23.5 & 42 & 18.6 & 13 & 22.1 & 55 \\
\hline & TBA/Dai & 11.2 & 20 & 34.3 & 24 & 17.7 & 44 \\
\hline & Others & 0.6 & 1 & & & 0.4 & 1 \\
\hline \multirow{6}{*}{$\begin{array}{l}\text { Mode of transport to } \\
\text { reach health care } \\
\text { service }\end{array}$} & $\begin{array}{l}\text { Service } \\
\text { provider visited } \\
\text { at home }\end{array}$ & 37.4 & 67 & 25.7 & 18 & 34.1 & 85 \\
\hline & On foot & 2.8 & 5 & 8.6 & 6 & 4.4 & 11 \\
\hline & Own transport & 10.1 & 18 & 8.6 & 6 & 9.6 & 24 \\
\hline & $\begin{array}{l}\text { Private } \\
\text { transport }\end{array}$ & 43.6 & 78 & 54.3 & 38 & 46.6 & 116 \\
\hline & $\begin{array}{l}\text { Community } \\
\text { Transport }\end{array}$ & 0.6 & 1 & & & 0.4 & 1 \\
\hline & Others & 5.6 & 10 & 2.9 & 2 & 4.8 & 12 \\
\hline \multicolumn{2}{|l|}{ Total } & 100.0 & 179 & 100.0 & 70 & 100.0 & 249 \\
\hline
\end{tabular}




\section{Availability of transport}

The mode of transport to a health facility was also an issue that was discussed during the survey. More than a quarter (25.7 percent) of the respondents in urban areas and more than one third (37.4 percent) in rural areas said that service providers visited them at home. More than half (54.3 percent) of the women in urban areas and 43.6 in rural areas used private transport to reach a health center, while 8.6 percent in urban and 10.1 percent in rural areas used their own transport to reach a health facility.

Whatever the mode of transport used, 18 percent of the respondents were able to reach the a health facility within 15 minutes. Another 28 percent reached a facility within 16-30 minutes, while 15 percent reached a facility after 1-2 hours of traveling. A further 4 percent took more than 2 hours to reach a health facility. Figure 7.15 shows the distribution of respondents by the time they took to reach a facility at the time of delivery.

Figure 7.15: $\quad$ Time taken to reach the bealth facility for childbirth

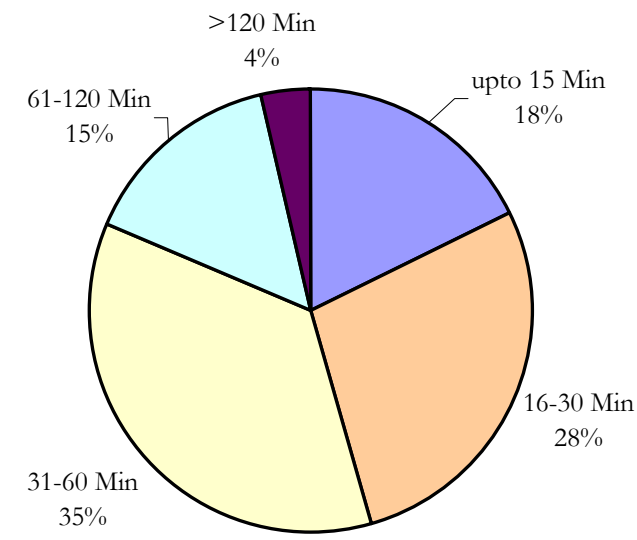

Figure 7.16 depicts the median time taken to find transport, reach a health facility and obtain services upon arrival at the health facility. Overall, it took an average of 30 minutes to find transport, and almost 38 minutes of traveling to reach a health facility. After reaching the health facility, it took an average of 20 minutes to obtain delivery services. Therefore, from the moment decision to seek treatment is made, it takes respondents in Jaffarabad an average of one and a half hour to obtain treatment from a Health Professional for delivery. 
Figure 7.16: $\quad$ Median time to get the transport, to reach the bealth facility and to obtain the treatment after reaching the facility

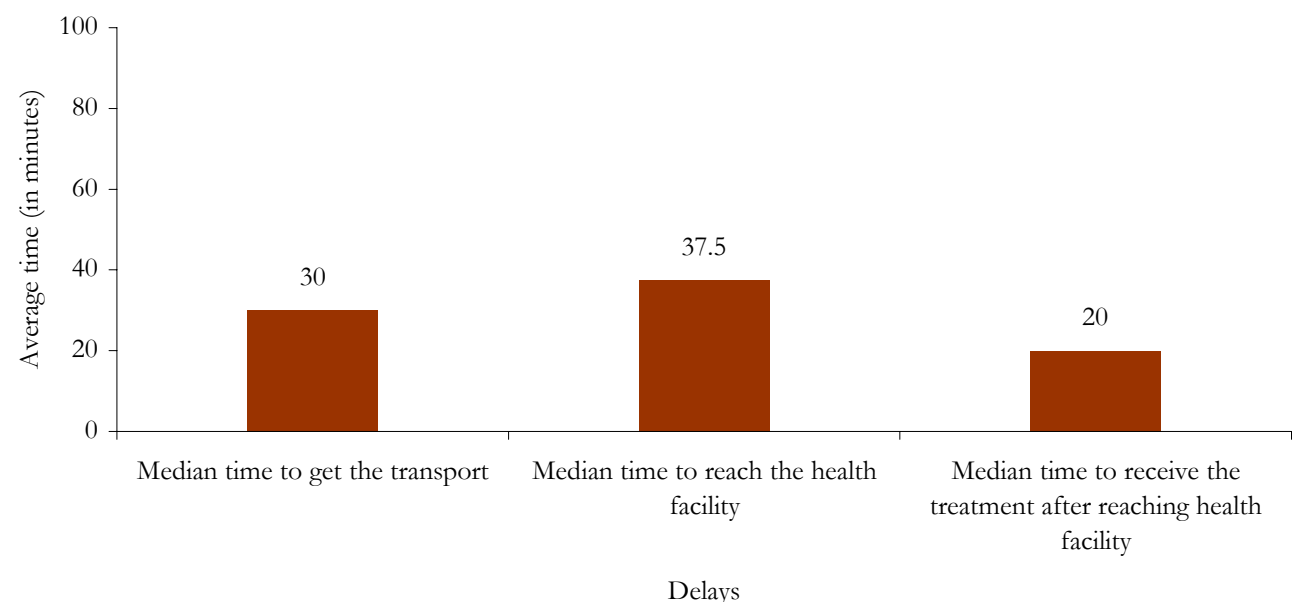

\section{Postpartum Care}

The postpartum period is a critical time for both mother and the newborn. Respondents were asked about the quality and level of postpartum care they received after their last delivery. Table 7.7 shows that 81 percent of women in rural areas and 44 percent women in urban areas did not receive any postnatal check-ups after their last delivery. Only 12 percent in rural areas and 15 percent in urban areas said that they went for postnatal check-ups. Among those 17 percent of women in urban areas and more than 9 percent in rural areas sought care within the twenty-four hours following childbirth.

Table 7.6 also shows that about one third (34.5 percent) of the women in rural areas and half (50.6 percent) of the women in urban areas said that they experienced complications during the postpartum period.

Table 7.6:

History of postpartum care

\begin{tabular}{|c|c|c|c|c|c|c|c|}
\hline \multirow{2}{*}{ History } & & \multicolumn{2}{|c|}{ Rural } & \multicolumn{2}{|c|}{ Urban } & \multicolumn{2}{|c|}{ Total } \\
\hline & & Percent & Number & Percent & Number & Percent & Number \\
\hline \multirow{3}{*}{$\begin{array}{l}\text { Have a postnatal check- } \\
\text { ups }\end{array}$} & Yes & 12.2 & 76 & 15.6 & 24 & 12.9 & 100 \\
\hline & No & 81.2 & 506 & 44.2 & 68 & 73.9 & 574 \\
\hline & $\begin{array}{l}\text { Delivered in } \\
\text { Hospital }\end{array}$ & 6.6 & 41 & 40.3 & 62 & 13.3 & 103 \\
\hline $\begin{array}{l}\text { No. of days after delivery, } \\
\text { have first check-up }\end{array}$ & Same day & 9.2 & 7 & 16.7 & 4 & 11.0 & 11 \\
\hline \multirow{2}{*}{$\begin{array}{l}\text { Experience complications } \\
\text { during postpartum period }\end{array}$} & Yes & 34.5 & 228 & 50.6 & 83 & 37.7 & 311 \\
\hline & No & 65.5 & 432 & 49.4 & 81 & 62.3 & 513 \\
\hline Total & & 100.0 & 660 & 100.0 & 164 & 100.0 & 824 \\
\hline
\end{tabular}




\section{Newborn/Infant care}

The care provided to a newborn upon birth is crucial to the baby's health. Survey questions regarding initial infant and childcare help determine the cause of newborn morbidity and mortality.

\section{Child Care during Birth}

Respondents were asked where their child was placed immediately after delivery. About a quarter of the respondents in rural and only 5 percent in urban areas said that their newborns were put with the mother immediately after delivery.

Table 7.7: $\quad$ History of newborn care

\begin{tabular}{|c|c|c|c|c|c|c|c|}
\hline \multirow{2}{*}{\multicolumn{2}{|c|}{ History }} & \multicolumn{2}{|c|}{ Rural } & \multicolumn{2}{|c|}{ Urban } & \multicolumn{2}{|c|}{ Total } \\
\hline & & Percent & Number & Percent & Number & Percent & Number \\
\hline \multirow{6}{*}{$\begin{array}{l}\text { Placed child } \\
\text { immediately after } \\
\text { delivery }\end{array}$} & On floor & 3.6 & 22 & & & 2.9 & 22 \\
\hline & On mattress & 5.1 & 31 & 16.1 & 24 & 7.3 & 55 \\
\hline & On a piece of cloth & 48.9 & 296 & 55.0 & 82 & 50.1 & 378 \\
\hline & Put with the mother & 26.0 & 157 & 4.7 & 7 & 21.8 & 164 \\
\hline & Others & 12.7 & 77 & 19.5 & 29 & 14.1 & 106 \\
\hline & Don't know & 3.6 & 22 & 4.7 & 7 & 3.8 & 29 \\
\hline \multirow{3}{*}{$\begin{array}{l}\text { Child dried } \\
\text { up/cleaned before } \\
\text { giving bath }\end{array}$} & Yes & 94.9 & 574 & 98.7 & 147 & 95.6 & 721 \\
\hline & No & 2.1 & 13 & & & 1.7 & 13 \\
\hline & Don't know & 3.0 & 18 & 1.3 & 2 & 2.7 & 20 \\
\hline
\end{tabular}

Figure 7.17 shows that 82 percent of the newborns were of normal size whereas 15 percent were smaller and 2 percent were bigger than average. All the women were also asked to report the time when they first bathed their newborn. Figure 7.18 shows that only 14 percent of the babies were given a bath after the recommended time of 6 hours following birth. It also shows that 71 percent of the babies were given a bath within the first hour of birth.

Figure 7.17: $\quad$ Percentage of newborns according to their size (small, normal and big) at birth

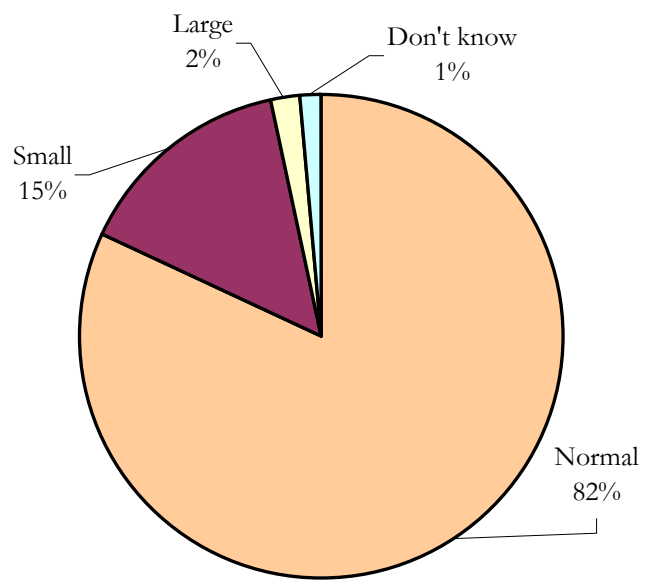




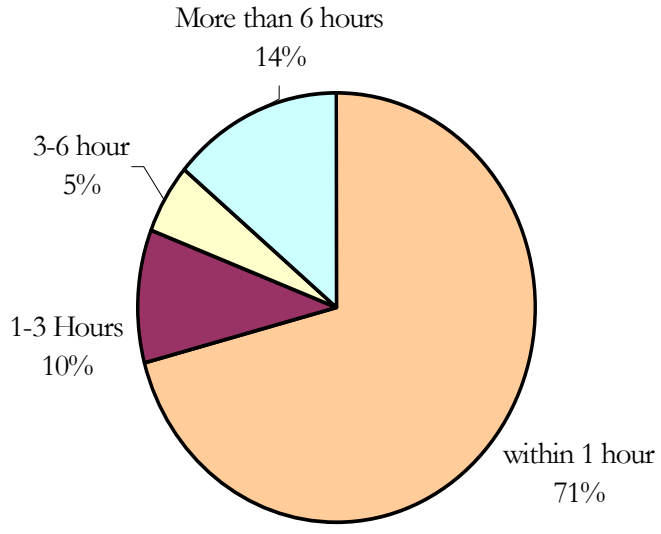

\section{Colostrum and Breastfeeding}

Respondents were also asked if they ever breastfed their infants. Over 96 percent in rural and 93 percent women in urban areas indicated that they did in fact breastfed their child. However, the percentage of women who did not breastfeed was higher in urban centers than in rural areas.

Colustrum is another very important indicator of newborn health, and respondents were asked if they gave colustrum to their newborn babies. Figure 7.19 shows that about three quarters of the women in rural areas and 70 percent in urban areas indicated that they gave colostrum to their newborns. About 62 percent of the women in urban areas and about 44 percent in rural areas provided their newborns with food supplements other than breast milk within the first three days.

\section{Newborn Medical Check-ups}

Respondents were also asked if any physical and/or medical examinations were conducted on the newborn baby. About 93 percent of the respondents in rural areas and more than 70 percent in urban areas indicated that they did not have any medical or physical check-ups made of their newborn babies after their birth. A lack of physical and medical examinations after birth may result in complications being left undetected and untreated, which in turn could be harmful to the health of a newborn. 
Figure 7.19: $\quad$ Newborn feeding and health indicators

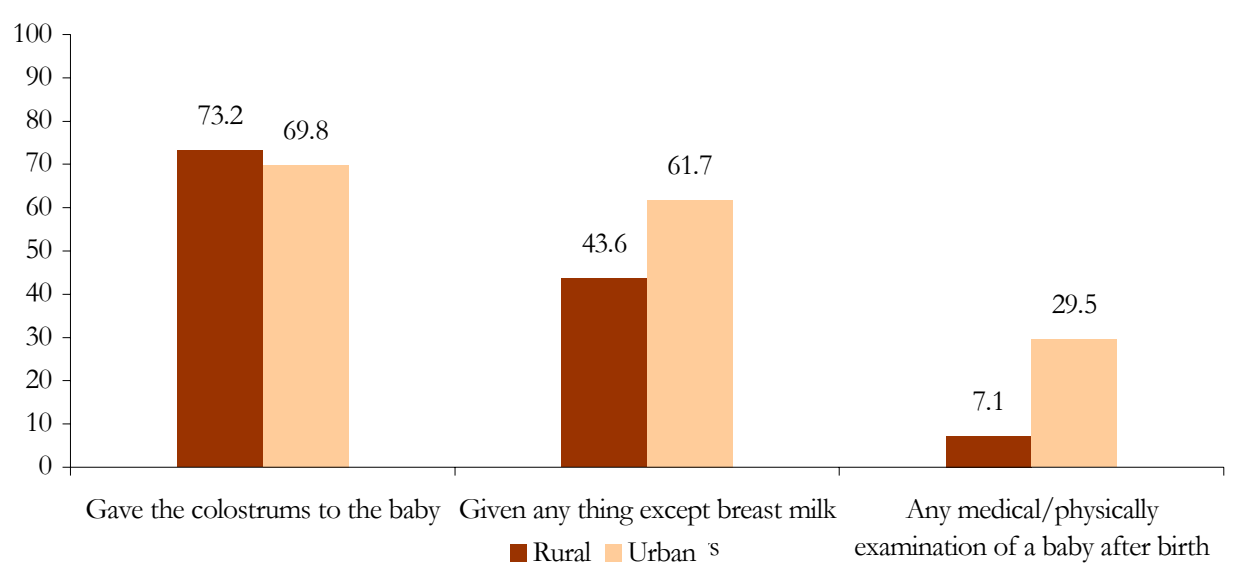

Respondents were asked to recall any complications or symptoms they noted in their newborns soon after delivery. Figure 7.20 shows breathing problems, fever with or without rigors and weak cry were the symptoms most often cited by respondents.

Figure 7.20: $\quad$ Percentage of newborns with danger signs/symptoms soon after deliver

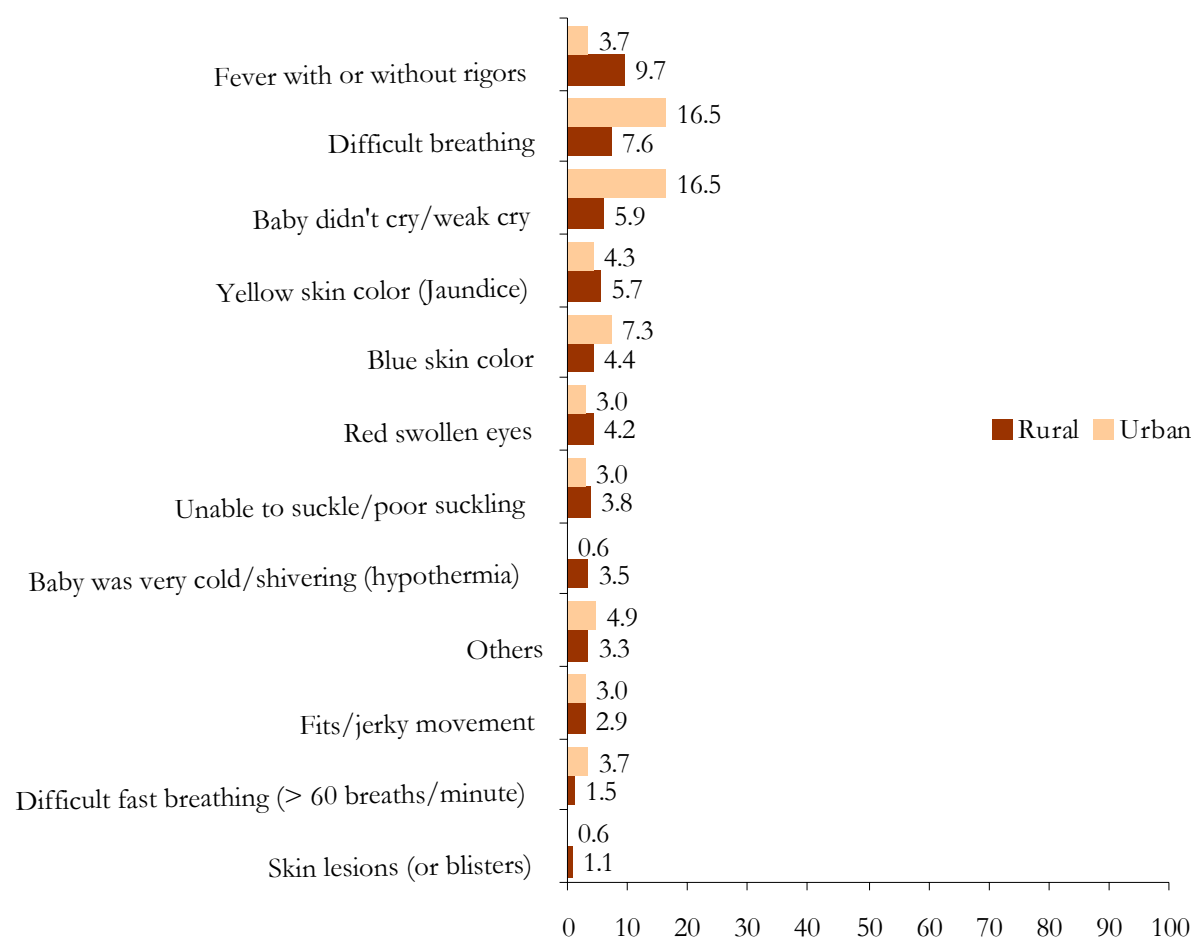


Figure 7.21 indicates symptoms or complications appearing in newborns within the first seven days after birth. Yellow skin color (jaundice) was the most commonly noted symptom in newborns within the first seven days of their birth.

Figure 7.21: $\quad$ Percentage of newborns with danger signs/symptoms within 7-days after last delivery

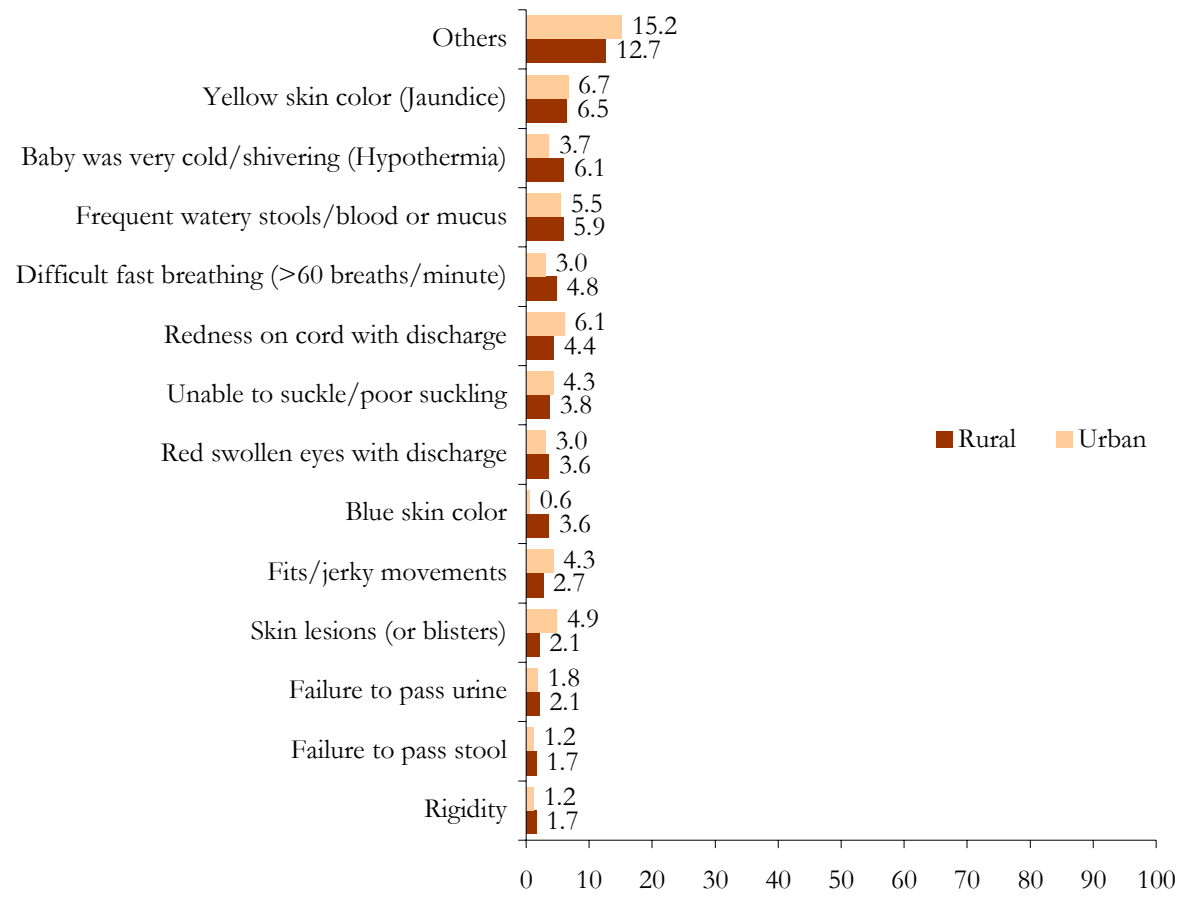

Respondents were asked to indicate where they obtained treatment for their newborn after noting the above-mentioned complications. Figure 7.22 shows that more than half of the respondents in both urban and rural areas said they took their children to private hospitals/clinics. More than 17 percent in rural areas and 19 percent in urban areas failed to get any treatment for their newborns.

Figure 7.22: $\quad$ Place where treatment was sought for newborn complications

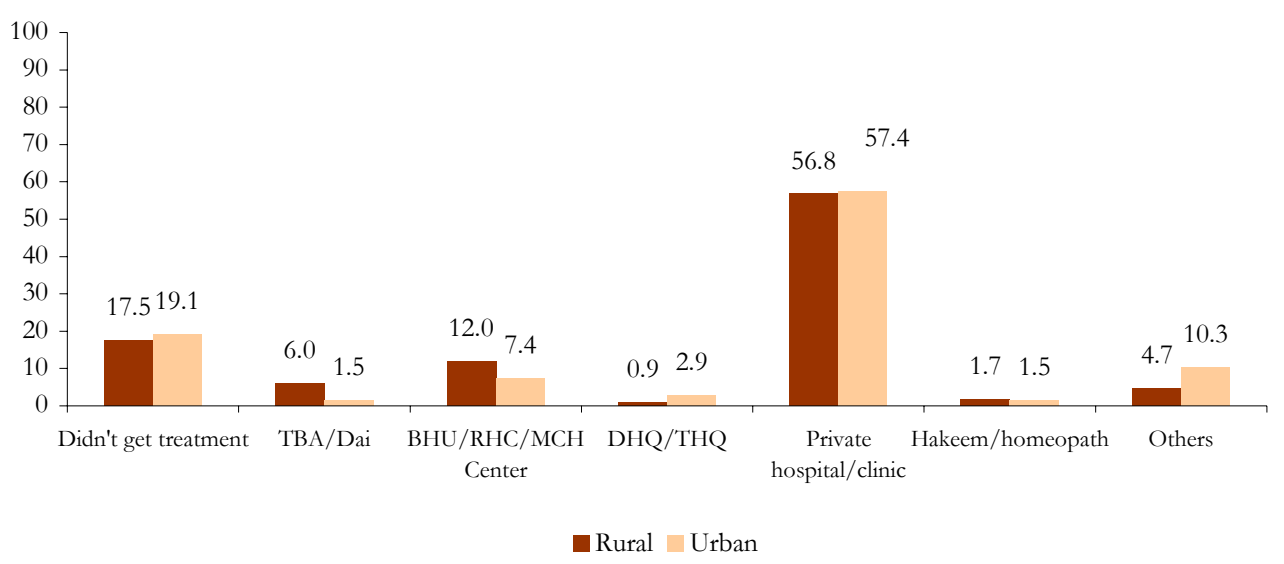


Respondents were asked to indicate the status of health of their last child. Figure 7.23 shows that about 96 percent of children in rural areas and 92 percent in urban areas were alive at the time of survey. About three quarters ( 75.9 percent) of women in urban areas and 83 percent women in rural areas were breastfeeding their children at the time of survey. More than 43 percent women in urban areas and about a quarter (23.5 percent) of the women in rural areas reported that their children had had at least one episode of diarrhea during the two weeks preceding the survey. More than 7 percent in urban areas and 10 percent in rural areas reported that their children had suffered from ARI (Acute Respiratory Infection) during the two weeks preceding the survey.

Figure 7.23: $\quad$ Status and bealth of last live birth

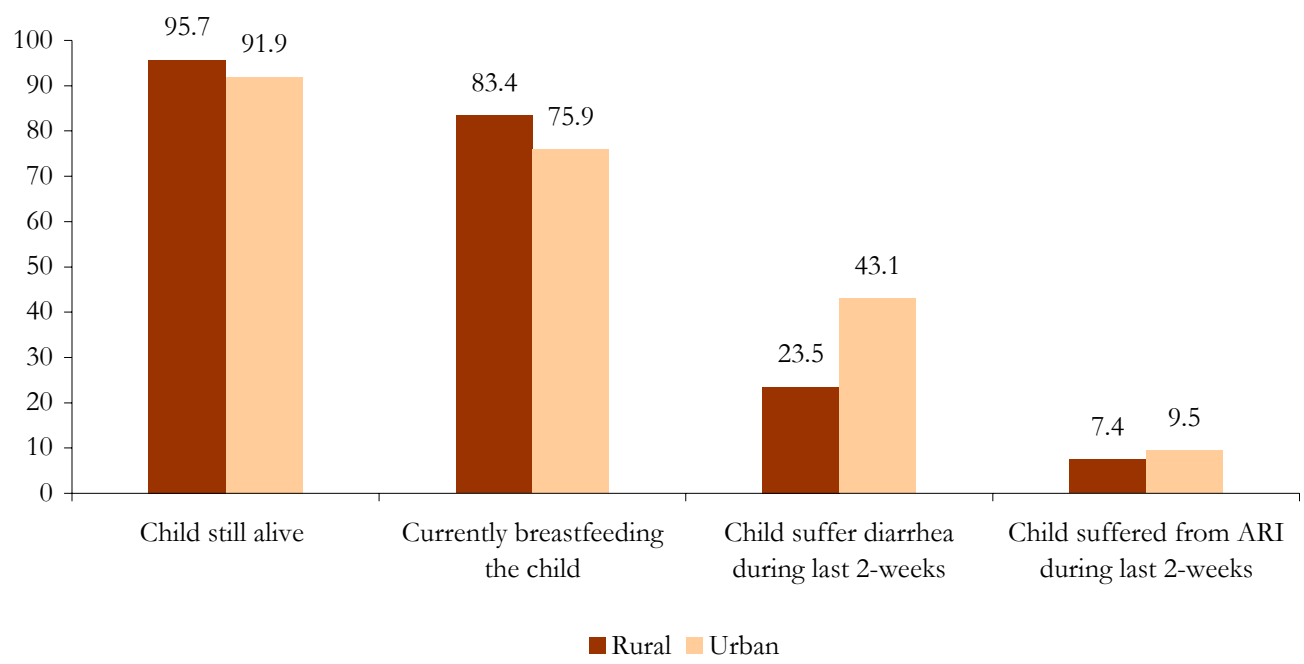




\section{Chapter \\ 8}

\section{Conclusions}

The baseline household survey conducted in Jaffarabad is an essential tool in the process of understanding the different attitudes towards, and misconceptions regarding pregnancy and neonatal care. Since PAIMAN is intended to improve the health of all pregnant women as well as their newborn children, it is important to understand the obstacles that stand in the way of good health. Since the baseline survey is based largely on the opinions and experiences of married women of reproductive age (MWRA), the information obtained is from the very individuals who are to be the primary recipients of the work done through PAIMAN.

The overall age-sex distribution in Jaffarabad shows a sex ratio of 106 to 100 which is better than the sex ratio of 108 obtained in 1998 Population Census. It may be due to an improvement in the overall enumeration of the female population in individual households. Another sign of progress is the clear delay in female marriages, which marks an improvement in the status of women compared to the 1998 Population Census. However, women still tend to get married earlier than men.

Findings also show that half of the respondents of Jaffarabad have no access to any of the three media channels television, radio or newspapers. In order to educate and inform this segment of the population regarding maternal and infant mortality and birth preparedness, more grassroot methods must be adopted. These grassroots efforts may include inter-personal communication through community workers, community gatherings, speeches and health education sessions. The majority of the women interviewed in both urban and rural areas believed that television was the most trustworthy form of media.

Regarding antenatal care, an overwhelming majority believed it necessary for women to receive antenatal check-ups, while 21.5 percent and 6.1 percent of married women in rural and urban areas respectively felt that it was not necessary. The findings show that 27 percent of all pregnant women in rural areas and one-third of the pregnant women in urban areas went for an antenatal check-up during their last pregnancy. It is quite clear that while most women want to receive antenatal checkups and feel they are a necessary part of neonatal care, many are not able to access this service. Findings show that important tests like weight measurement were carried out on only 38.2 percent women in urban areas and 26.4 percent in rural areas during their antenatal visits. Less than 20 percent of the pregnant women in rural and about one-third in urban areas were informed about pregnancy complications during their antenatal visits.

Respondents were asked to indicate the complications they believed to be dangerous and that required medical attention. The findings show that a quarter of married women both in urban and rural areas 
knew three or more danger signs during pregnancy. A quarter in urban and rural areas were unable to name a single sign of complications during pregnancy.

The baseline findings show that only 31 percent of married women in rural areas and more than 49 percent in urban centers indicated that they received TT shots during their last pregnancy. A very large portion of rural women ( 84.7 percent) and urban women (54.3 percent) indicated that they took no iron or folate supplements during their pregnancy.

The baseline findings also show that more than three quarters of women in rural areas indicated that they delivered their babies at home. Only 3 percent of women delivered their babies at government facilities and about 17 percent at private hospital. In urban areas, more than half of the women said that they delivered their babies at home, and 42 percent at private hospitals/clinics. Only 2 percent of respondents availed government health facilities in urban areas. It shows that the use of government health facilities is very low in Jaffarabad.

Caesarean section deliveries appear to be very low in both urban and rural areas (2.4 percent and 1 percent respectively). About 30 percent of the respondents in rural areas indicated that they experienced excruciatingly abnormal pain during their last delivery, whereas 40.2 percent in urban areas reported the same thing. Prolonged labor, premature rupture of membranes and excessive bleeding were some other complications that were reported.

Married women in Jaffarabad generally undervalue the importance of postnatal care. About 81 percent of respondents in rural areas and 44.2 percent in urban areas did not feel that postnatal care was necessary. Furthermore, about half of the respondents in both urban areas and in rural areas of Jaffarabad believed that only some women in their area received postnatal care.

As in the case of pregnancy, many women are not aware of the complications that may arise during delivery. The findings show that less than 8 percent of women in both areas are able to recognize at least three or more danger signs during delivery. It becomes very difficult to save a pregnant woman who does not recognize danger signs during pregnancy, therefore failing to seek medical assistance in time. Deliveries can only be made safe if married women are educated regarding danger signs so that they are able to decide when to seek treatment. Innovative approaches are therefore needed to make these communities more aware of issues regarding maternal and newborn health.

Although baseline survey findings indicate that excessive vaginal bleeding is the best known danger sign during the postpartum period, not all women were aware of this fact. Unfortunately, many women are also unaware of danger signs that may appear in newborns, especially in the first seven days after delivery. The postpartum period is a critical time for mother and newborn. A very large portion of the married women did not receive any postnatal check-ups after their last pregnancy. More than 81 percent of women in rural areas received no postnatal check-ups, whereas the figure was 44.2 percent even in urban areas. Among those who went for postnatal care, 11 percent went within the first twenty-four hours following childbirth.

A very large percentage in both urban and rural areas indicated that they received their pregnancyrelated information from their in-laws, family members and friends. Only 3.2 percent in rural areas indicated that a Lady Health Worker was the source of their information. District Headquarter Hospitals and Tehsil Headquarter Hospitals were a source of information for only 1 percent of the rural and 3.7 percent of the urban population in Jaffarabad. 
Lack of arrangement of transport to a health facility is a major cause of delay and can often lead to maternal and newborn mortality. It is very important to arrange transport ahead of time in order to eliminate that delay. Most communities do not have any arrangements made for transport, provision of blood and finances for women at the time of need during delivery. This is a major obstacle to safe birth practices as women are then forced to deliver at home and may be exposed to infections and complications.

The various sections of the survey allow for a comprehensive analysis of all areas concerned with maternal and infant health and well-being. The separation of rural and urban areas makes it easier to compare results and analyze the reasons behind the differences. The indicators obtained will be used to monitor and evaluate the success of the project upon completion. 


\section{References}

Caldwell, J., Routes to Low Mortality in Poor Countries. Population and Development Review, Vol. 12, No. 2. (Jun., 1986), pp. 171-220.

Federal Bureau of Statistics, "Socio-Economic Indicators at District Level, Punjab," Statistics Division, Government of Pakistan, (2002).

Hollander, D., Antenatal Education Helps Turkish Women Adopt Health-Promoting Behaviour. International Family Planning Perspectives, Vol. 30, No. 1. (Mar., 2004), pp. 45-46.

JHPIEGO/Maternal and Neonatal Health Program, "Monitoring Birth Preparedness and Complication Readiness: Tools and Indicators for Maternal and Newborn Health," (2004).

Mahmood, Arshad, Determinants of Neonatal and Post-Neonatal Mortality in Pakistan. The Pakistan Development Review, Vol. 41, No. 4, Part II (Winter 2002), pp. 723-744.

Mahmood, Arshad, Socioeconomic Factors, Personal Illness Control and Infant and Child Mortality in Pakistan. Pakistan Population Review, Vol. 3, No. 1 (1992), pp. 67-86.

Martin, Linda G.; J. Trussell; Florentina Reyes Salvail; Nasra M. Shah, Co-variates of Child Mortality in the Philippines, Indonesia, and Pakistan: An Analysis Based on Hazard Models. Population Studies, Vol. 37, No. 3. (Nov., 1983), pp. 417-432.

Nawaz, Shuja, The Mass Media and Development in Pakistan. Asian Survey, Vol. 23, No. 8. (Aug., 1983), pp. 934-957.

Ringheim, Karin, When the Client is Male: Client-Provider Interaction from a Gender Perspective, International Family Planning Perspectives, Vol. 28, No. 3 (Sept., 2002), pp. 170-175.

Robbins, P.T., Global Approaches to Development. Sociology of Development, University of London, (2001), pp. 29-37.

Sathar, Zeba; Nigel Crook; Christine Callum; Shahnaz Kazi, Women's Status and Fertility Change in Pakistan. Population and Development Review, Vol. 14, No. 3. (Sep., 1988), pp. 415432.

Simmons, George B., Family Planning Programs or Development: How Persuasive is the New Wisdom? International Family Planning Perspectives, Vol. 5, No. 3. (Sep., 1979), pp. 101-110.

Syed, Sabiha H., Communications Channels and Family Planning in Pakistan. Studies in Family Planning, Vol. 10, No. 2. (Feb., 1979), pp. 53-60.

www.unesco.org 